\title{
LOS LAPAROCERUS SCHOENHERR, 1834 DE LAS CANARIAS ORIENTALES, ISLAS SALVAJES Y MARRUECOS (COLEOPTERA, CURCULIONIDAE, ENTIMINAE)
}

\begin{abstract}
A. Machado*
RESUMEN

A. Machado. 2011. Los Laparocerus Schoenherr, 1834 de las Canarias orientales, islas Salvajes y Marruecos (Coleoptera, Curculionidae, Entiminae). Grael/sia, 67(2): 205-241.

Esta contribución al conocimiento del género Laparocerus Schoenherr, 1834 está dedicada a las Canarias orientales, islas Salvajes y Marruecos. Se redescribe Laparocerus rasus Wollaston, 1864 y se le asignan dos nuevas subespecies localizadas en Fuerteventura: $L$. rasus betancor $\mathbf{n}$. spp. y $L$. rasus jandiensis $\mathbf{n}$. ssp. De esta misma isla se describen varias especies nuevas: L. maxorata n. sp., L. colonnellii n. sp., L. calvus, n. sp., L. xericola n. sp., L. fraterculus n. sp. y L. longipennis n. sp.; de la isla de Lanzarote L. curvipes famara n. ssp., y de las islas Salvajes $L$. garretai albosquamosus n. spp. Se redescribe la única especie confirmada de Marruecos, Laparocerus susicus (Escalera, 1914), a la que se adscriben L. susicus montanus n. spp., del interior, y L. susicus inexpectatus nom. nov.), de la región costera de Tiznit. Para la especie marroquí se plantea la hipótesis de una retrocolonización a partir de las islas Canarias, a la vez que se comentan algunas citas dudosas y ejemplares cuya atribución específica queda pendiente de resolver. Se aportan claves en español e inglés para separar los Laparocerus conocidos de este ámbito geográfico.
\end{abstract}

Palabras clave: Taxonomía; nuevos taxones; Laparocerus; Homonimia; Curculionidae; Entiminae; Macaronesia; Marruecos; Salvajes; islas Canarias; Lanzarote; Fuerteventura; retrocolonización.

\section{ABSTRACT}

A. Machado. 2011. The Laparocerus Schoenherr, 1834 from the Eastern Canaries, Salvage Islands and Morocco (Coleoptera, Curculionidae, Entiminae). Graellsia, 67(2): 205-241 (in Spanish).

This contribution to the knowledge of the genus Laparocerus Schoenherr, 1834 in Macaronesia concerns species from the Eastern Canaries, Salvage Islands and Morocco. Laparocerus rasus Wollaston, 1864 is redescribed and two new subspecies localised in Fuerteventura are ascribed to it: $L$. rasus betancor $\mathbf{n}$. spp. and $L$. rasus jandiensis $\mathbf{n}$. ssp. Several new species are described from that same island: L. maxorata n. sp., L. colonnellii n. sp., L. calvus n. sp., L. xericola n. sp., L. fraterculus n. sp., and L. longipennis n. sp.; from the island of Lanzarote $L$. curvipes famara $\mathbf{n}$. ssp., and from the Selvage Islands $L$. garretai albosquamosus n. spp. The only confirmed species form Morocco, Laparocerus susicus (Escalera, 1914), is redescribed and L. susicus montanus n. spp., from the interior, and $L$. susicus inexpectatus nov. nom., from the coastal region of Tiznit are assigned

* c/ Chopin 1, 38208 La Laguna, Tenerife. e-mail: antonio.machado@telefonica.net 
to it. A retro-colonization from the Canary Islands to the continent is hypothesized for this Moroccan species. Doubtful records and unresolved species are commented on, and keys in Spanish and English for identifying all Laparocerus inhabiting this geographical context are provided.

Keywords: Taxonomy; new taxa; Laparocerus; Curculionidae; Entiminae; Homonymy; Macaronesia; Morocco; Canary Islands; Selvagens; Lanzarote; Fuerteventura; back colonisation.

\section{Introducción}

El género Laparocerus Schoenherr, 1834 se distribuye exclusivamente en los archipiélagos de Madeira, Salvajes y Canarias, además de una especie en Marruecos occidental. El número de taxones del nivel específico asciende por el momento a 185, y la presente contribución aporta once más, procedentes de las Canarias orientales, islas Salvajes y Marruecos. Esta contribución se suma a otras dedicadas por el autor a las demás islas, como parte del estudio monográfico del género emprendido.

Hasta la fecha se han citado solo tres especies de Laparocerus de las Canarias orientales (Fuerteventura y Lanzarote), una de las islas Salvajes, y otra de la costa occidental de Marruecos, cuya identidad fue aclarada recientemente (Machado, 2006; Pelletier, 2007). La fáunula de esta región árida de la Macaronesia se incrementa considerablemente con el número de nuevos taxones que aquí se describen, destacando la presencia de dos grupos de especies exclusivos de la región considerada (grupo de L. maxorata y grupo de $L$. rasus), salvo por la sorprendente excepción de L. curvipes s.l. Lindberg, 1953 en el primer grupo, que cuenta con una subespecie en Tenerife. Estos grupos son monofiléticos según estudios genéticos realizados (pendientes de publicar), y su asignación subgenérica queda pendiente de la revisión conjunta del género. Sorprende también la especie endémica de las islas Salvajes que pertenece al grupo de Laparocerus tessellatus, característico de las Canarias centrales y occidentales.

Después de descartar algunos ejemplares de colección con etiquetas de localidad aparentemente erróneas (se comentan al final de la sección sobre material y método), el esquema faunístico de la región considerada queda de momento como sigue:

Grupo de L. maxorata

Laparocerus maxorata $\mathrm{n}$. sp.

Fuerteventura

Laparocerus fraterculus $\mathrm{n}$. sp.

Laparocerus longipennis $\mathrm{n}$. $\mathrm{sp}$.
Laparocerus calvus n. sp.

Fuerteventura

Laparocerus curvipes espanoli Roudier, 1954

Fuerteventura

Laparocerus curvipes famarae n. ssp. Lanzarote

Grupo de L. rasus

Laparocerus rasus rasus Wollaston, 1864

Lanzarote y Montaña Clara

Laparocerus rasus betancor $\mathrm{n}$. ssp. Fuerteventura

Laparocerus rasus jandiensis $\mathrm{n}$. ssp. Fuerteventura

Laparocerus susicus susicus (Escalera, 1914) Marruecos

Laparocerus susicus montanus n. ssp. Marruecos

Laparocerus susicus inexpectatus nom. nov. Marruecos

Laparocerus xericola n. sp. Fuerteventura y Lanzarote

Laparocerus colonnellii $\mathrm{n}$. sp.

Fuerteventura

Laparocerus dispar Wollaston, $1864 \quad$ Lanzarote

Grupo de L. tessellatus

Laparocerus garretai garretai (Uyttenboogaart, 1940)

Salvaje Grande

Laparocerus garretai albosquamosus $\mathrm{n}$. ssp.

Gran Pitón (Salvajita)

La única especie confirmada de Marruecos, Laparocerus susicus, se distribuye en un área conocida por los botánicos como el "enclave macaronésico continental" (Braun-Blanquet \& Maire, 1924) por presentar especies afines sobre todo a la flora de las Canarias orientales y Cabo Verde, circunstancia que también se da en la fauna entomológica (Peyerimhoff, 1946). Laparocerus susicus pertenece al grupo de Laparocerus rasus, cuyo complejo precisa un análisis molecular en profundidad para desvelar mejor las relaciones entre los varios taxones, pues el análisis morfológico del presente estudio sugiere que se trata de una radiación aún no consolidada, probablemente asociada al proceso de aridificación de toda la región mediterránea sudoccidental. La presencia de caracteres derivados compartidos entre $L$. susicus s.l. y $L$. rasus s.l. inducen a pensar que la especie marroquí no es un relicto, sino un neoendemismo que proviene de una retrocolonización reciente del Continente a partir 


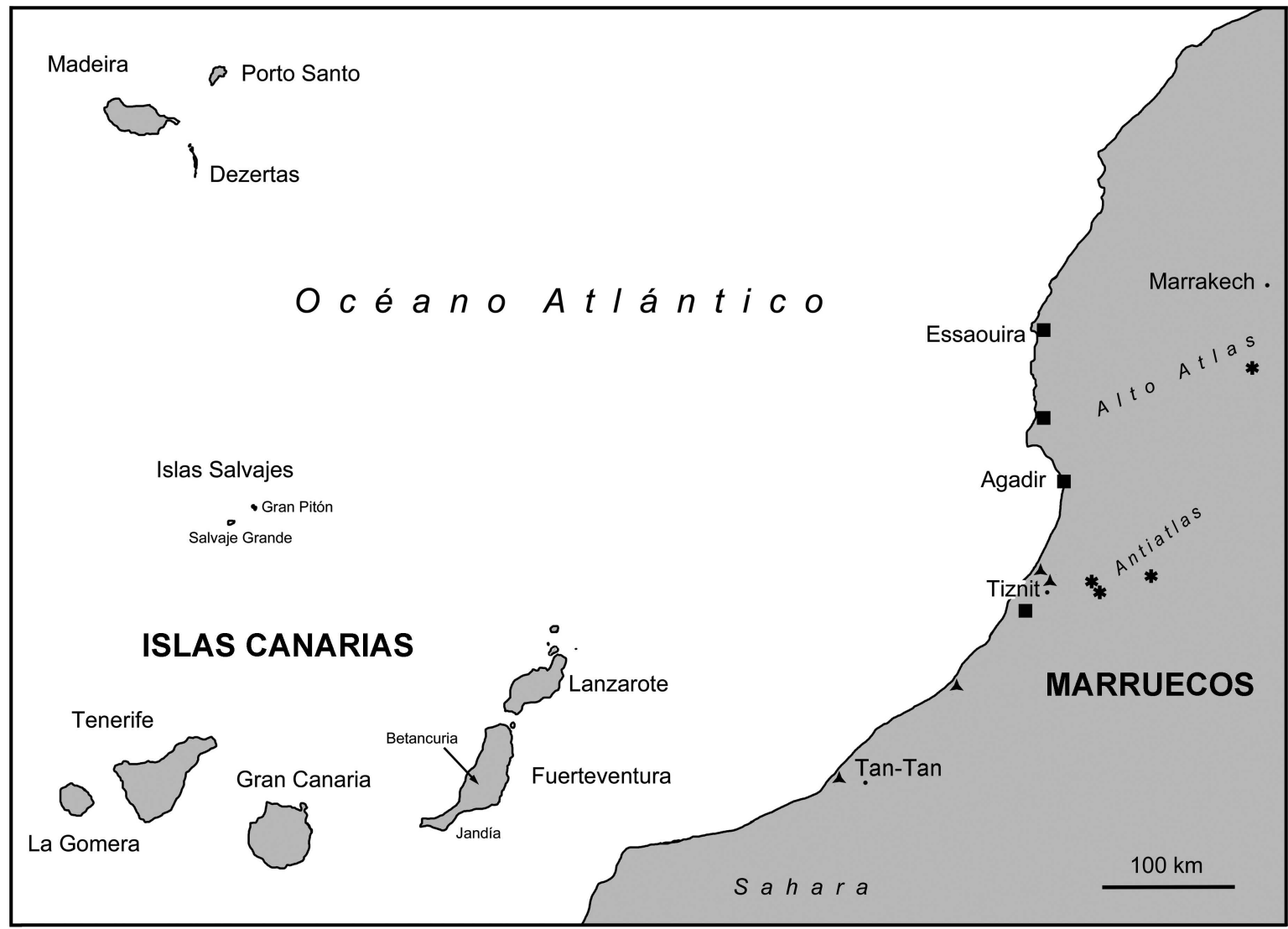

Fig. 1.- Mapa de la zona de estudio y distribución de Laparocerus en Marruecos: Laparocerus susicus susicus (Escalera, 1914), * L. susicus montanus n. ssp., y $\wedge$ L. susicus inexpectatus n. ssp.

Fig. 1.- Map of the study area and distribution of Laparocerus in Morocco: 1914), * L. susicus montanus $\mathbf{n}$. ssp., y ^ L. susicus inexpectatus $\mathbf{n}$. ssp.

de las Canarias orientales. Esta hipótesis habrá que confirmarla por vía molecular, pero es plausible si se considera que ya se han constatado casos de retrocolonización en especies vegetales de Aeonium (v. Mort et al., 2002) y Convolvulus (Carine et al., 2004).

\section{Material y métodos}

El material objeto de estudio proviene de colecciones privadas e institucionales, y del recolectado por el autor en las islas durante varias campañas de prospección a lo largo de la última década, incluida dos realizadas en Marruecos en abril de 2003 y enero de 2005 (Fig. 1). El total de ejemplares referenciados en este trabajo asciende a 2305. Para las series típicas se ha escogido una sola localidad o localidades muy próximas, a fin de minimizar la variación genética. Los holotipos se han depositado en el Museo de Ciencias Naturales de Santa Cruz de Tenerife. Las siglas empleadas para referir a las diferentes colecciones son las siguientes:

AAC Colección Agustín Aguiar Clavijo. La Laguna, España.

AL Colección Andrea Liberto. Roma, Italia.

AS Colección Artur Serrano. Lisboa, Portugal.

AMC Colección Antonio Machado Carrillo. La Laguna, España.

DEI Deutsches Entomologisches Institut. Müncheberg, Alemania.

EC Colección Enzo Colonnelli. Roma, Italia.

GO Colección Giuseppe Osella. L'Aquila, Italia.

JP Colección Jean Pelletier. Monnaie, Francia.

MAZ Colección Miguel Ángel Alonso-Zarazaga. Madrid, España.

MM Colección Michael Morris. Dorchester, Reino Unido.

MMF Museu Municipal do Funchal. Madeira, Portugal.

MNCN Museo Nacional de Ciencias Naturales. Madrid, España.

MNHN Muséum National d'Histoire Naturelle. París, Francia. 
MPE Colección Miguel Ángel Peña Estévez. Telde, España.

MZUR Museo di Zoología di la Università di Roma "La Sapienza". Roma, Italia.

NHM The Natural History Museum. Londres, Reino Unido.

NMNH National Museum of Natural History "Naturalis", Leiden.

NMW Naturhistorisches Museum Wien. Viena, Austria.

NRS Naturhistoriska Riksmuseet. Estocolmo, Suecia.

PS Colección Peter Stüben. Mönchengladbach. Alemania.

POM Colección Pedro Oromí Masoliver. La Laguna, España.

RGB Colección Rafael García Becerra. S/C de La Palma, España.

TFMC Museo de Ciencias Naturales. Santa Cruz de Tenerife, España.

ULL Departamento de Zoología, Universidad de La Laguna.

UMO University Museum, Hope Entomological Collections, Oxford.

En la Colección Kraatz, conservada en el «Deutsches Entomologisches Institut» existen tres ejemplares de Laparocerus con etiqueta de localidad "Morocco /M. Quedenfeldt", sin más detalles. Además de la etiqueta de la Colección Kraatz, llevan otras de determinación como "Desbrochersella heueta Desbr." y "Laparocerus susicus Esc. / M. González". Se trata en realidad de tres ejemplares del complejo Laparocerus freyi-tessellatus, propios de las Canarias occidentales. El teniente Max Quedenfeldt (1851-1891) entomólogo, etnógrafo, sociólogo y geógrafo de afición, realizó cuatro viajes de estudios a Marruecos y, al menos en su último viaje de 1887, recaló en Canarias, donde pasó tres meses y colectó abundantemente antes de embarcar hacia Cabo Jubi desde Arrecife en Lanzarote, en el mes de abril (Hantzsch, 1907). El equívoco en la etiqueta de localidad es altamente probable y descartamos estos ejemplares del presente estudio.

En la colección de la Universidad de La Laguna se han encontrado un ejemplar de Laparocerus tinguaro Machado, 1996 y otro de L. tessellatus (Brullé, 1839), ambos inmaturos, con etiquetas de localidad del islote de Montaña Clara, al norte de Lanzarote (leg. H. López). Estas especies son propias del macizo de Anaga en Tenerife, y hemos de asumir que se trata igualmente de una confusión de localidades.

Las disecciones fueron realizadas siguiendo los procedimientos entomológicos al uso. Las fotografías se tomaron con una cámara digital Nikon D70, con objetivo AF Micro Nikon $60 \mathrm{~mm} \mathrm{1:28} \mathrm{D} \mathrm{y} \mathrm{anillo} \mathrm{de}$ extensión, usando luego el programa CombineZM de Alan Hadley para la fusión de toma secuencial. Los dibujos se realizaron con ayuda de una cámara clara montada sobre microscopio o lupa binocular, y para las mediciones se utilizó la lupa equipada con un micrómetro en el ocular. Las tallas se refieren a la longitud del insecto, descontado el rostro. Las letras $\mathrm{L}$, A y $\mathrm{H}$ en la expresión de las ratio significan longi- tud, ancho y altura máximas, respectivamente. La terminología empleada es la que presenta el autor en su trabajo dedicado a la morfología de Laparocerus undatus Wollaston, 1864 (Machado, 2010).

\section{Parte sistemática}

\section{Grupo de Laparocerus maxorata}

\section{Laparocerus maxorata $\mathrm{n} . \mathrm{sp}$.}

(Figs. 2A y 3)

Material eXaminado. Fuerteventura: Holotipo $10^{\top}$ de Jandía, Pico de la Zarza (UTM 28R 563311 3108654) 800 m, 5-3-2011 leg. A. Machado (TFMC/CO-15962)._- Paratipos: misma localidad y fecha, 85 exx leg. A. Machado (AMC, 2 MNHN), 44 exx leg. R. García (RGB), 69 exx leg. A. Aguiar (AAC); 2 exx 9-2-1978 leg. A. Machado (AMC), 4 exx 20-122002 leg. S. Scholz (AMC), 1 ex 27-4-2002 leg. H. Contreras (ULL), 13 exx 27-2-1990 leg. E. Colonnelli (11 MZUR, 2 ULL), 1 ex 1-2-1991 leg. E. Colonnelli (EC).

No paratipos: Pico de la Matanza 38 exx 10-2-1991 leg. E. Colonnelli (EC). Divisoria del Aguililla 400-500 m, 52 exx 201-1991 leg A. Liberto (AL, 6 AMC). Cumbres de Jandía 500600 m, 1 ex 19-4-1974, 4 exx 10-5-1974, 2 exx 27-2-1990, 2 exx 15-2-1997 leg. P. Oromí (ULL), 3 exx 2-12-2001, 2 exx 28-4-2002 leg. A. Machado (AMC).

Medidas Del holotipo $\left(\sigma^{7}\right)$. Longitud: total ( $\sin$ rostro) $7,6 \mathrm{~mm}$, rostro $0,78 \mathrm{~mm}$, escapo $1,70 \mathrm{~mm}$, funículo 1,84 (desmómeros I-IV respectivamente $0,40 / 0,46 / 0,26 / 0,20 \mathrm{~mm}$ ), maza $0,58 \mathrm{~mm}$, ojo $0,47 \mathrm{~mm}$, pronoto $1,67 \mathrm{~mm}$, élitros $5,20 \mathrm{~mm}$, tibias (pro- /meso- /meta-) 2,20 /1,850 /2,15 mm. Anchura: cabeza (a nivel de los ojos) $1,44 \mathrm{~mm}$, (interocular) 0,84 $\mathrm{mm}$; rostro (a nivel de los pterigios) $0,90 \mathrm{~mm}$, (mínimo dorsal) 0,64 $\mathrm{mm}$ (mínimo ventral) $0,62 \mathrm{~mm}$; escapo $0,16 \mathrm{~mm}$, maza $0,17 \mathrm{~mm}$, ojo $0,38 \mathrm{~mm}$, pronoto (anterior /máxima /posterior) 1,47 / 2,12/1,90 mm y élitros (máxima) 3,35 mm. Altura: abdomen 2,60 mm.

DESCRIPCIÓN. Machos: Longitud 6,1-8,4 mm (media 7,2 mm), cuerpo oblongo-ovalado, subcilíndrico; tegumento brillante, punteado, de color pardo negruzco (antenas parcialmente rufescentes), vestimenta abierta de escamitas finas lanceoladas, tumbadas, de color flavo con visos dorados o cobrizos (formando a veces dibujo parcheado sobre los élitros), y pilosidad irregular larga, fina y erecta, más o menos desarrollada en todo el élitro (ocasionalmente reducida al tercio apical).

Antenas gráciles, no muy largas; escapo arqueado a la mitad, engrosado en el cuarto apical (capi- 


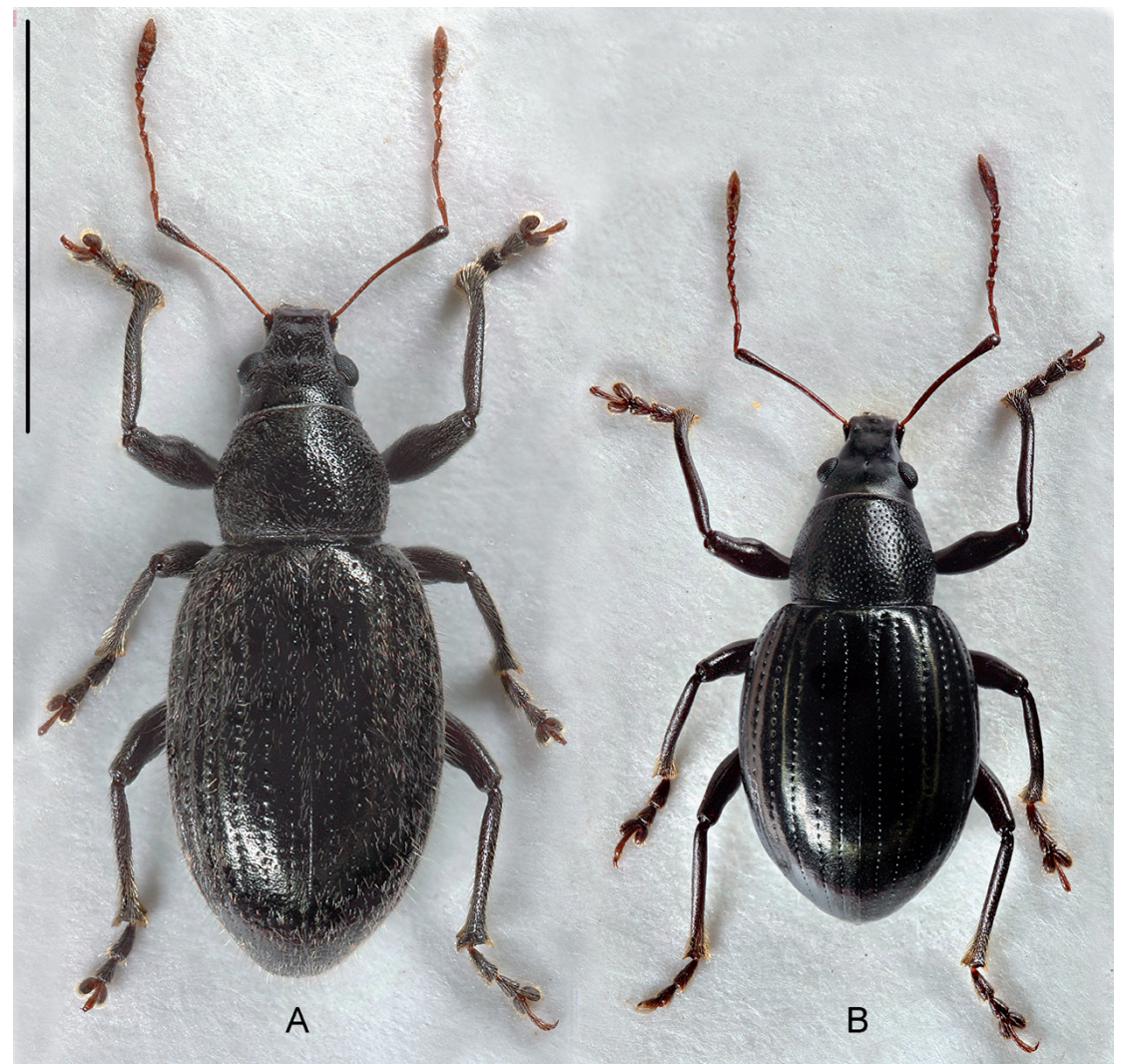

Fig. 2.- Holotipos $\left(\mathrm{O}^{\mathrm{T}}\right)$ de Laparocerus maxorata n. sp. (A) y Laparocerus calvus n. sp. (B). Escala 5 mm.

Fig. 2.- Holotypes ( $\left.\sigma^{7}\right)$ of Laparocerus maxorata n. sp. (A) and Laparocerus calvus n. sp. (B). Scale 5 mm.

tado); funículo algo más largo que el escapo, $1^{\text {er }}$ desmómero poco mayor que el $2^{\circ}$, y el $3^{\circ}$ que el $4^{\circ}$; el $7^{\circ}$ cónico, más ancho que el $6^{\circ}$; maza fusiforme $(\mathrm{L} / \mathrm{A}=3,4)$, algo más larga que los tres desmómeros precedentes juntos.

Cabeza de base ancha; rostro trapezoidal, algo estrangulado dorsalmente (canal escrobal anterior visible desde arriba), pterigios paralelos, apenas salientes; prorrostro liso, en declive, a modo de placa rostral (quilla epistomal mal perfilada, pero reconocible por su abultamiento); metarrostro lateralmente no levantado, romo, generalmente con ligera depresión anterior; frente algo deprimida transversalmente; fóvea frontal grande, a menudo prolongada como surco hacia atrás, a veces también hacia delante (línea media). Ojos ovales (L/A = $1,24)$, pequeños ( $\mathrm{L} \leq 0,5$ distancia interocular) moderadamente convexos y prominentes (convexidad del 30\%), surco periocular estrecho. Tegumento con punteado mediocre y escamitas lanceoladas y otras piliformes, más largas y menos tumbadas.

Pronoto transversal $(\mathrm{L} / \mathrm{A}=0,8)$, sin reborde; lados arqueados, más convergentes por delante que por detrás; punteado doble denso, muy marcado y conspicuo (puntos mediocres bastante separados) sobre fondo liso; vestimenta de escamas rala, poco aparente (las piliformes más abundantes); línea media estrecha, insinuada.

Escudete triangular, amplio, muy punteado y tapizado de escamas.

Élitros oval-alargados ( $\mathrm{L} / \mathrm{A}=1,5-1,6)$, de convexidad bastante uniforme, vez y media la anchura del pronoto; base algo cóncava; ángulo humeral redondeado (hombros no marcados); estrías con puntos gruesos, doble de grande que los del pronoto, separados 1/4 de su diámetro (disco). Interestrías prácticamente planas, lisas o con rugosidad transversal (puntos pequeños muy superficiales); 6-7 

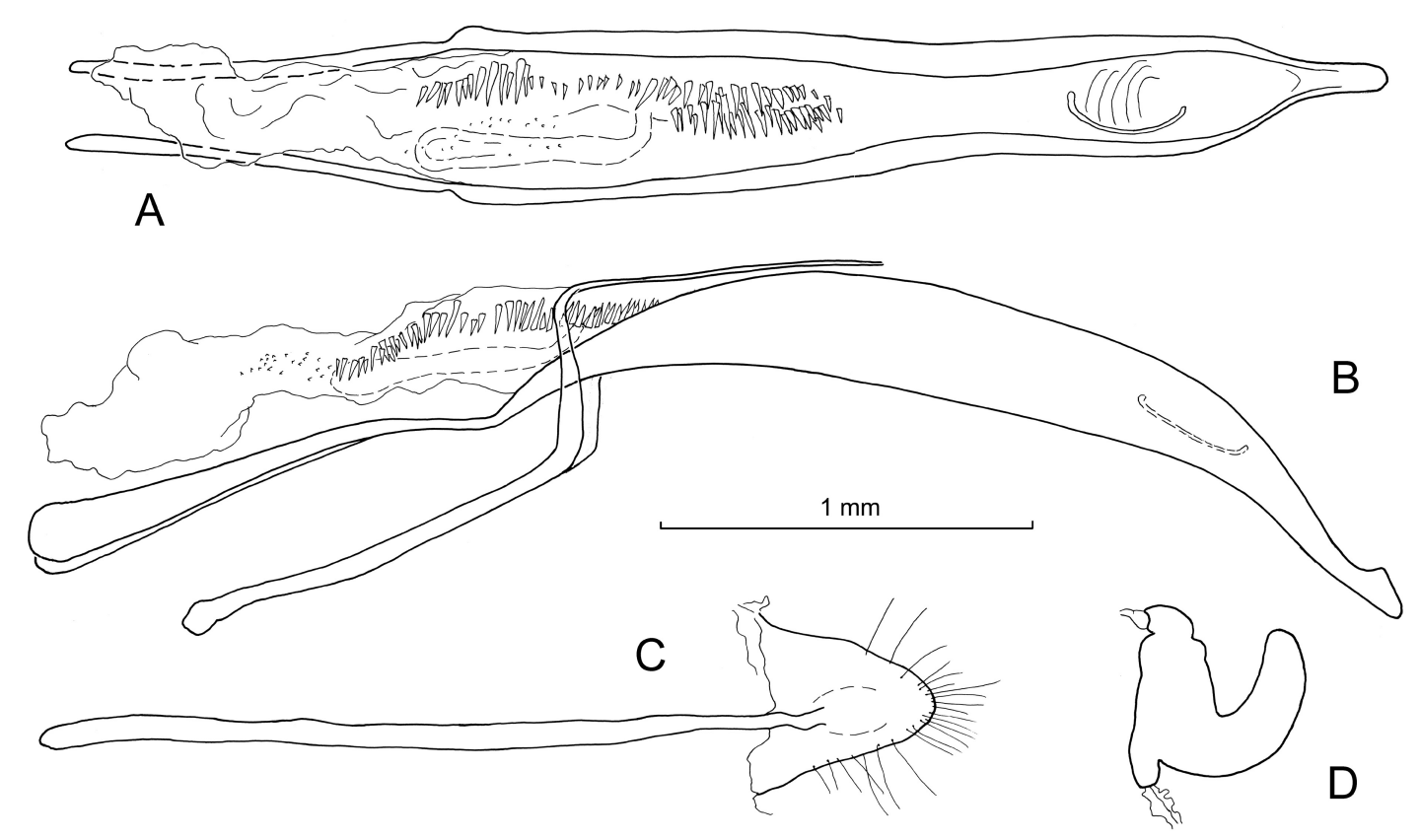

Fig. 3.- Laparocerus maxorata n. sp. Edeago en vista doral (A) y vista lateral (B); urosternito VIII femenino (C) y espermateca (D).

Fig. 3.- Laparocerus maxorata n. sp. Aedeagus in dorsal view (A) and lateral view (B); female urosternite VIII (C) and spermatheca (D).

escamitas adpresas a lo ancho e hileras de puntos algo mayores portando pelos suberectos finos y largos (longitud heterogénea) a veces reduciéndose hacia la base, o incluso, restringidos al tercio apical. Las escamas se desprenden con suma facilidad.

Cara ventral con rugosidad transversal, salvo último ventrito; punteado superficial y separado, pilosidad fina, abierta, tumbada. Saliente intermesocoxal cordiforme, poco elevado. Último ventrito truncado apicalmente y ligeramente escotado.

Patas gráciles, delgadas, bastante pilosas (tibias punteadas); protibias curvadas en el tercio apical, el ápice apenas ensanchado hacia fuera y mucho hacia dentro, con mucrón amplio y robusto, almohadilla ventral corta, densa y encajada; mesotibias con mucrón obtuso, poco saliente; metatibias de longitud similar a las protibias, ápice ancho y mucrón (pre-mucrón) triangular amplio y robusto. Tarsos estrechos.

Edeago (Figs. 3A-B): Lóbulo medio arqueado en el quinto apical; ápice estrechado, paralelo, de punta roma (vista dorsal), y con quilla sagital (visto de perfil); saco interno hacia atrás no o apenas reba- sando los temones, un campo doble y denso de dientes a lo largo de su tramo medio (a veces parcialmente segregado en dos); divertículo ciego estrecho, el gonoporal curvado y estrecho en la base, amplio apicalmente.

Hembras: Longitud 6,6-8,5 mm (media 7,54 $\mathrm{mm}$ ) muy parecidas al macho, con élitros más inflados y anchos (anchura élitro/pronoto $=1,8$ en vez de 1,6); puntos de las estrías elitrales menores; tibias sin mucrón, las protibias rectas, poco ensanchadas apicalmente. Último ventrito terminado en arco redondo. Esternito VIII (Fig. 3C) con placa apical triangular y roma; apodema 4,4x la longitud de la placa. Espermateca con lóbulo glandular no muy largo y oblicuo (Fig. 3D).

Etimología. El epíteto específico maxorata es el nombre en aposición, de uno de los dos reinos aborígenes de la isla de Fuerteventura, concretamente el que comprendía Jandía, en su extremo meridional, donde habita la especie.

OBSERVACIONES. Laparocerus maxorata n. sp. se caracteriza por su tamaño mediano, forma 
oblongo-alargada, rostro trapezoidal, protibias masculinas curvadas apicalmente, tegumentos del pronoto con puntuación doble muy conspicua y los élitros con abundantes pelos finos, muy largos y erectos. En las Canarias orientales solo podría confundirse con L. colonnellii $n$. sp. que presenta pelos en los élitros, pero más cortos, arqueados y escasos, además de tener ojos mayores, ser menor de talla, y presentar la cabeza y pronoto con tegumento lustroso con puntos muy superficiales e inconspicuos. En otras islas hay especies de Laparocerus con pilosidad sedosa, larga y fina, como es el caso en L. lepidopterus Wollaston, 1863, L. inflatus Wollaston, 1865, L. hirtus Wollaston, 1864, L. sanchezi Roudier, 1957 o L. inaequalis Wollaston, 1863, pero sus élitros son de forma ancha y deprimida, o notoriamente globosos. Solo L. inconspectus Roudier, 1957 de Gran Canaria, presenta un cuerpo alargado, pero se trata de una especie mucho más grande y robusta, rostro paralelo, ojos mayores, protibias masculinas rectilíneas apenas curvadas apicalmente, las metatibias con cepillos apicales de pelos largos, etc.

Algunos ejemplares de L. maxorata n. sp., incluido el tipo, presentan la almohadilla del primer artejo metatarsal reducida a la mitad distal. Destaca también el desarrollo de la pilosidad elitral, que es de longitud irregular, erecta o suberecta y abundante, extendida generalmente por todo el élitro o reduciéndose progresivamente hacia la base. Hay unos pocos ejemplares donde se reduce mucho e incluso queda restringida al tercio apical. El hecho de que tanto las escamas como la pilosidad se desprendan con cierta facilidad obliga a una inspección minuciosa.

DisTRIBUCIÓN Y ECOLOGÍA. Laparcerus maxora$t a$ n. sp. es endémico de Fuerteventura, donde vive aparentemente restringido a las cumbres de la península de Jandía, en el extremo meridional de la isla. En estas crestas, por encima de los $600 \mathrm{~m}$ de altitud, existen condiciones especiales de humedad por influencia directa del mar de nubes de los alisios. La especie es invernal y nocturna, y se ha colectado exclusivamente sobre Nauplius sericeum (Asteraceae). Es abundante en el invierno avanzado y primavera, y bastante escasa a comienzos de invierno (diciembre), cuando emergen $L$. rasus y $L$. curvipes espanoli con los que cohabita en la misma localidad y planta.

\section{Laparocerus fraterculus $\mathrm{n} . \mathrm{sp}$.}

(Figs. 4 y 17B)

MATERIAl EXAmINADO. Fuerteventura: Holotipo $10^{7}$ (mutilado) Jandía, Pico de la Matanza 10-2-1991 leg. E. Colonelli (TFMC/CO-15963)._- Paratipo: 1 우 (solo abdomen) mismos datos (AMC).

No paratipo: Jumillo (La Antigua) 8-3-1986 1 ㅇ leg. C. Jeanne (AMC).

MedidAs DEL HOLOTIPo $\left(\sigma^{7}\right)$. Longitud: total ( $\sin$ rostro) $4,0 \mathrm{~mm}$, rostro $0,46 \mathrm{~mm}$, escapo $0,92 \mathrm{~mm}$, funículo $0,98 \mathrm{~mm}$, ojo $0,28 \mathrm{~mm}$, pronoto $0,84 \mathrm{~mm}$, élitros 2,75 mm, tibias (pro-/meta-) 1,14/1,12 mm. Anchura: cabeza (a nivel de los ojos) 0,84 $\mathrm{mm}$, (interocular) $0,48 \mathrm{~mm}$; rostro (a nivel de los pterigios) $0,50 \mathrm{~mm}$, (mínimo dorsal) $0,36 \mathrm{~mm}$ (mínimo ventral) $0,49 \mathrm{~mm}$; escapo $0,12 \mathrm{~mm}$, ojo $0,22 \mathrm{~mm}$, pronoto (anterior /máxima /posterior) $0,84 / 1,14 / 1,02 \mathrm{~mm}$ y élitros (máxima) $1,87 \mathrm{~mm}$. Altura: abdomen 1,56 mm.

Diagnosis $\left(\sigma^{x}\right)$. Talla pequeña (longitud 4,0 $\mathrm{mm}$ ), cuerpo oblongo, convexo, con tegumento brillante de color pardo (ennegrecido al menos en cabeza y pronoto); vestimenta de escamitas lanceoladas flavas tumbadas, formando dibujo en los élitros. Escapo antenal fino en la base y gruesamente capitado, ligeramente arqueado al medio. Rostro corto trapezoidal, prorrostro liso a modo de placa (quilla epistomal algo marcada); prorrostro acanalado, pterigios paralelos nada sobresalientes (canal escrobal visible desde arriba); ojos moderadamente prominentes salientes (convexidad 30\%), con surco perioftálmico estrecho, fóvea frontal estrecha y larga; tegumento brillante con punto precisos dispersos, con microrreticulación patente longitudinal en la frente, transversal en el vertex. Pronoto (L/A $=0.7$ ) con lados moderadamente curvados, sin sinuosidad anterior o posterior, con puntos gruesos foveiformes bastante juntos $(<1 / 3$ de diámetro) y algunos menores sobre fondo brillante; las escamitas testáceas, separadas y dispuestas transversalmente; línea media desarrollada. Élitros $(\mathrm{L} / \mathrm{A}=1,5)$ oblongos (claramente más estrechos que en L. dispar), convexos, sin hombros, con los puntos de las estrías tan gruesos como los del pronoto; tegumento brillante con 6-7 escamas lanceoladas largas de color testáceo a lo ancho ( $2^{\mathrm{a}}$ interestría); unas pocas cerditas blanquecinas arqueadas en el ápice. Protibia bruscamente torcida $\left(>20^{\circ}\right)$ en su tercio apical (como en L. maxorata n. sp.), el ápice ensanchado, con ángulo externo más sobresaliente provisto de mucrón robusto y agudo; metatibia con 


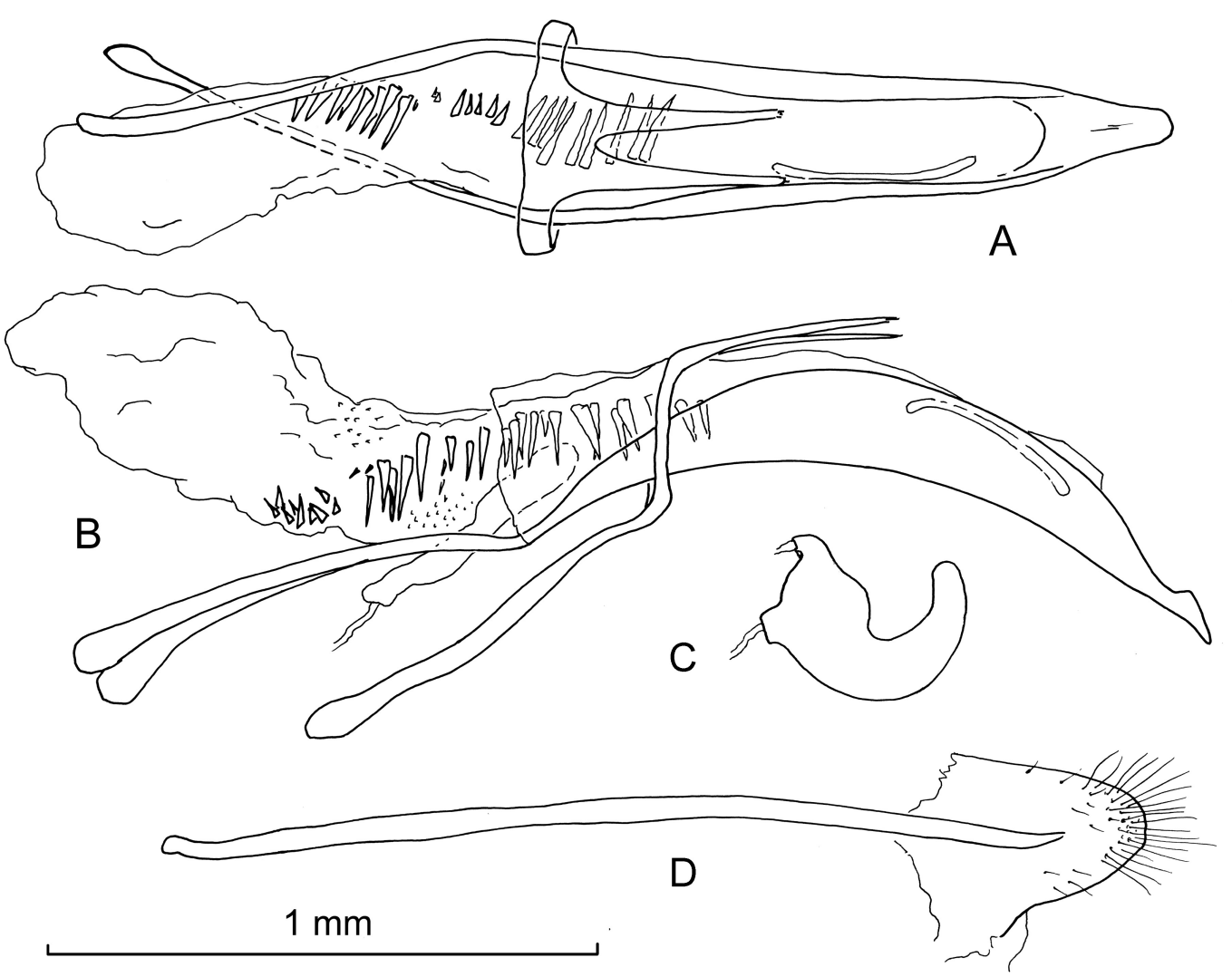

Fig. 4.- Laparocerus fraterculus n. sp. Edeago en vista dorsal (A) y vista lateral (B); espermateca (C) y urosternito VIII femenino (D).

Fig. 4.- Laparocerus fraterculus n. sp. Aedeagus in dorsal view (A) and lateral view (B); spermatheca (C) and female urosternite VIII (D).

mucrón diminuto; tarsómeros cortos, triangulares. Cara ventral con pilosidad fina blanquecina semierguida, doble de larga que las escamitas dorsales; pelos algo más largos en el metasterno, separados; el tegumento liso, negro, brillante, con rugosidad transversal en el primer ventrito. Saliente intermesocoxal muy fino, prácticamente inexistente (marcado por hilera de pelos). Edeago (Fig. 4).

La hembra es algo mayor, con élitros más inflados y anchos $(\mathrm{L} / \mathrm{A}=1,45)$, con los puntos de las estrías más pequeñas e intervalos más planos; tibias inermes. Espermateca (Fig. 4C) con el lóbulo glandular muy reducido; urosternito VIII (Fig. 4D).

ETimología. El epíteto específico fraterculus significa en latín pequeño hermano o hermano menor, en alusión a su parentesco con L. maxorata y talla menor.
OBSERVACIONES. De esta nueva especie se conocen solo tres ejemplares. Por un lado, un macho mutilado y algo inmaturo (cuerpo entero, un escapo, una pata anterior y otra posterior) y el abdomen de una hembra con tres patas, ambos colectados en la península de Jandía. Existe además una hembra completa (longitud 5,05 $\mathrm{mm}$ ) procedente de Jumillo, localidad próxima a La Antigua y situada más al norte, en la parte central de la isla. Se ha designado holotipo al único macho, a pesar de estar mutilado, por ser el ejemplar que presenta mayor número de caracteres diagnósticos. De hecho, la diagnosis que antecede se basa sólo en la pareja de Jandía, y queda pendiente hacer una descripción más completa cuando se conozca mejor su variabilidad. La hembra de Jumillo (La Antigua) se ha excluido de la serie típica por prudencia, ya que otras especies (i.e. Laparocerus rasus ) presentan 


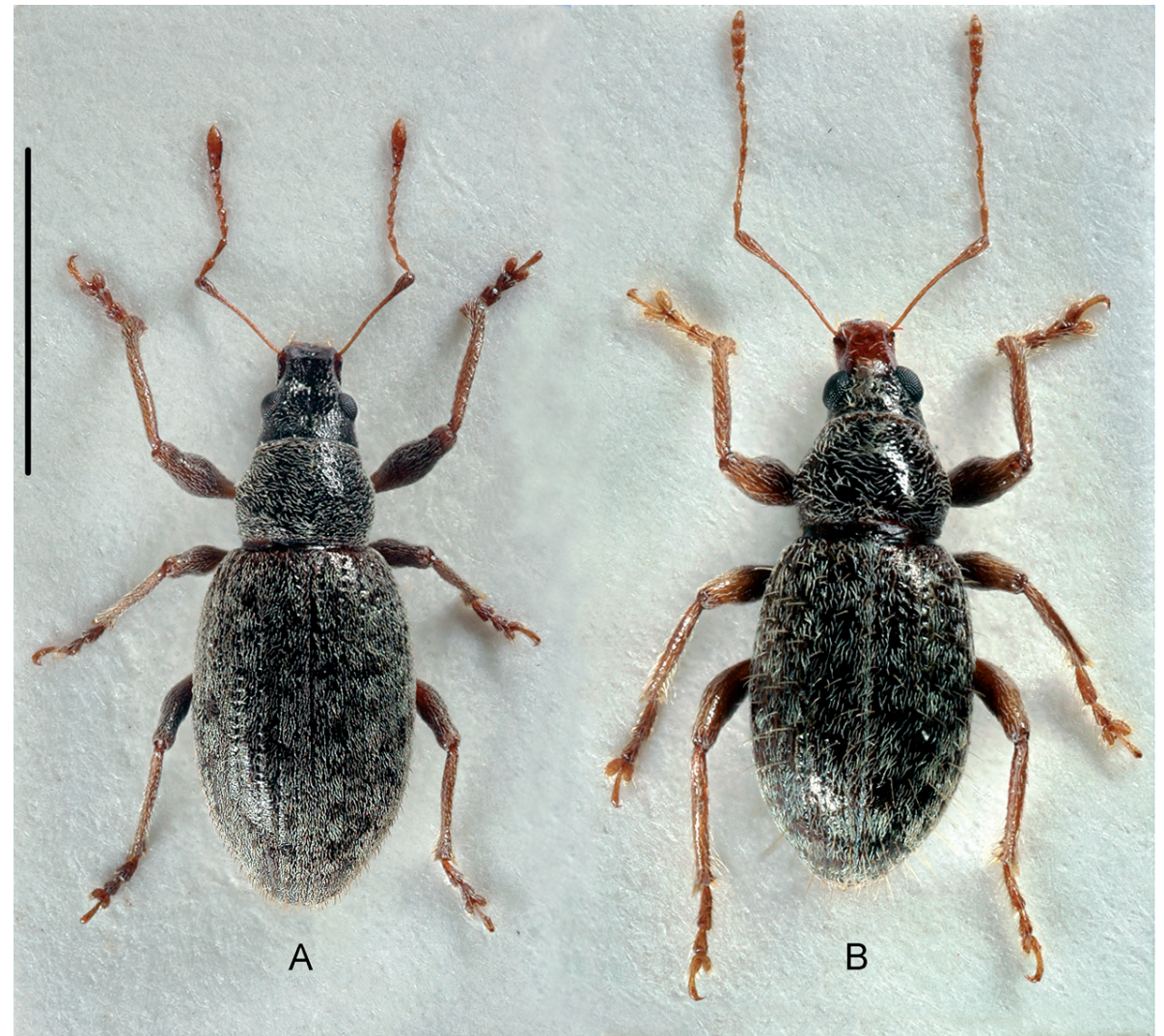

Fig. 5.- Holotipos $\left(\mathrm{O}^{\mathrm{T}}\right)$ de Laparocerus longipennis n. sp. (A) y Laparocerus colonnellii n. sp. (B). Escala 3 mm.

Fig. 5.- Holotypes $\left(\mathrm{O}^{7}\right)$ of Laparocerus longipennis n. sp. (A) and Laparocerus colonnellii $\mathbf{n}$. sp. (B). Scale 3 mm.

poblaciones diferenciadas entre Jandía y el resto de la isla. Por lo pronto, esta hembra única carece de la microrreticulación cefálica, el surco frontal se prolonga más hacia atrás, y las cerditas blanquecinas arqueadas de los élitros son algo más largas y están más extendidas en todo el tercio apical.

Laparocerus fraterculus n. sp. es fácil de reconocer por su tamaño pequeño, cuerpo oblongo $\left(\sigma^{7}\right)$, escapo fino en la base, grueso y abruptamente capitado en el ápice (grueso en la base, débil y brevemente capitado en $L$. dispar), cabeza con ojos moderadamente prominentes y vértex con microrreticulación marcada, el pronoto de tegumento brillante con puntos gruesos foveiformes bastante juntos y algunos menores, el tegumento de los élitros es brillante, carece de pelos largos y presenta a lo sumo algunas cerdas blanquecinas arqueadas hacia el ápice elitral. Las protibias del macho se tuercen bruscamente $\left(>20^{\circ}\right)$ a un tercio de su ápice, como en L. maxorata n. sp., especi con la que aparentemente está emparentada, pero que es mucho mayor y con pilosidad elitral llamativa.

\section{Laparocerus longipennis $\mathbf{n}$. sp.}

(Figs. 5A y 6)

Material examinado. Fuerteventura: Holotipo $10^{\pi}$ de Tarajalejo, La Lajita FV 56 km 5,2 (UTM 29R 058407 312241) 26-1-2008, leg. A. Machado (TFMC/CO-15964).Paratipos: mismos datos de colecta 172 exx (AMC, 2 RG, 2 $\mathrm{ACC})$.

MEDidAs DEL HOLOTIPo $\left(\sigma^{x}\right)$. Longitud: total ( $\sin$ rostro) $4,70 \mathrm{~mm}$, rostro $0,52 \mathrm{~mm}$, escapo $1,00 \mathrm{~mm}$, funículo 0,98 (desmómeros I-IV respectivamente $0,21 / 0,21 / 0,15 / 0,13 \mathrm{~mm})$, maza $0,40 \mathrm{~mm}$, ojo $0,27 \mathrm{~mm}$, pronoto $0,93 \mathrm{~mm}$, élitros $3,30 \mathrm{~mm}$, tibias (pro- /meso- /meta-) 1,34 /1,14 /1,36 mm. Anchura: cabeza (a nivel de los ojos) $0,86 \mathrm{~mm}$, (interocular) 


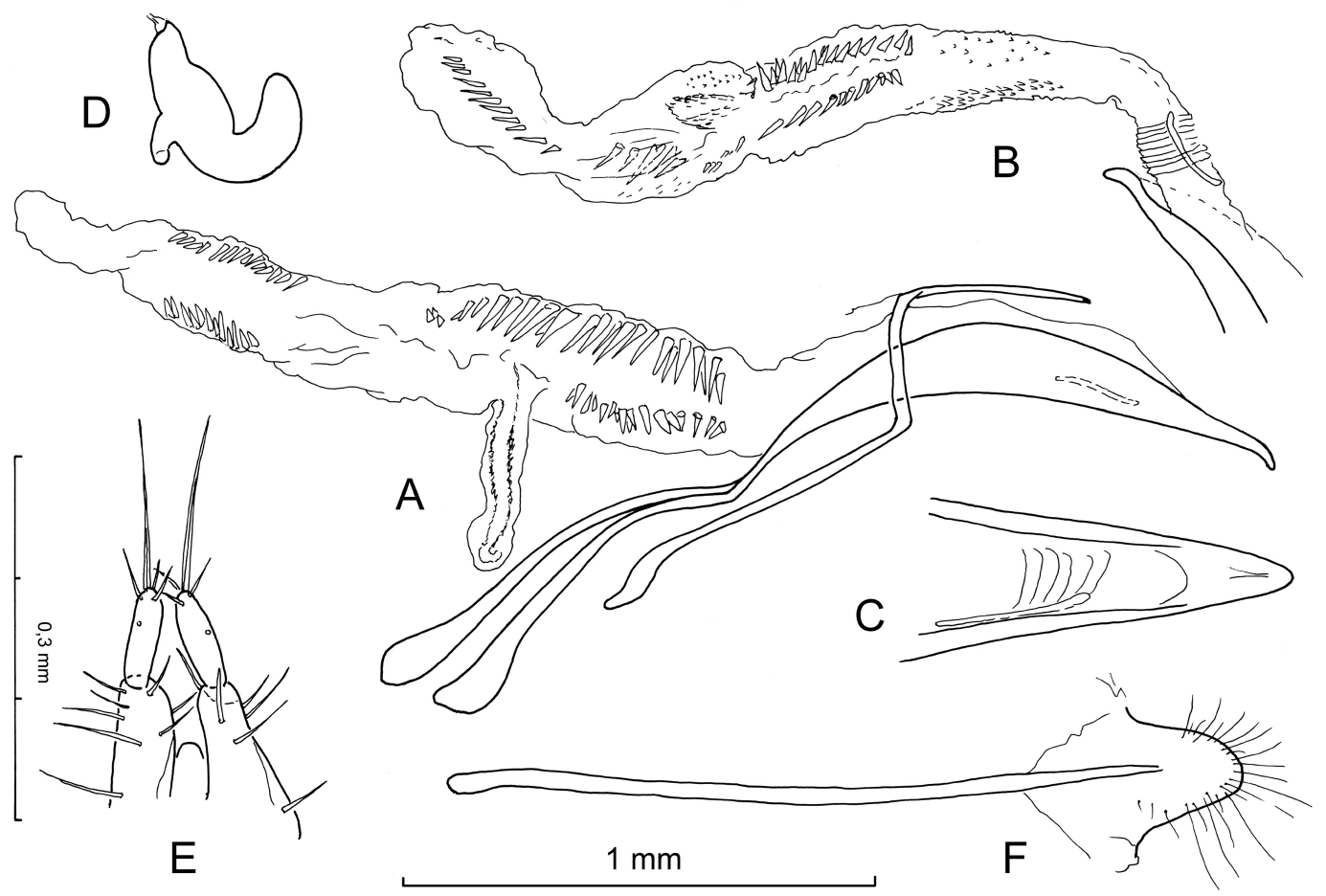

Fig. 6.- Laparocerus longipennis n. sp. Edeago en vista lateral (A), detalle del saco interno evaginado (B) y detalle del ápice en vista dorsal (C), espermateca (D), gonostilos (E) y urosternito VIII (F).

Fig. 6.- Laparocerus longipennis n. sp. Aedeagus in lateral view (A), detail of everted internal sac (B) and detail of apex in dorsal view (C), spermatheca (D), gonostyti (E) and female urosternite VIII (F).

$0,49 \mathrm{~mm}$; rostro (a nivel de los pterigios) $0,58 \mathrm{~mm}$, (mínimo dorsal) $0,42 \mathrm{~mm}$ (mínimo ventral) 0,56 $\mathrm{mm}$; escapo $0,11 \mathrm{~mm}$, maza $0,13 \mathrm{~mm}$, ojo $0,22 \mathrm{~mm}$, pronoto (anterior /máxima /posterior) $0,94 / 1,24 /$ $1,14 \mathrm{~mm}$ y élitros (máxima) 2,00 mm. Altura: abdomen $1,54 \mathrm{~mm}$.

DESCRIPCIÓN. Machos: Laparocerus de talla pequeña (longitud 4,3-5,2 mm; media 4,65 mm), variable, cuerpo oblongo generalmente muy alargado y convexo (subcilíndrico). Tegumento brillante de color pardo negruzco (ejemplares maduros), con antenas, tarsos y tibias pardo-testáceas; vestimenta de escamitas finas doradas, pequeñas, tumbadas, formando a veces dibujo en parches en los élitros; éstos con abundantes setas muy cortas y suberectas, dispuestas en hileras.

Antenas cortas, delgadas; escapo ligeramente arqueado al medio, breve y abruptamente capitado; funículo casi tan largo como el escapo, desmómero $1^{\circ}$ algo más grueso que el $2^{\circ}$, igual de largo, $3^{\circ}$ algo más largo que el $4^{\circ}$; maza elíptica, robusta $(\mathrm{L} / \mathrm{A}=$ $3,1)$ algo más larga que los tres desmómeros previos reunidos.

Cabeza de base ancha, rostro estrecho (L/A $\approx$ $8,5)$, pterigios pequeños, paralelos, nada o apenas sobresalientes; quilla epistomal completa, mal definida; metarrostro estrechado dorsalmente (canal escrobal y base de las antenas visibles desde arriba), los márgenes algo levantados, paralelos o algo convergentes hacia delante, moderadamente acanalado a su largo (depresión prolongada en la frente); fóvea frontal estrecha, a modo de surco profundo, prolongado hacia el vértex. Ojos pequeños, ovales $(\mathrm{L} / \mathrm{A}=$ $1,23)$, uniformemente convexos, moderadamente prominentes $($ convexidad $=30 \%)$. Tegumento brillante, con punteado variable (generalmente bien impreso), bastante escaso en prorrostro y canal metarrostral.

Pronoto transversal $(\mathrm{L} / \mathrm{A}=0,75)$, sin rebordes, lados poco curvados, sinuosos por delante, formando collarín (constricción) más o menos definido. 
Tegumento liso con punteado doble bastante uniforme (puntos mayores bien impresos, separados \pm un diámetro, los pequeños \pm superficiales); escamitas muy finas en disposición transversal. Línea media inexistente.

Escudete triangular, ancho, cubierto de escamitas.

Élitros convexos, de aspecto bastante alargado (3,5-4,1x la longitud del pronoto) arqueados o subparalelos lateralmente, poco acuminados; máxima anchura generalmente hacia la mitad; declive apical suave; $\mathrm{L} / \mathrm{A}=1,5)$, ángulo humeral más o menos redondeado, prácticamente sin hombros. Estrías con puntos algo más gruesos que los del pronoto; interestrías apenas convexas, con 6-7 escamitas a lo ancho e hilera longitudinal de setas cortas erguidas (no mayores que una uña), arqueadas, formando un manto uniforme; la mayoría con punta brevemente bífida (ver a gran aumento). Tegumento brillante, con chagrinado coriáceo amplio, variable, generalmente superficial.

Patas gráciles, poco pilosas (las escamitas, adpresas); tibias delgadas, protibias sinuosas $\mathrm{y} \pm$ curvadas apicalmente, ensanchadas en el ápice hacia dentro, con mucrón cónico puntiagudo (terminal), el ángulo externo ampliamente curvado; mesotibias y metatibias con mucrones más cortos, pequeños.

Cara ventral. Saliente intermesocoxal apenas o nada elevado, bastante inconspicuo. Tegumento brillante, con microrrugosidad transversal en metasterno, $1^{\text {er }}$ y parte del $2^{\circ}$ ventrito, punteado en los demás. Pilosidad fina, corta y abierta; más fina y doble de larga en base de los fémures, trocánteres, cara posterior de las mesocoxas, zona mediana de metasterno y $1^{\text {er }}$ ventrito abdominal. Último ventrito truncado apicalmente.

Edeago (Fig. 6A). Lóbulo medio arqueado en la base, aguzado progresivamente hacia el ápice (vista dorsal), punta roma, brevemente torcida hacia abajo; temones largos y gruesos apicalmente; saco interno tubular, moderadamente largo, lóbulo gonoporal corto, emplazado ventralmente, con bandas longitudinales de dentículos; saco ciego con dos campos dobles de dientes fuertes, uno preapical y otro pre-mediano. Con el saco evaginado se aprecian otros campos adicionales de dentículos más débiles, Fig. 6B).

Hembras: Longitud 3,6-5,4 $\mathrm{mm}$ (media $=4,63$ $\mathrm{mm}$ ), muy parecidas al macho, algo más infladas pero de iguales proporciones (generalmente, los élitros más subparalelos y anchos en la mitad basal); protibias rectas (no curvadas en gancho apicalmente), con mucrón mucho más pequeño; meso y metatibias inermes. Último ventrito abdominal redondeado apicalmente. Espermateca (Fig. 6C), esternito VIII (Fig. 6F); bolsa copulatriz tapizada parcialmente por fuertes dientes.

ETimología. El epíteto específico longipennis es un adjetivo latino que hace referencia a la llamativa longitud de los élitros, superior a lo que es habitual en sus congéneres.

OBSERVACIONES. Laparocerus longipennis n. sp. destaca a primera vista por su tamaño pequeño, cuerpo estrecho, alargado y subcilíndrico, vestimenta de escamitas de aspecto algo pulverulento, y élitros con abundantes setas pequeñas dispuestas en hileras. Los élitros, aunque variables en curvatura lateral y longitud, son siempre más largos de lo común, entre 3,5 y 4 veces la longitud del pronoto. Estas proporciones no se alcanzan en ningún Laparocerus de las Canarias orientales, aunque sí y se superan en algunas especies de las islas occidentales. Así ocurre en L. benchijigua Machado, 2007 y L. acutipennis Machado, 2007 (ratio 5,4), ambas de La Gomera y fáciles de separar porque presentan setas mucho más largas en los élitros, o éstos son notoriamente acuminados (segunda especie). Una singularidad característica de L. longipennis n. sp. es que una buena parte de las pequeñas setas emergentes en los élitros son bifurcadas en su ápice. Los datos moleculares disponibles (secuencias parciales de COII y 16SrRNA, pendientes de publicar) relacionan esta nueva especie con el conjunto formado por las cuatro especies anteriores.

DisTRIBUCIÓN Y ECOLOGÍA. La especie es endémica de la isla de Fuerteventura, y aunque hasta la fecha solo se ha encontrado en una localidad (cuenca de Tarajalejo), es de suponer que se distribuye en ambientes similares -llanadas dominadas por matorral de quenopodiáceas - que tanto abundan en esta isla. Fue colectada en gran número durante la noche y en pleno invierno, principalmente sobre Salsola vermiculata.

\section{Laparocerus calvus $\mathbf{n}$. sp.}

(Figs. 2B y 7)

Material examinado. Fuerteventura: Holotipo $10^{7}$ de Jandía, Pico de la Zarza (UTM 28R 563311 3108654) 800 m, 5-3-2011 leg. A. Machado (TFMC/CO-15965)._- Paratipos, misma localidad y fecha 24 exx leg. A. Machado (AMC, 1 

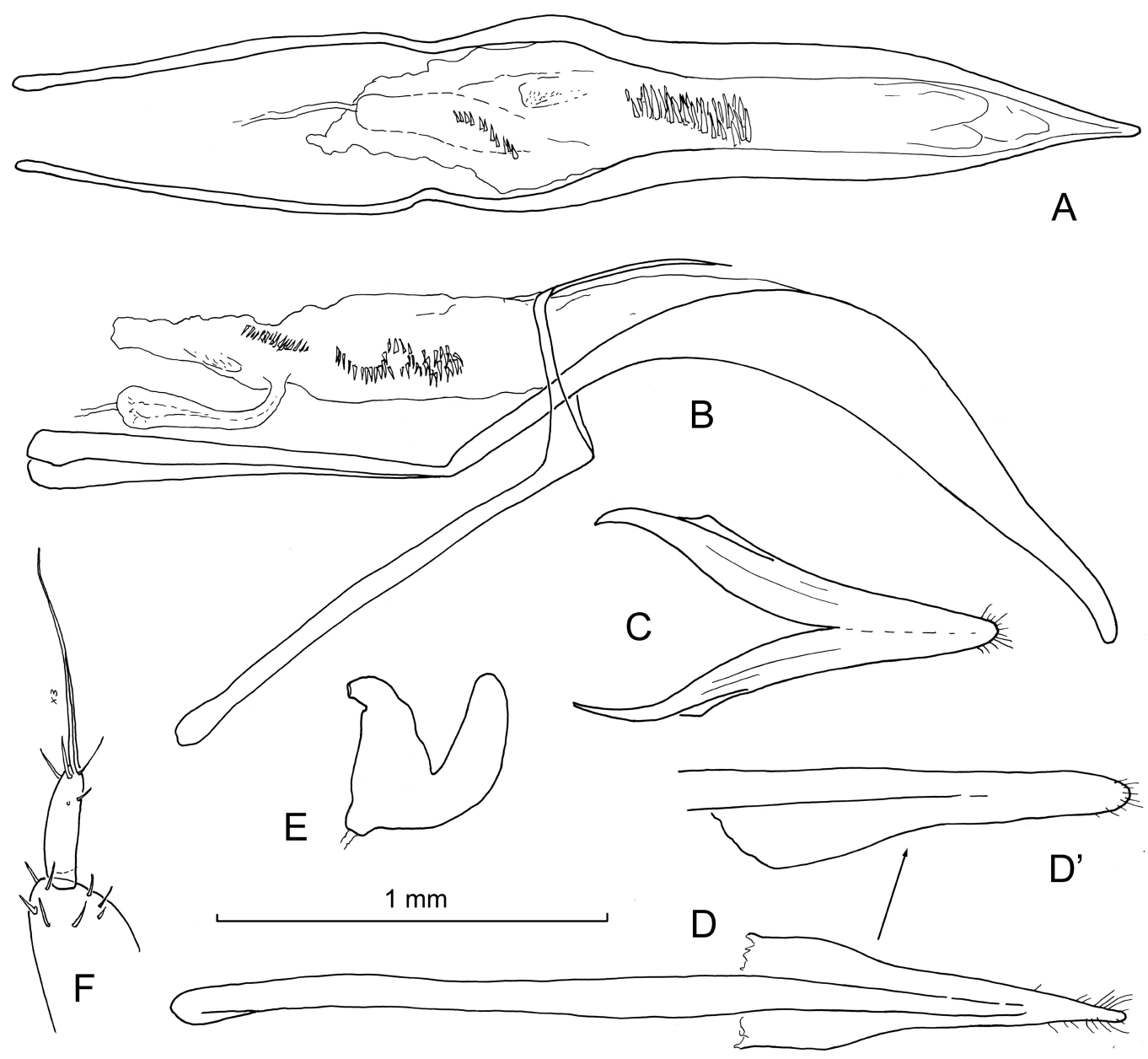

Fig. 7.- Laparocerus calvus n. sp. Edeago en vista dorsal (A) y vista lateral (B); terguito femenino VIII (C), urosternito VIII (D) y detalle de la placa apical en vista lateral (D'), espermateca (E) y gonostilo (F).

Fig. 7.- Laparocerus calvus n. sp. Aedeagus in dorsal view (A) and lateral view (B); female tergite VIII (C), urosternite VIII (D) and detail of its apical plate in lateral view (D'), spermatheca (E) and gonostylus (F).

MNHN), 23 exx leg. R. García (RGB), 24 exx leg. A. Aguiar (AAC); 10 exx 21-12-2003, 10 exx 20-12-2002, 8 exx 18-21978, 600 m, 7 exx 2-12-1001 leg A. Machado (AMC); 4 exx 1-2-1991 leg. E. Colonnelli (EC), 1 ex 27-2-1990 leg. E. Colonnelli (MZUR). Morro del Jorao 550 m, 21 exx 15-1-2005 leg. A. Machado (AMC). Cumbres de Jandía 2 exx 27-2-1990, 2 exx 12-5-1977, 3 exx 15-2-1977, 6 exx 10-5-1974, 3 exx 102-1997, 3 exx 17-2-1995 leg. P. Oromí (ULL, ULL); 1 ex 6-31986 leg. C. Jeanne (JP). Pico del Fraile 9 exx 12-3-1984 leg. E. Colonnelli (MZUR). Pico de la Matanza 11 exx 10-2-1991 leg. E. Colonnelli (EC). Divisoria del Aguililla 400-500 m, 4 exx 20-1-1991 leg. A. Liberto (AL). Bco Viñamar 600-800 m, 2 exx 17-12-1989 leg. S. Scholz (MPE).

Medidas DEL Holotipo $\left(\sigma^{7}\right)$. Longitud: total ( $\sin$ rostro) $5,8 \mathrm{~mm}$, rostro $0,70 \mathrm{~mm}$, escapo $1,65 \mathrm{~mm}$, funículo 1,65 (desmómeros I-IV respectivamente $0,40 / 0,31 / 0,20 / 0,20 \mathrm{~mm})$, maza $0,64 \mathrm{~mm}$, ojo $0,39 \mathrm{~mm}$, pronoto $1,40 \mathrm{~mm}$, élitros $3,90 \mathrm{~mm}$, tibias (pro- /meso- /meta-) 2,05/1,70/1,90 mm. Anchura: cabeza (a nivel de los ojos) 1,26 mm, (interocular) $0,77 \mathrm{~mm}$; rostro (a nivel de los pterigios) $0,77 \mathrm{~mm}$, (mínimo dorsal) 0,56 mm (mínimo ventral) 0,66 $\mathrm{mm}$; escapo $0,17 \mathrm{~mm}$, maza $0,17 \mathrm{~mm}$, ojo $0,30 \mathrm{~mm}$, pronoto (anterior /máxima /posterior) $1,40 / 1,85 /$ $1,80 \mathrm{~mm}$ y élitros (máxima) $3,00 \mathrm{~mm}$. Altura: abdomen $2,48 \mathrm{~mm}$.

DESCRIPCIÓN. Machos: Longitud 5,0-6,4 mm $($ media $=5,58 \mathrm{~mm})$. Laparocerus de talla mediana, 
cuerpo elíptico, ancho y subgloboso. Tegumento de color negro, satinado en cabeza y pronoto, brillante en élitros, con débil viso dorado en cabeza y élitros, y viso azulino muy ligero en pronoto; extremidades a veces algo parduscas (escapo algo rojizo en la base), patas con escamitas lanceoladas muy pequeñas, adpresas y muy separadas, poco conspicuas; pilosidad reducida a los extremos de las tibias y tarsos; cabeza, pronoto y élitros dorsalmente glabros.

Antenas robustas; escapo 1,2x la longitud del pronoto, poco arqueado, grueso en su tramo medio, brevemente estrechado en la base y ensanchado apicalmente (subcapitado); funículo tan largo como el escapo, desmómero $1^{\circ}$ algo menor que el $2^{\circ}, 3^{\circ} \mathrm{y}$ $4^{\circ}$ iguales; maza fusiforme $(\mathrm{L} / \mathrm{A}=3,7)$, más larga que los tres desmómeros previos reunidos.

Cabeza fuertemente cónica, de aspecto "pulido" (aristas romas); rostro de base ancha, notoriamente estrangulado hacia delante (sección cuadrangular); pterigios pequeños, subparalelos, poco salientes (base antenal visible desde arriba); prorrostro delimitado por el declive, algo más ancho que el metarrostro; quilla epistomal débil, roma; metarrostro de márgenes laterales romos, débilmente deprimido a lo largo; frente ampliamente deprimida hacia los lados; foseta frontal estrecha, corta y precisa (a veces algo prolongada en línea hacia atrás). Ojos pequeños, ovales $(\mathrm{L} / \mathrm{A}=1,3)$ moderadamente prominentes (convexidad 30\%), bastante separados (distancia interocular 2x diámetro ocular mayor); surco periocular profundo, salvo sector posteroventral. Tegumento con microrreticulación polígonal isodiamétrica muy marcada, con algunos micropuntos (poco mayores que celda del polígono) y alguna microqueta; desprovisto de escamas.

Pronoto transversal ( $\mathrm{L} / \mathrm{A}=0,6-0,7)$, sin rebordes, de lados poco curvos; más estrechado por delante que en la base; punteado mediocre, preciso, muy regular (puntos separados 1-2 diámetros) sobre fondo con microrreticulación fuerte igual que la de la cabeza, pero menos densa; ocasionalmente un esbozo de línea media. Glabro.

Escudete triangular muy pequeño, liso, algo inclinado sobre el reborde.

Élitros ovales acuminados apicalmente, anchos y muy convexos $(\mathrm{L} / \mathrm{A}=2,8)$; la base rectilínea, apenas más ancha que la del pronoto (prácticamente sin hombros). Estrías marcadas por puntos mediocres y profundos (reduciéndose hacia los márgenes); intervalos ligeramente convexos, el sutural a menudo algo elevado en la base (incipiente carina) y la estría $1^{\text {a }}$ deprimida. Tegumento brillante, sin escamas, con microrreticulación transversal superficial, más marcada en los flancos; microquetas dispersas, visibles a gran aumento y con luz rasante.

Patas largas y gráciles; protibias muy largas (mayores que las metatibias), notoriamente arqueado-sinuosas en su mitad distal, algo engrosadas hacia el ápice; ángulo externo romo, el interno expandido y con fuerte mucrón agudo; mesotibias ligeramente arqueadas, con mucrón pequeño; metatibias rectas, mucrón pequeño. Tarsos grandes, estrechos, con pilosidad escasa.

Cara ventral: Tegumento con microescultura isodiamétrica extendida y vestimenta rala de escamitas inclinadas lanceoladas (cortas) y piliformes (algo más largas). Saliente intermesocoxal estrecho, aquillado, poco prominente. Metasterno y ventritos $3^{\circ} \mathrm{y}$ $4^{\circ}$ cortos; ventrito $5^{\circ}$ truncado apicalmente, brevemente escotado al medio, con una depresión longitudinal mediana.

Edeago (Figs. 7A-B): Lóbulo medio muy arqueado en el tercio basal, aguzado apicalmente, la punta brevemente torcida hacia abajo (visto de perfil); saco interno corto (no rebasa los temones), sin esclerito ostiolar, un campo de dentículos mediano proximal, otro menor mediano y una plaquita ligeramente esclerosada en el divertículo ciego (estrecho); divertículo gonoporal curvado y estrecho en la base, amplio apicalmente.

Hembras: Longitud 4,7-6,6 mm (media 5,62 $\mathrm{mm})$. Similares al macho, élitros más redondos y globosos (declive apical más abrupto) con puntos de las estrías menores y más superficiales; escapo más delgado en su tramo medio y más claramente capitado; protibias más cortas (menores que metatibias) menos arqueadas, menos engrosadas apicalmente y mucrón menos potente, último ventrito acuminado. Terquito VII y esternito VIII (Figs. 7C-D) apicalmente estrechos y agudos (en "v" invertida); espículo ventral muy corto; espermateca con lóbulo glandular corto, con forma de pezón (Fig. 7E).

OBSERVACIONES. Esta nueva especie se distingue bien de otros Laparocerus de talla similar por combinar la ausencia de pelos y escamas, color negro con viso dorado en cabeza y élitros (ligeramente azulino en el pronoto), la microescultura isodiamétrica muy marcada en la mitad anterior, punteado abierto y preciso en el pronoto (satinado), la cabeza fuertemente cónica y las protibias arqueadas en ambos sexos (más largas en el macho). No cabe confusión con ninguna de las otras especies presen- 
tes en la isla de Fuerteventura, pues éstas tienen pilosidad o escamas en los élitros, y si son pocas o se han desprendido como suele ocurrir en L. curvipes espanoli, entonces el pronoto es brillante en vez de satinado, y el punteado es muy superficial, nada aparente. Según los datos moleculares disponibles (sin publicar) la especie está directamente relacionada con el conjunto de L. maxorata n. sp. y L. curvipes espanoli Roudier, 1954.

DisTRIBUCIÓN Y ECOLOGÍA. Laparocerus calvus n. sp. es otro endemismo local de las cumbres de Jandía, en el extremo meridional de Fuerteventura. La especie es invernal y nocturna, y se ha colectado exclusivamente sobre Nauplius sericeum (Asteraceae) junto a L. maxorata n. sp., L. rasus y L. curvipes espanoli.

Laparocerus curvipes espanoli Roudier, 1954

Laparocerus (Wollastonicerus) espanoli Roudier, 1954: 84 — Gurrea \& Sanz, 2000: 338.

Laparocerus curvipes espanoli, in Roudier, 1957: 22 - Lindberg \& Lindberg, 1958: 24 - Machado \& Oromí, 2000: 213.

MAterial EXAminAdo. Fuerteventura: 1 우 (holotipo) "Fuerteventura" [sin más datos] (Coll. Roudier, MNHN). Jandía: 1 ex 2-1980 leg. A. Cobos (MAZ), 1 ex leg. H. Franz (NMW). Jandía: Morro del Jorao 550 m, 67 exx 15-1-2005 leg. A. Machado (AMC); Pico de la Zarza 600-850 m, 4 exx 27-21990, 21 exx 1-2-1991 leg. E. Colonnelli (MZUR), 1 ex 19-21978, 7 exx 5-3-2011 leg. A. Machado (AMC), 13 exx 5-3-2011 leg. R. García (RGB), 5 exx 5-3-2011 leg. A. Aguiar (AAC), 11 exx 20-12-2002 leg. S. Scholz (AMC). Pico de la Matanza 32 exx 10-2-1991 leg. E. Colonnelli (EC). Pico del Fraile 600 m, 13 exx 12-3-1984 leg. E. Colonnelli (1 MNHN, 12 MZUR). Pico del Mocán 600 m, 1 ex 14-1-1989 leg. S. Scholz (MPE). Divisoria del Aguillilla 400-500 m, 12 exx 311-1991 leg. A. Liberto (AL). Cumbres de Jandía 7 exx 10-51974, 2 exx 10-2-1997, 5 exx 15-2-1997 leg. P. Oromí (POM); 5 exx 2-12-2001 leg. A. Machado (AMC); 3 exx 31-1-1991 leg. E. Colonnelli (POM). Betancuria: Morro Velhoso $640 \mathrm{~m} 7-$ 3-2011, 2 exx leg. A. Machado (AMC), 6 exx leg. R. García (RGB), 4 exx leg. A. Aguiar (AAC); Betancuria: Tegú 600 m, 11 exx leg. R. Sciaky (7 MZUR, 4 AMC), idem. 11 leg. E. Colonnelli (MZUR). La Oliva, 2 exx 13-2-1977 leg. J.M. Fernández (TFMC).

Diagnosis. Longitud $0^{\pi} \sigma^{\pi}$ 5,8-6,6 mm, 우 우 5,9-7,3 mm. Cuerpo oval, globoso, brillante, de color negro; con vestimenta rala de escamitas adpresas, cortas y glaucas, formando dibujo en parches más o menos definido. Rostro convergente hacia delante, ojos moderadamente prominentes; mandíbulas con tres setas largas en su cara exterior. Escapo sinuoso engrosándose suavemente en el tercio apical. Pronoto globoso, sin constricción en el margen anterior; punteado fino, separado y superficial; sin línea media. Élitros $\mathrm{O}^{\prime}$ ovales $(\mathrm{L} / \mathrm{A}=1,3)$, en ㅇ de forma ovoide, globosos y cortos ( $/ \mathrm{A}=$ 1,3); interestrías planas. Procoxas, mesocoxas y cara posterior de la mitad basal del fémur pilosas. Protibia masculina deprimida y arqueada en el plano sagital, estrangulada preapicalmente y algo torcida hacia dentro, el ápice expandido hacia ambos lados (más hacia dentro que hacia fuera). Machos con premucrón corto y agudo, metamucrón amplio, triangular y laminar. Edeago con el saco interno muy corto, sin esclerito ostiolar, con un extenso campo doble de dientes; esternito VIII femenino con espículo bastante arqueado; la placa terminal transversal y estrecha.

OBSERVACIONES. Laparocerus curvipes Lindberg, 1953 fue descrito sobre material colectado en San Miguel, en el sur de la isla de Tenerife. En 1954, André Roudier describe L. espanoli sobre una única hembra proveniente de Fuerteventura, sin precisión de localidad. En 1957, este mismo autor estudia un macho de Haría, en Lanzarote, cuyo edeago y protibias curvadas apicalmente coinciden con los de un paratipo de L. curvipes, por lo que asimila espanoli Roudier, 1954 a este taxón a título de subespecie, sin concretar las diferencias morfológicas. Roudier destaca asimismo la singular distribución de la especie, presente en Tenerife y en las Canarias Orientales, postulando que debería aparecer en Gran Canaria, lo que no ha ocurrido hasta el presente. Ciertamente, se trata de un caso corológico extraordinario en el género Laparocerus, sobre todo si se considera que las demás especies del grupo al que pertenece - que he dado en llamar grupo de L. maxorata n. sp.- son exclusivas de Fuerteventura. Esta afiliación está confirmada con datos moleculares (pendientes de publicar) para las dos subespecies que pueblan las Canarias orientales: L. curvipes famarae y L. curvipes espanoli, y falta por corroborar con la subespecie de Tenerife. Las figuras 9A-E muestran las genitalias de ejemplares de la localidad típica, San Miguel, en esta isla, y son del todo concordantes, particularmente la disposición transversal de la placa apical del esternito VIII femenino y la curvatura de su espículo (Fig. 9D). No se trata, pues, de un Machadotrox Alonso-Zarazaga \& Lyal, 1999 (= Wollastonicerus Uyttenboogaart, 1936), subgénero al que fue atribuido $L$. curvipes por presentar las protibias dilatadas en abanico en su ápice, carácter que es homoplásico, lo mismo que la torcedura apical. 


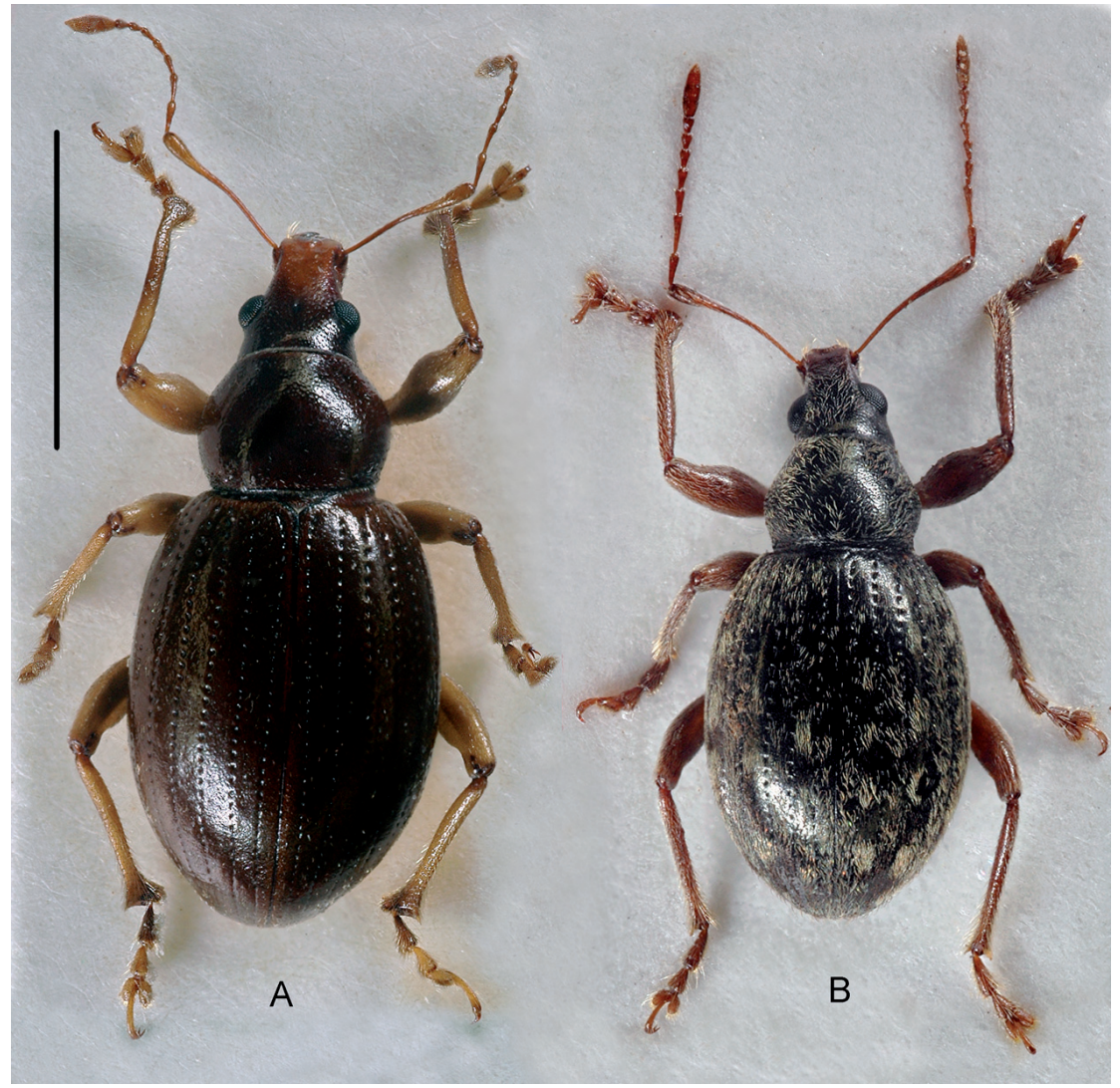

Fig. 8.- Holotipos $\left(\sigma^{7}\right)$ de Laparocerus curvipes famarae n. ssp. (A) y Laparocerus xericola n. sp. (B). Escala 3 mm.

Fig. 8.- Holotypes $\left(\sigma^{7}\right)$ of Laparocerus curvipes famarae n. ssp. (A) and Laparocerus xericola n. sp. (B). Scale 3 mm.

DisTRIBUCIÓN Y ECOLOGÍA. Subespecie endémica de la isla de Fuerteventura, donde habita tanto en el macizo meridional de Jandía, como en el macizo central de Betancuria, siempre a altitudes máximas, que en esta isla rondan los 500-800 m. Convive en estas localidades con L. maxorata n. sp., L. rasus s.l. y $L$. calvus alimentándose de la misma planta, Nauplius sericeus (Asteraceae), pero también sobre herbáceas (Sonchus sp.). En el Museo de Ciencias Naturales de Tenerife existen dos ejemplares colectados en La Oliva, en la parte norte y más llana de la isla, pero no se han vuelto a encontrar en dicha localidad.

\section{Laparocerus curvipes famarae $\mathrm{n}$. ssp.}

(Figs. 8A y 9F-I)

Material eXAminado. Lanzarote: Holotipo $10^{7}$ de Famara, Ermita de las Nieves, 590 m. (UTM 28R 643259 3220644) 112-2001, leg. A. Machado (TFMC/CO-15966)._- Paratipos: 34 exx misma localidad y datos (AMC), todos los ejemplares de la serie algo inmaturos; 1 ex. 27-11-1988, leg. P. Oromí (ULL).

Medidas DEL holotipo $\left(\mathrm{O}^{\mathrm{T}}\right)$. Longitud: total ( $\mathrm{sin}$ rostro) $5,9 \mathrm{~mm}$, rostro $0,62 \mathrm{~mm}$, escapo $1,46 \mathrm{~mm}$, funículo 1,44 (desmómeros I-IV respectivamente $0,32 / 0,28 / 0,20 / 0,18 \mathrm{~mm}$ ), maza $0,52 \mathrm{~mm}$, ojo $0,38 \mathrm{~mm}$, pronoto $1,33 \mathrm{~mm}$, élitros $4,20 \mathrm{~mm}$, tibias (pro- /meso- /meta-) 1,80/1,57/1,20 mm. Anchura: cabeza (a nivel de los ojos) $0,92 \mathrm{~mm}$, (interocular) $0,66 \mathrm{~mm}$; rostro (a nivel de los pterigios) $0,70 \mathrm{~mm}$, (mínimo dorsal) 0,50 mm (mínimo ventral) 0,64 $\mathrm{mm}$; escapo $0,15 \mathrm{~mm}$, maza $0,18 \mathrm{~mm}$, ojo $0,32 \mathrm{~mm}$, pronoto (anterior /máxima /posterior) 1,12 / 1,78/ $1,50 \mathrm{~mm}$ y élitros (máxima) $2,95 \mathrm{~mm}$. Altura: abdomen 2,30 $\mathrm{mm}$.

DiAgNOSIS DIFERENCIAL. Longitud $\sigma^{7} \sigma^{7}$ 5,8-6,6 $\mathrm{mm}$, 우 우 5,9-7,3 $\mathrm{mm}$. Se distingue de la subespecie tiponominal y de L. curvipes espanoli, por tener los 


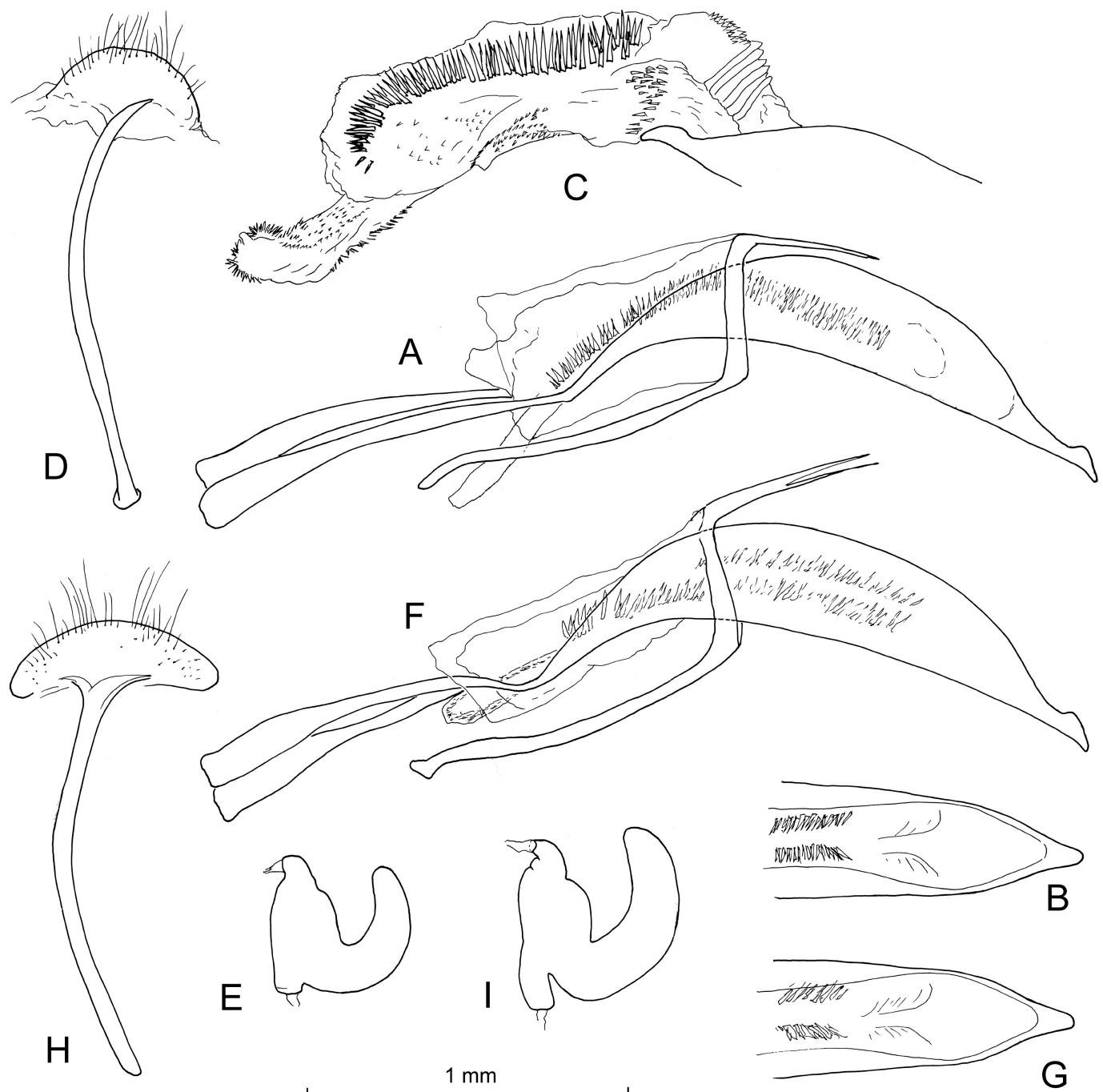

Fig. 9.- Laparocerus curvipes curvipes Lindberg, 1953 (Tenerife, San Miguel), edeago en vista lateral (A), detalle del ápice en vista dorsal (B), detalle del saco interno evaginado (C), urosternito VIII femenino (D) y espermateca (E). Laparocerus curvipes famarae n. ssp., edeago en vista lateral $(F)$, detalle del ápice en vista dorsal $(G)$, urosternito VIII femenino $(H)$ y espermateca (I).

Fig. 9.- Laparocerus curvipes curvipes Lindberg, 1953 (Tenerife, San Miguel), aedeagus in lateral view (A), detail of its apex in dorsal view (B), detail of the everted internal sac (C), female urosternite VIII (D) and spermatheca (E). Laparocerus curvipes famarae $\mathbf{n}$. ssp., aedeagus in lateral view (F), detail of its apex in dorsal view (G), female urosternite VIII (H) and spermatheca (I).

ojos menos prominentes, el escapo menos mazudo, los élitros prácticamente desprovistos de escamas (algunas micro-escamitas piliformes residuales poco conspicuas), y de forma ovaladas igual en ambos sexos $(L / A=1,4)$ aunque más inflados en la hembra.

Edeago (Fig. 9F) sin diferencias relevantes con el de las otras subespecies; la placa terminal igual- mente transversal y estrecha (Fig. 9G). La espermateca tiene el lóbulo glandular más largo (Fig. 9I) que en la subespecie tiponominal (Fig. 9E).

ETIMOLOGía. El epíteto subespecífico deriva del topónimo Famara, en genitivo, macizo del norte de la isla de Lanzarote donde habita el insecto. 
OBSERVACIONES. En general, las tallas de las subespecies de Fuerteventura y Lanzarote son menores que la de la subespecie tiponominal de Tenerife; en ésta, además, la línea media del pronoto está bien definida.

En Canarias existen varias especies de Laparocerus de color negruzco y cuerpo ovalado de aspecto glabro (vestimenta de escamas escasa o ausente) que pueden recordar a L. curvipes famarae. Por lo general, son de talla más grande, los ojos son mayores y mucho más planos, las mandíbulas tienen más de tres setas grandes en su cara externa, el pronoto presenta punteado fuerte o está algo constreñido despúes del margen anterior formando un "collarín", las protibias son rectas o están ampliamente escotadas por dentro (mitad distal), o bien los élitros presentan callo humeral o interestrías mucho más convexas: L. aethiops Wollaston, 1864, L. laevis Roudier, 1957, L. hupalupa Machado, 2007, etc.

DisTRIBUCIÓN Y ECOLOGÍA. Laparocerus curvipes famarae $\mathrm{n}$. $\mathrm{sp}$. vive exclusivamente en el macizo de Famara, al noroeste de la isla de Lanzarote. Se ha colectado en abundancia de noche, alimentándose de hojas de Cynara horrida (Asteraceae), en el pedregal poco vegetado que culmina el cerro. Las condiciones climáticas son equiparables a las del hábitat de su vicariante en Fuerteventura, mientras que la subespecie de Tenerife (ssp. curvipes) se ha localizado en las medianías de sotavento, también sobre los $600 \mathrm{~m}$ de altitud, comiendo Argyranthemum sp (Asteraceae) en tabaibales bien vegetados.

\section{Grupo de Laparocerus rasus}

\section{Laparocerus rasus rasus Wollaston, 1864}

(Figs. 11A-C y 12H)

Laparocerus rasus Wollaston, 1864: 354 - Wollaston, 1865: 322 Marseul, 1872: 527 - Winkler, 1932: 1448; Uyttenboogaart, 1937: 105 - Lona, 1938: 439 - Uyttenboogaart, 1940: 55 - Lindberg \& Lindberg, 1958: 33 - Gurrea \& Sanz, 2000: 346 - Machado \& Oromí, 2000: 78, 216 - Oromí et al., 2003: 178 - Machado, 2006: 2033.

MATERIAL EXAMINADO. Lanzarote: Haría, $10^{7}$ lectotipo 1-1858 leg. T.V. Wollaston (NHM), 3 exx idem paralectotipos (NHM), 4 exx idem paralectotipos (UMO).- Haría 3 exx 25-2-1973; Cumbre de Famara, 3 exx 31-12-1971; Bco. de la Pocela , 6 exx, 24/26-12-1971 leg. G. Israelson (NRS). Risco de Famara 1 ex 3-2-1890 leg. Alluaud (MNHN). Haría 24 exx 18-2-2007 leg. R. García (RGB). Guinate: Los Helechos 2-12-1999, 1 ex. leg. R. Gaedike (DEI). Valle de Malpaso N, 300 m 75 exx 10-
12-1999, 9 ex 1-12-2001, 24 exx 29-11-2002, Mirador de Haría 2 exx 19-2-1995, 2 exx 12-2-1997; 1 ex 3-12-1988; Malpaís de La Corona, 15 m 25 exx 10-12-1999; Famara (Ermita de Las Nieves) 450 m 2 exx 10-12-1999, 107 exx 112-2001; Infra Ye, 190 m 10 exx 19-12-1999 ; Haría, Bco. Cuchillo, 350 m, 6 exx 29-11-2002; Los Valles 300 m, 4 exx 29-11-2002 leg. A. Machado (AMC). Montaña Clara: Caldera, interior SE, 1 ex 14-4-2002 leg. B. Rodríguez., 1 ex 23-2-1995, 1 ex 14-4-2002, 1 ex 27-11-2002 leg. A. J. Pérez, 1 ex 25-1-2002, 1 exx. leg. M. Arechavaleta 27-1-2002, 27-12002 leg. H. López; (cresta) 1 ex 15-4-2002, 2 exx 2-12-2001 leg. B. Rodríguez (ULL).

REDESCRIPCIÓN. Machos: Laparocerus de tamaño medio (longitud 5,4-7,1 mm, media $6,58 \mathrm{~mm}$ ), cuerpo oval-alargado, moderadamente convexo, con extremidades largas. Tegumento de brillo satinado y color pardo, testáceo en patas, antenas y rostro; vestimenta densa de escamitas largas y finas (aspecto sedoso), de color dorado, testáceo, glauco o hialino, formando parches claros y oscuros en los élitros; en el pronoto el disco generalmente oscuro y las escamitas claras hacia los márgenes.

Antenas largas y gráciles; escapo 1,4x más largo que el pronoto, poco arqueado, fino y capitado en su quinto apical; desmómero II algo mayor que el I; maza fusiforme $(\mathrm{L} / \mathrm{A}=3,5)$ casi tan larga como los tres desmómeros previos reunidos.

Rostro casi tan largo como ancho en la base, paralelo o ligeramente convergente hacia delante, poco más estrecho dorsal que ventralmente, los márgenes romos (poco marcados); pterigios paralelos y largos; prorrostro bien demarcado (placa rostral), liso y glabro, con quilla epistomal completa, levantada; metarrostro con ligera depresión puntiforme anterior, no acanalado; frente no deprimida, fóvea frontal puntiforme, muy profunda. Ojos grandes, poco prominentes (convexidad 25\%), tangentes al canto de la frente. Mandíbulas con tres setas largas en su cara externa. Tegumento con punteado pequeño y débil (salvo prorrostro).

Pronoto transversal $(\mathrm{L} / \mathrm{A}=0,7)$, lados más o menos curvados, máxima anchura a la mitad, brevemente constreñido antes del margen anterior (collarín, a menudo rufescente), éste a veces ligeramente escotado al medio; el margen posterior en declive abrupto (rebordeado); base ligeramente cóncava. Tegumento brillante con punteado doble delicado, preciso y denso, no muy profundo (2-3 puntos menores entre los mayores). Línea media ocasionalmente presente (incompleta).

Élitros elíptico-ovalados $(\mathrm{L} / \mathrm{A}=1,6)$, truncados en la base en línea recta; hombros prácticamente inexistentes, máxima anchura algo pasada la mitad; 
tercio apical algo acuminado. Disco moderadamente convexo, estrías con puntos grandes (mayores que los del pronoto) separados 1-1,2 diámetros; interestrías algo convexas, con 12-15 escamitas lanceoladas adpresas a lo ancho, y algunas cerdas recurvadas inconspicuas, más desarrolladas en el tercio apical. Tegumento satinado con microescultura pruinosa-reticulada, poco marcada.

Patas largas, delgadas, con pilosidad tibial más larga en cara distal interna; protibia (igual de larga que metatibia) algo sinuosa, ápice romo, poco ensanchado hacia dentro, almohadilla protibial muy reducida; mucrón dentiforme; mesomucrón más fuerte; metamucrón grande, laminar y transversal (a lo largo del margen interno del área articular), a cuyo pie se abre una muesca poco pronunciada que termina en un diente romo (Fig. $12 \mathrm{H})$ y sobre la que se extienden varios pelos largos curvados apicalmente. Tarsos robustos, con tarsómero basal bastante largo y subrectangular.

Cara ventral con pilosidad rubia separada $\mathrm{y}$ corta, salvo fémures en la base, trocánteres, coxas, esternitos torácicos y $1^{\circ}$ abdominal en su tramo medio con pelos largos y finos. Saliente intermesoxocal cariniforme, poco levantado, con cresta de pelos largos. Último esternito abdominal truncado, ligeramente escotado al medio.

Edeago (Figs. 11A-B) con punta sinuosa, afilada y sin talón (vista de perfil), subtriangular y terminada en lengüeta roma (vista dorsal). Saco interno tubular, no más largo que los temones, con doble campo basal de dientes mediocres, campo mediano anterior corto con pocos dientes robustos, y en el divertículo ciego un campo basal de dientes mediocres, y dos distales paralelos de dentículos apretados; divertículo gonoporal estrecho, emplazado ventro-lateralmente, y más corto que el divertículo ciego.

Hembras: Igual que el macho pero más grandes (longitud 6,3-8,9 mm; media 7,4), élitros inflados y ovoides, menos acuminados $(\mathrm{L} / \mathrm{A}=1,4)$, más anchos en la base, con hombros y lados menos curvados; poco convexos en el disco; puntos de las estrías más pequeños y separados (2,7 diámetros entre sí); interestrías planas. Tibias inermes, protibias rectas; tarsos menos robustos. Último esternito abdominal ojival. Espermateca con lóbulo espermático estrecho y recurvado, el glandular largo y acodado (Fig. 11C): esternito VIII liguliforme con espículo largo ( $=3,3 \mathrm{x}$ longitud de placa terminal). Gonapófisis terminales, estrechas y alargadas.
OBSERVACIONES. Wollaston (1864) describió dos especies de las Canarias orientales. Laparocerus dispar y L. rasus, esta última a partir de ejemplares del norte de Lanzarote, separando como "var beta", un único ejemplar procedente de Fuerteventura en el que apreció ciertas diferencias. El caso es que este grupo de especies es más complejo y se extiende también a Marruecos. La mayoría de ellas se parecen morfológicamente a L. rasus, lo que justifica la redescripción que antecede y que servirá de referente para las diagnosis diferenciales, aunque los miembros de este grupo nunca son fáciles de separar.

Existen dos caracteres morfológicos estables y útiles: las metatibias masculinas presentan un mucrón espiniforme normal o muestran un diente y muesca terminal, seguido de un mucrón laminar dispuesto transversalmente al eje de la tibia, como es el caso en L. rasus. Por otra parte, la punta del edeago es de perfil sinuoso simple y, en vista dorsal, poco aguzada (subtriangular), o bien tiene forma de bota invertida con un pequeño talón (visto de perfil) y se estrecha bruscamente y es agudo en el ápice (vista dorsal). En L. rasus rasus de Lanzarote se combinan las metatibias con muesca y la punta del edeago simple, al igual que en ejemplares de la zona central de Fuerteventura (macizo de Betancuria y sus estribaciones), pero los ejemplares de Jandía, en el extremo sur de la isla, muestran la punta del edeago con forma de bota invertida. Esta configuración del edeago la presentan también $L$. xericola n.sp., con metatibias de mucrón simple, y L. susicus, de Marruecos, donde aparecen tanto la forma de mucrón simple como la provista de muesca.

Los datos moleculares disponibles y aún sin publicar (secuencias parciales de la COII y 16SrRNA mitocondrial) no son concluyentes como para aclarar la presunta homoplasia de uno de estos dos caracteres, y muestran relaciones bastante discrepantes con la morfología, reflejando a nivel de estos marcadores una separación incompleta de linajes (s. Maddison \& Knowles, 2006). Habría que analizar más ejemplares y tal vez más marcadores. Todo apunta a que el grupo se encuentra en pleno proceso de diversificación, aparejado posiblemente a la reciente aridificación del clima en la región.

DisTRIBUCIÓN Y ECOLOGÍA. Laparocerus rasus rasus es endémico de la isla de Lanzarote y sus islotes, habiéndose confirmado su presencia al menos en el de Montaña Clara. Se distribuye en la parte septentrional de la isla, tanto en el macizo de Famara cuya cumbre es algo más húmeda, como en las llanadas 


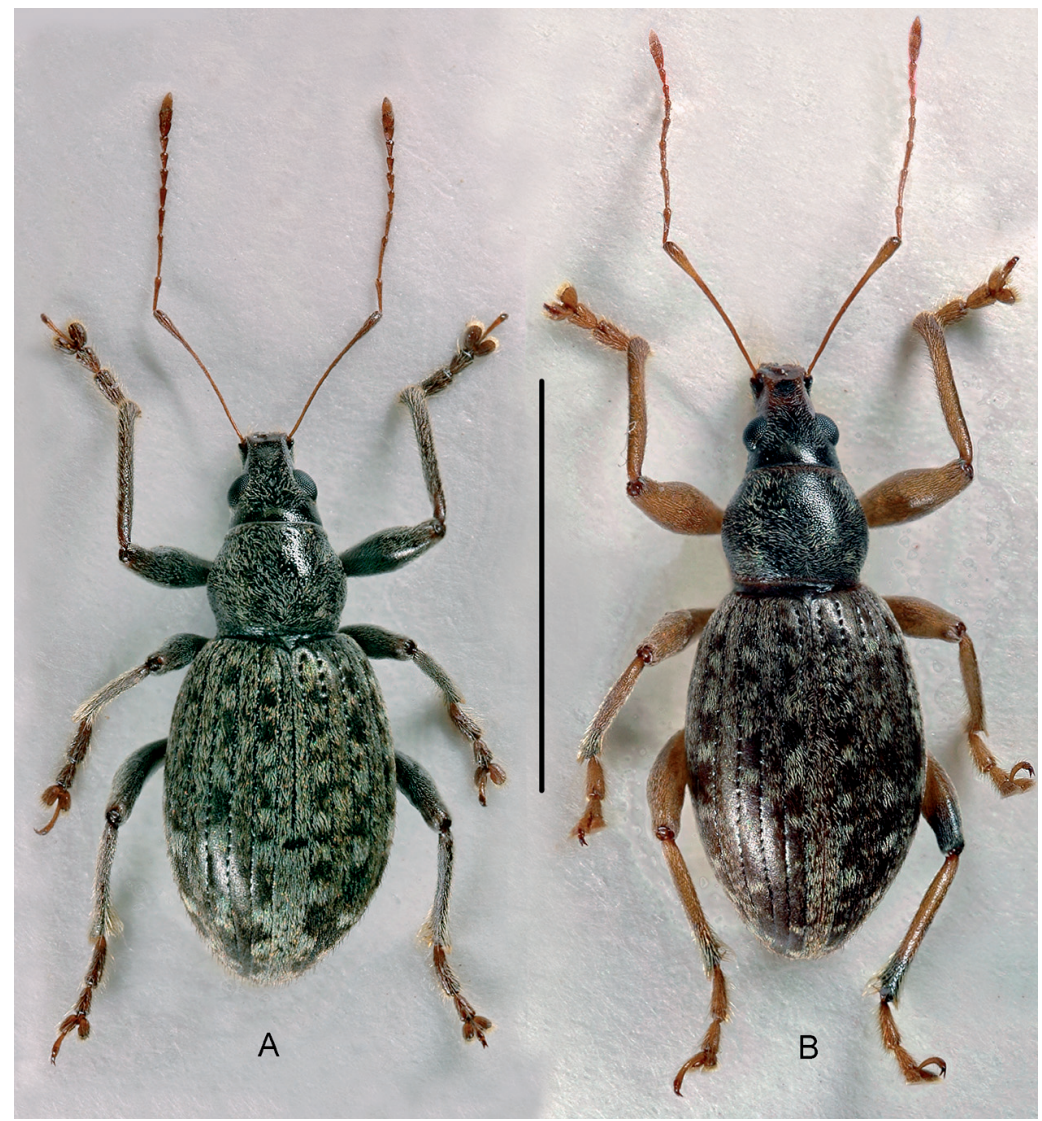

Fig. 10.- Holotipos ( $\left(^{\top}\right)$ de Laparocerus rasus betancor n. ssp. (A) y Laparocerus rasus jandiensis n. ssp. (B). Escala 5 $\mathrm{mm}$.

Fig. 10.- Holotypes ( $\mathrm{O}^{\mathrm{T}}$ ) of Laparocerus rasus betancor n. ssp. (A) and Laparocerus rasus jandiensis n. ssp. (B). Scale 5 $\mathrm{mm}$.

orientales. Habita en terrenos arcillosos con tabaibas, aulagas o vegetación rupícola, y también en malpaíses antiguos bien vegetados (malpaís de La Corona). Es un insecto nocturno, bastante común y polífago. Se ha colectado alimentándose sobre Senecio kleinia, Cynara horrida, y Carlina sp. (Asteraceae), Lycium afrum (Solanaceae), Aeonium sp. (Crassulaceae), y Tamarix canariensis (Tamaricaceae).

\section{Laparocerus rasus betancor $\mathbf{n}$. ssp.}

(Figs. 10A, 11D-E y 12F-G)

Material examinado. Fuerteventura: Holotipo $10^{\pi}$ de Betancuria, Morro Velhoso, 640 m, 7-3-2011 leg. A. Machado (TFMC/CO-15967). - Paratipos, 26 exx mismos datos; ibidem 116 exx 3-12-2001, 57 exx 27-1-2008 leg. A. Machado
(AMC), 38 exx 7-3-2011 leg R. García (RGB), 39 exx 7-32011leg. A. Aguiar (AAC). Risco del Carnicero 550 m, 2 exx 21-1-1990 leg. P. Oromí (ULL).

No paratipos: Betancuria: Tegú, 600 m, 11 exx 10-3-1984 leg. R. Sciaky (4 EC, 7 MZUR), 6 exx 2-3-1990 leg. E. Colonnelli (MZUR). Pájara: Degollada de los Granadillos, 4 exx 20/31-11991 leg. A. Liberto (AL). Mte. Betancuria, 1 ex sin fecha leg. H. Franz (NMW), Betancuria 1 exx 4-3-1986 leg. C. Jeanne (JP). Tiscamanita: Llano de las Mujeres 36 exx 14-1-2005; Tefía 2 exx 3-12-2001; La Antigua: Majada Blanca 150 m, 10 exx 13-1-2005 leg. A. Machado (AMC).

DiAgNOSIS DIFERENCIAL. Longitud $\sigma^{\pi} \sigma^{\pi}$ 4,7-6,9 $\mathrm{mm}($ media $=6,3 \mathrm{~mm})$, 우 우 6,9-8,1 $\mathrm{mm}($ media $=$ $7,4 \mathrm{~mm}$ ). Semejante a la subespecie rasus, pero de talla generalmente algo menor, tegumento más oscuro, cerdas recurvadas de los élitros más prominentes y menos inclinadas (en ambos sexos), al menos en la 


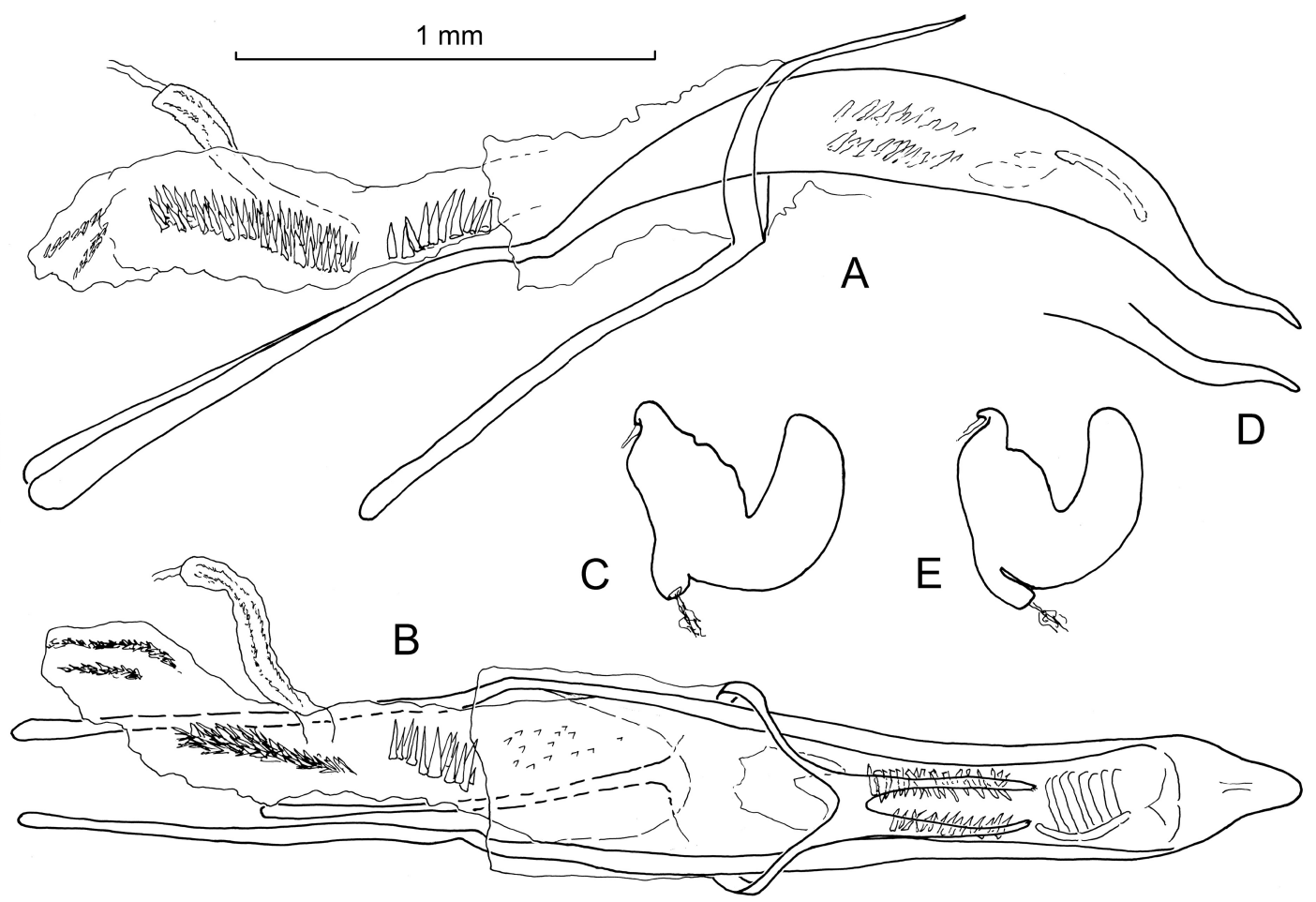

Fig. 11.- Laparocerus rasus rasus Wollaston, 1864 (Ermita de Las Nieves, Lanzarote), edeago en visión lateral (A), en visión dorsal (B) y espermateca (C). Laparocerus rasus betancor $\mathbf{n}$. ssp., detalle del ápice del edeago en vista lateral (D) y espermateca (E).

Fig. 11.- Laparocerus rasus rasus Wollaston, 1864 (Ermita de Las Nieves, Lanzarote), aedeagus in lateral view (A), in dorsal view (B), and spermatheca (C). Laparocerus rasus betancor $\mathbf{n}$. ssp., detail of apex of aedeagus in lateral view (D), and spermatheca $(E)$.

mitad distal, donde superan en longitud a una uña. Dorso del rostro con los cantos laterales bien perfilados (no romos); patas algo más largas y menos robustas; la muesca premucronal de las protibias masculinas más profunda y mucrón más desarrollado; los tarsos más estrechos. La punta del edeago es igual (lisa y ancha, Figs. 11D y 12F), pero el saco interno es más largo, los campos de dientes del tramo medio y vestibular (basal) están más desarrollados, y el divertículo gonoporal es tan largo como el ciego.

Los ejemplares de las zonas bajas (La Antigua y Tiscamanita, $150 \mathrm{~m}$ ) presentan longitudes medias menores $\left(\sigma^{2}=5,35 \mathrm{~mm}\right.$ y $ᄋ$ 을 $\left.=5,95 \mathrm{~mm}\right)$ que los de altitud, (serie típica colectada sobre los $600 \mathrm{~m}$ ).

ETimología. El epíteto subespecífico es un sustantivo en aposición, concretamente el apellido castellanizado de Jean de Béthencourt (1360-1422), caballero normando conquistador de la isla de Fuerteventura, y en cuya memoria se nombró la antigua capital de la isla y el macizo de Betancuria, donde habita la especie.

DisTRIBUCIÓN Y ECOLOGÍA. Endemismo de la isla de Fuerteventura distribuido por el macizo central de Betancuria, donde es común en las cumbres expuestas a la humedad, alimentándose de Cynara horrida y Nauplius sericeum (Asteraceae). También se ha colectado en las llanuras orientales, al pie del macizo, sobre Lycium intricatum (Solanaceae) y Salsola vermiculata (Chenopodiaceae).

\section{Laparocerus rasus jandiensis n. ssp.}

(Figs. 10B, 12A-E)

Laparocerus rasus var, $\beta$ (?) Wollaston, 1864: 354

Material eXAminado. Fuerteventura: Holotipo $10^{7}$ de Cumbres de Jandía, 600 m (UTM 28R 5622623107836 ) 2-12-2001 leg. A. Machado (TFMC/CO-15968). - Paratipos, mismos datos 210 exx (AMC); 2 exx 10-5-1974, 4 exx 15-2-1977 leg. Oromí (ULL). 


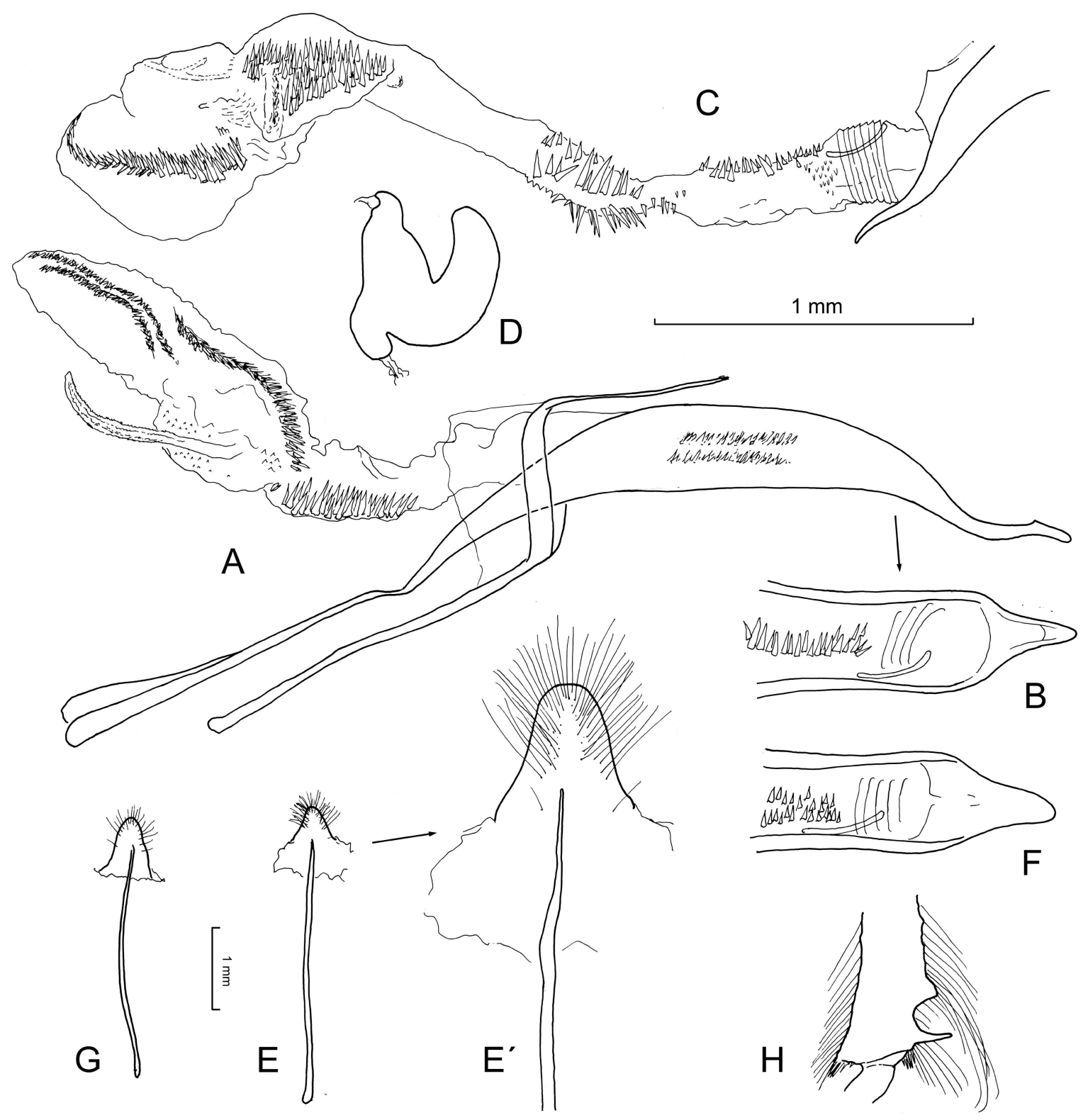

Fig. 12.- Laparocerus rasus jandiensis n. ssp., edeago en visión lateral (A), detalle de su ápice en visión dorsal (B), detalle del saco interno evaginado (C), espermateca (D), urosternito VIII femenino (E) y detalle (E'). Laparocerus rasus betancor n. ssp., detalle del ápice del edeago en visión dorsal (F), urosternito VIII femenino (G). Laparocerus rasus rasus Wollaston, 1865, detalle del ápice de la metatibia masculina $(H)$.

Fig. 12.- Laparocerus rasus jandiensis n. ssp., aedeagus in lateral view (A), detail of its apex in dorsal view (B), detail of the everted internal sac (C), spermatheca (D), female urosternite VIII (E), and detail of it (E'). Laparocerus rasus betancor n. ssp., detail of apex of aedeagus in dorsal view (F), female urosternite VIII (G). Laparocerus rasus rasus Wollaston, 1865, detail of the apex of male metatibia $(\mathrm{H})$. 
No paratipos: Divisoria del Aguililla, 5 exx 20/31-1-1991 leg. A. Liberto (AL). Pico de la Matanza, 28 exx 10-2-1991 leg. E. Colonnelli (EC). Pico de la Zarza (750-850 m) 2 exx 20-122002 leg. S. Scholz, 1 ex 5-3-2011 leg. A. Machado (AMC), 1 ex 1-2-1991 leg. E. Colonnelli (EC); 5 exx 5-3-2011 leg. R. García (RGB). Jandía, Morro del Jorao 550 m, 44 exx 15-12005 leg A. Machado (AMC).

DiAGNOSIS DIFERENCIAL. Longitud $\sigma^{\top} \sigma^{\pi} 5,6-7,3$ $\mathrm{mm}$ (media $6,8 \mathrm{~mm}$ ) 우 ㅇ 6,5-8,4 mm (media 7,4 $\mathrm{mm}$ ). Aspecto externo igual que la subespecie tiponominal, pero el tegumento del pronoto presenta fondo micrroreticulado en vez de liso, y los puntos mayores son más escasos aunque algo más diferenciados. Los márgenes del rostro están bien perfilados (menos romos), los pterigios algo más prominentes, lo mismo que los ojos. Las antenas son algo más gruesas y el engrosamiento apical más progresivo (menos abrupto); los élitros menos convexos y menos curvados en la mitad anterior (máxima anchura a menudo pasada la mitad), y apenas cuentan con una pocas cerdas recurvadas en el ápice. La muesca premucronal de la metatibia masculina es más profunda y el mucrón laminar terminal está más desarrollado (tanto o más que en ssp. betancor). Los élitros en la hembra son más cuadrangulares en su mitad basal (lados subparalelos y convergentes), con hombros más marcados, y el disco algo deprimido (ovales y más convexos en rasus). El edeago, visto de perfil (Fig. 12A), termina en forma de bota invertida, con pequeño talón; el divertículo gonoporal es bastante menor que el ciego, y los campos de dentículos en éste (basal y par terminal) son más largos.

ETIMOlogía. El epíteto específico hace referencia a la península de Jandía, en la isla de Fuerteventura, donde habita el insecto.

OBSERVACIONES. El parecido externo de esta subespecie con L. rarus rasus y L. rasus betancor n. sp es considerable, salvo por diferencias poco relevantes (reticulación del pronoto, ausencia de cerdas elitrales). No obstante, la punta aguzada del edeago con el ápice en forma de bota invertida es una diferencia importante en relación el perfil liso y punta ancha que presentan las otras dos. Cabría considerar que se trata de una especie independiente y más relacionada con L. xericola $\mathrm{n}$. sp. (punta del edeago igual), a pesar de diferir en la forma del mucrón metatibial masculino, pero habrá que esperar a profundizar más en los análisis moleculares para aclarar estas relaciones.

DisTRIBUCIÓN Y ECOLOGÍA. Especie restringida a la península de Jandía, en el extremo meridional de la isla de Fuerteventura, donde habita las crestas (400-640 m) que reciben humedad de las nubes arrastradas por los alisios. Cohabita con L. calvus n. sp., L. maxorata n. sp. y L. curvipes espanoli Roudier, 1954, alimentándose de la misma planta leñosa, Nauplius sericeus (Asteraceae) que allí abunda, pero también de otras especies como Chenopodium sp. (Chenopodiaceae), Mercurialis annua (Euphorbiaceae), Senecio kleinia (Asteraceae) o Lycium intricatum (Solanaceae).

\section{Laparocerus susicus susicus (Escalera, 1914)}

(Figs. 14A-C)

Cyclobarus susicus Escalera, 1914: 424.

Laparocerus, in Ruter, 1945: 44 - Kocher, 1961: 56 — Machado, 2006: 2038

Material examinado. Marruecos: Agadir, 10 (lectotipo) leg. M.M. Escalera (MNCN, Coll. Escalera), 1 ㅇ (paralectotipo) mismos datos (MNHN, Coll Ruter). Mogador 2 exx 3-1906 leg. M.M. Escalera (MNCN). Agadir, Tarhazout km 21 Immouzer $300 \mathrm{~m}, 1$ ex 28-12-2000. Agadir $1 \mathrm{~km} \mathrm{~N}, 30 \mathrm{~m}, 5$ exx 21-12-2002, idem 2 km N 80 m 4 exx 20-12-2002 leg C. Germann (AMC). Agadir: La Fortalessa 60 m, 15 exx 21-12005; Agadir: Tamri 24 m, 1 ex 13-4-2003, 46 exx 24-1-2005; Tiznit-Gourizim 280 m (29R0414486 3277736) 14 exx 22-12005 leg. A. Machado (AMC).

REDESCRIPCIÓN: Machos. Laparocerus de tamaño mediocre (longitud 4,6-5,7 $\mathrm{mm}$ (media 5,3 mm) cuerpo oval-alargado y aspecto muy parecido a $L$. rasus Wollaston, 1864. Tegumento de brillo apagado, color pardo oscuro, más claro en las extremidades; vestimenta densa (aspecto sedoso) de escamitas finas doradas, testáceas o hialinas, en el pronoto las escamitas claras hacia los márgenes (disco oscuro), en los élitros formando dibujo en parches; sin setas sobresalientes.

Antenas largas y gráciles; escapo filiforme, engrosado en su quinto apical (capitado): desmómeros I y II subiguales, delgados; maza fusiforme $(\mathrm{L} / \mathrm{A}=3,3)$, igual de larga que los tres desmómeros previos reunidos.

Rostro subparalelo, pterigios apenas sobresalientes, metarrostro plano. Ojos grandes, moderadamente salientes (convexidad 26-27\%). Tegumento nítidamente punteado; prorrostro (placa rostral) liso, con quilla epistomal bien desarrollada. Fóvea frontal profunda y corta. Vértex fina y precisamente punteado.

Pronoto transversal $(\mathrm{L} / \mathrm{A}=0,74)$, más ancho en la base que por delante (collarín poco marcado); lados moderadamente curvos, máxima anchura algo por detrás de la mitad. Tegumento con punteado abigarrado muy marcado; puntos grandes (2-3 


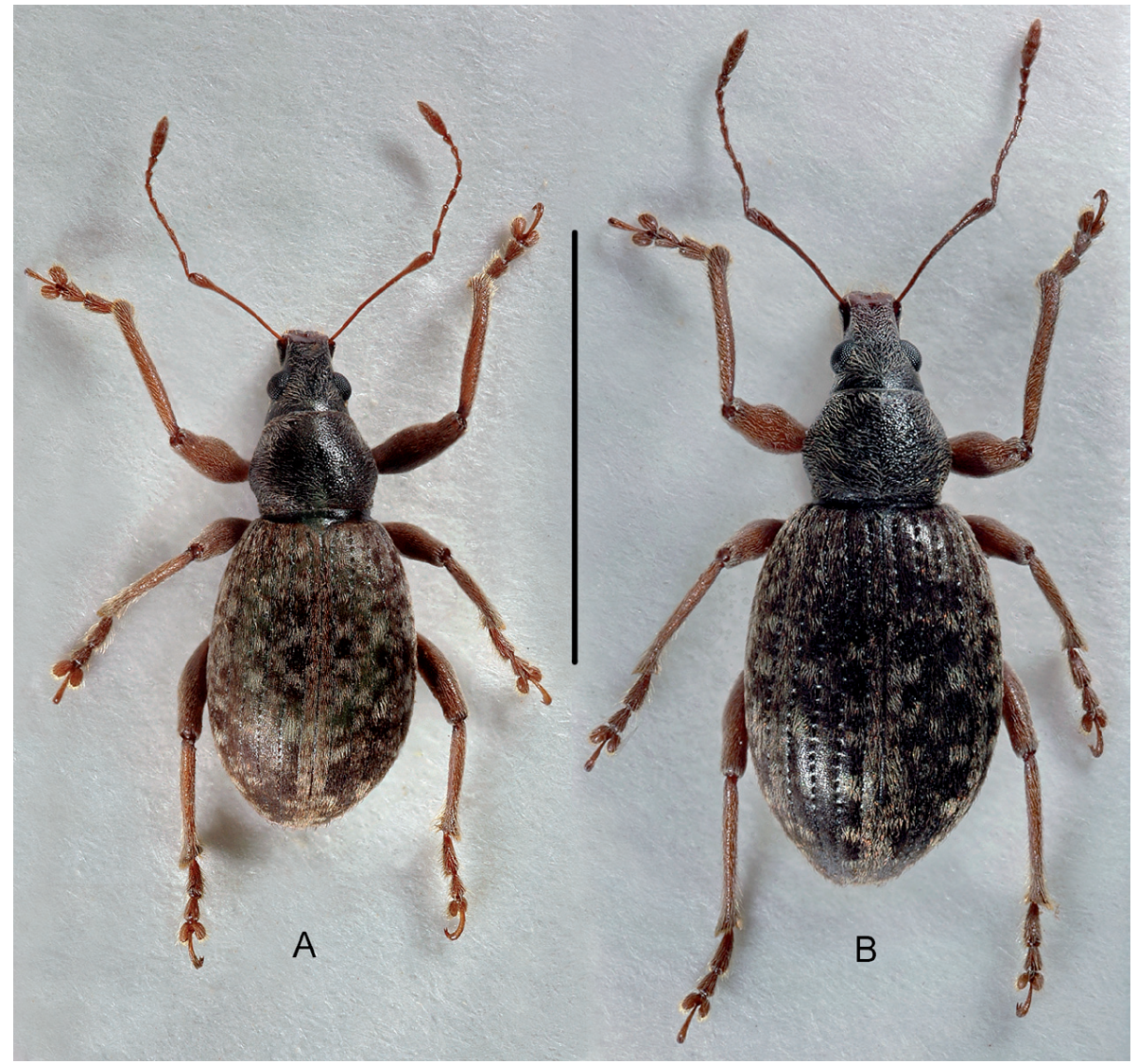

Fig. 13.- Holotipos $\left(\sigma^{7}\right)$ de Laparocerus susicus inexpectatus nom. nov. (A) y Laparocerus susicus montanus n. ssp. (B). Escala $5 \mathrm{~mm}$.

Fig. 13.- Holotypes $\left(\sigma^{7}\right)$ of Laparocerus susicus inexpectatus nom. nov. (A) and Laparocerus susicus montanus n. ssp. (B). Scale $5 \mathrm{~mm}$.

veces mayores que los pequeños), ambos bien definidos, profundos (en L. rasus los puntos grandes son menores, los pequeños superficiales, y están más separados). Línea media ocasionalmente presente, poco desarrollada.

Escudete triangular, con escamitas.

Élitros convexos, oblongo-ovales y algo acuminados; estrías bien marcadas, con punto gruesos (como los del pronoto) bien separados; interestrías planas o apenas convexas, con tegumento algo chagrinado y más de 12 escamitas a lo ancho ( $2^{\circ}$ intervalo). Algunas cerdas recurvadas en el ápice, inconspicuas.

Patas largas y delgadas. Tibias con pilosidad más desarrollada hacia su mitad apical y todas armadas con mucrón agudo simple y modesto. Protibias con ángulo apical externo muy redondea- do, brevemente encorvadas hacia dentro en el extremo; metatibias ligeramente escotadas internamente. Tarsos anchos, tanto como las tibias.

Cara ventral punteada, con pilosidad rubia separada y corta; más larga en el mesosterno, trocánteres, coxas, y esternitos abdominales (particularmente, el último). Saliente intermesoxocal no desarrollado. Último esternito abdominal moderadamente truncado.

Edeago (Figs. 14A-B). Lóbulo medio fuertemente estrechado en la punta (como en L. rasus betancor ssp. n.) y visto de perfil en forma de bota invertida poco angulosa y el talón dorsal apenas desarrollado, pero presente. Saco interno más largo que los temones, cinco campos de dientes bien desarrollados (el basal y el terminal son dobles), la esclerificación del tramo medio (visible como pieza 

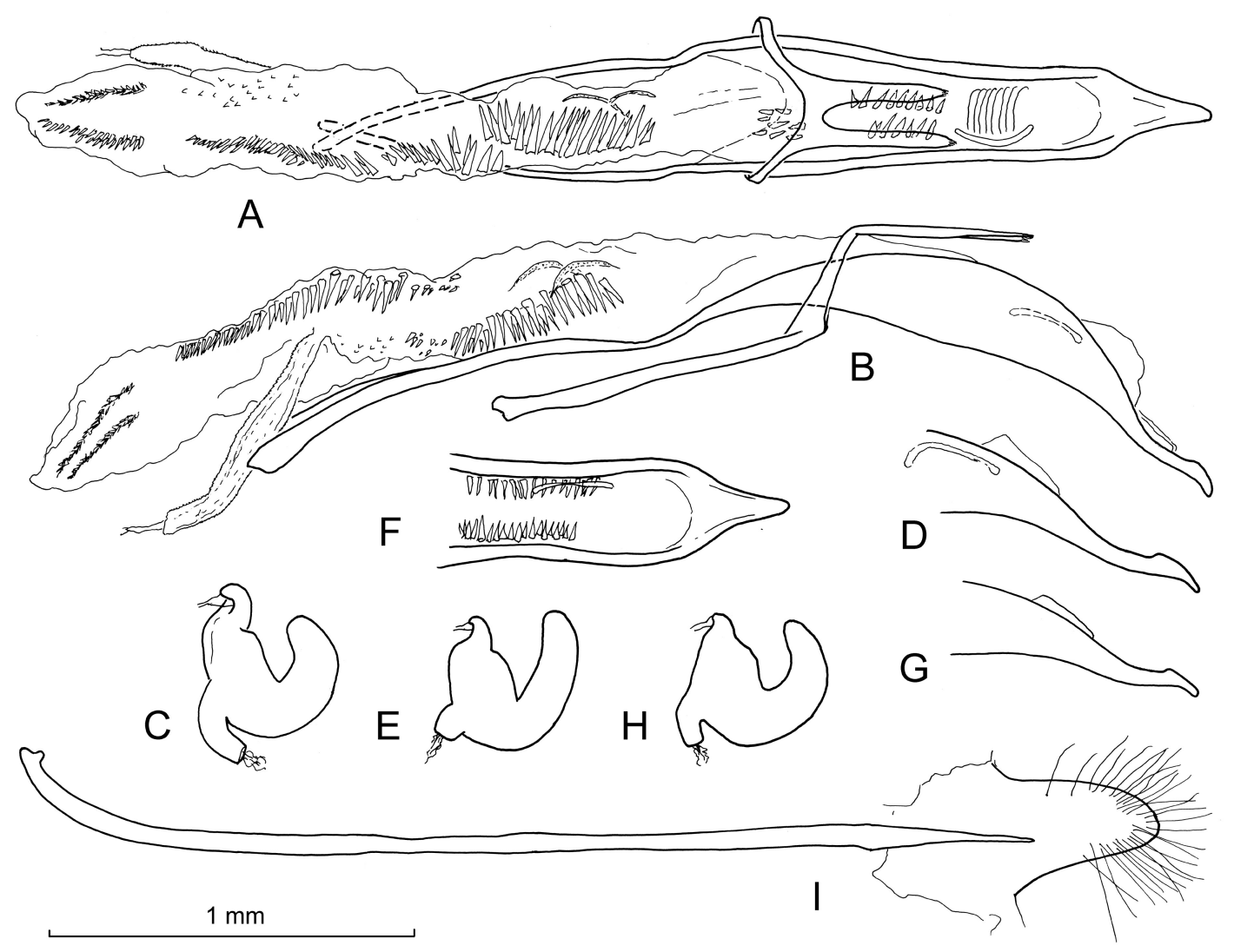

Fig. 14.- Laparocerus susicus susicus (Escalera, 1914) (La Fortaleza, Agadir), edeago en visión dorsal (A) y en visión lateral (B) y espermateca (C). Laparocerus susicus montanus n. ssp., detalle del ápice del edeago en visión lateral (D) y espermateca (E). Laparocerus susicus inexpectatus nom. nov., detalle del ápice del edeago en visión dorsal $(F)$ y lateral $(G)$; espermateca $(\mathrm{H})$ y urosternito VIII femenino (I).

Fig. 14.- Laparocerus susicus susicus (Escalera, 1914) (La Fortaleza, Agadir), aedeagus in dorsal view (A) and lateral view (B) and spermatheca (C). Laparocerus susicus montanus n. ssp., detail of apex of aedeagus in lateral view (D) and spermatheca (E). Laparocerus susicus inexpectatus nom. nov., detail of apex of aedeagus in dorsal view (F) and lateral view $(G)$, spermatheca $(H)$, and female urosternite VIII (I).

de tres ramas) más desarrollada que en L. rasus y el extremo apical del lóbulo visto de perfil con la sinuosidad menos pronunciada.

Hembras: Igual que el macho pero más grandes (longitud 6,0-7,2 $\mathrm{mm}$ (media 6,68 $\mathrm{mm}$ ); rostro algo más convergentes hacia delante; élitros más globosos y cortos, convexos dorsalmente; puntos de las estrías más pequeños; interestrías siempre planas. Tibias inermes, protibias no curvadas, tarsos menos robustos. Pilosidad ventral más uniforme; último esternito abdominal ojival. Espermateca con el lóbulo glandular largo y acodado (Fig. 14C).

OBSERVACIONES. Al igual que ocurre con Laparocerus rasus, su vicariante canario, L. susicus cuenta con poblaciones diferenciadas geográficamente, que aquí se presentan a título de subespecies. Todas guardan un parecido con L. rasus; sin embargo, el punteado fuerte y abigarrado del pronoto es común a todas ellas y permite separarlas fácilmente de cualquiera de la formas insulares, donde los puntos menores del pronoto son siempre superficiales, nunca profundos, ni bien marcados.

DisTRIBUCIÓN Y ECOLOGÍA. La forma tiponominal de L. sucicus se distribuye por la franja costera del SW de Marruecos, al menos desde Mogador hasta Tiznit, y se interna por algunos valles y montañas aledañas de escasa altitud (p. ej. $300 \mathrm{~m}$, Immouzer, Gourizim, Fig. 1). El insecto se alimenta durante la 
noche, especialmente de una planta suculenta, Kleinia antheuphorbium (Asteraceae), aunque también fue colectado sobre Asparagus sp. y ocasionalmente sobre Argania spinosa (Sapotaceae), árbol de gran porte y característico de la región. Ésta y las otras subespecies centran su actividad en invierno, como ocurre con los Laparocerus en las Canarias orientales.

\section{Laparocerus susicus montanus $\mathbf{n}$. ssp.}

(Figs. 13B y 14D-E)

Material examinado. Marruecos: Holotipo $10^{7}$ de Tiznit: Tasgirt $550 \mathrm{~m}, 23-1-2005 \mathrm{leg}$. A. Machado (TFMC/CO15969).- Paratipos: 126 exx mismos datos de colecta, 2 exx 16-4-2003 (AMC, 6 AAC). El Tnine-Tlasgrth 350 m, 4 exx 3112-2000; El Tnine-Gsan $4 \mathrm{~km}$ (50 km N Agadir) $500 \mathrm{~m}, 1 \mathrm{ex}$ 21-12-2000 leg P. Stueben (PS). Tiznit: Anezi-El Tnine 1200 m, 4 exx 24-12-2002 leg C. Germann (AMC). Djebel Imzi, Addar NE Anezi 650 m, 2 exx 1-5-2000 leg. R. Borovec (RB). Tiznit: Tasgirt $650 \mathrm{~m}, 1$ ex 1-5-2000 leg E. Colonnelli, idem 1 ex leg. G. Meloni (EC). El-Tnine-a-Dei 600 m, 30 exx 23-12005 leg. A. Machado (AMC).

No paratipos: Antiatlas $22 \mathrm{Km}$ N Tafraout 1200 m, 2 exx 2312-2002 leg P. Stueben (PS). Alto Atlas: Asni 1100 m 1 ex 2612-2002 leg C. Germann (AMC).

DiAgNOSIS DIFERENCIAL. Longitud $\sigma^{\pi} \sigma^{\pi}$ 4,8-6,9 $\mathrm{mm}$ (media 5,98 mm), 우 우 6,2-7,8 $\mathrm{mm}$ (media $6,91 \mathrm{~mm}$ ). Igual que la subespecie tiponominal, pero algo mayores. Escapo antenal ensanchándose progresivamente en su tercio distal (no de forma abrupta); metarrostro algo más convergente hacia delante; pronoto con máxima anchura hacia la mitad; élitros $O^{7}$ menos convexos, más oblongos y menos acuminados, lados menos curvados, estrechados por delante y con la máxima anchura algo pasada la mitad; puntos de las estrías algo mayores y redondos, interestrías a menudo más convexas; élitros $ᄋ$ bastante inflados, sub-cuadrangulares y notoriamente deprimidos en el disco (convexos en susicus s.str.). Protibias masculinas algo más ampliamente encorvadas apicalmente. Edeago similar, pero el talón dorsal del ápice del lóbulo medio algo más desarrollado (Fig. 14D). Espermateca con el lóbulo glandular corto y simple (Fig. 14E), en vez de largo y acodado .

ETIMOLOGíA. El epíteto subespecífico es el adjetivo latino "montanus", relativo a la montaña, montañés, en referencia al medio donde habita el insecto.

DistRIBUCIÓN Y ECOLOGÍA. Laparocerus susicus montanus n. ssp. es endémico de Marruecos y se distribuye mayormente por el interior montano del
Antiatlas. La distribución conocida de la especie en su conjunto (Fig. 1) cae dentro del llamado enclave macaronésico continental, al menos según lo ilustra Peyerimhoff (1946) que incluye también una porción del extremo occidental del Alto Atlas. De hecho, la subespecie que nos ocupa se ha encontrado en Asni, al pie del Toubkal. Otros autores son más restrictivos y no incorporan el Alto Atlas al supuesto enclave macaronésico (Reyes-Betancort et al., 2010).

Vive en hábitat de matorral, boscoso o descampado, a altitudes medias o altas (500-1200 m). El insecto es eurioico y bastante polífago. En Tasgrlt, en las estribaciones del Gebel Imzi (Antiatlas), lo he colectado de noche en gran abundancia sobre diversas plantas: Polygala balansae (Polygalaceae), Adenocarpus sp. y Genista tricuspidata (Fabaceae), Rhus tripartita (Anacardiacea), Bupleurum dumosum (Apiaceae), Aeonium korneliuslemsii (Crassulaceae), Clematis cirrhosa (Ranunculaceae), y algunos en Kleinia anteuphorbium (Asteraceae). Cabe destacar que en esta zona del Antiatlas crecen dragos (Dracaena draco ajgal) y bejeques (Aeonium leucoblepharum), claramente relacionadas con la flora canaria. También se obtuvieron de día ejemplares volteando piedras en descampados con vegetación de terófitos y prácticamente sin arbustos o arbolado.

\section{Laparocerus susicus inexpectatus nom. nov.}

(Figs. 13A y 14F-I)

Cyclomaurus tessellatus Hustache, 1932: 43 (tipo Tiznit) - Kocher, 1961: 53 - Reymond, 1951: 51

Laparocerus susicus, in Pelletier, 2006: 33 (syn.) - Machado, 2006: 2041 (syn.).

Material EXAMINADO. Marruecos: Holotipo $10^{\pi}$ algo imnaturo [holotipo de Cyclomaurus tessellatus Hustasche], Sous, Tiznit/Sous 12-1930 leg. Antoine (MNHN Coll. Hoffman).Paratipos. 3 exx mismos datos (MNHN Coll. Antoine); Aglou/Sous 6 exx 12-1930 leg. Antoine (MNHN Coll. Antoine). No paratipos: Tiznit-Aglou 150 m (UTM 28R 0426 3293) 21 exx 22-1-2005 leg. A. Machado (AMC). Tan-Tan, El Qualia, 1 abdomen (?) 19-3-1997 leg. E. Colonnelli (EC).

DiAgNOSIS DIFERENCIAL. Longitud $\sigma^{\pi} \sigma^{7}$ 4,6-5,7 $\mathrm{mm}($ media $=5,3 \mathrm{~mm})$, 우 우 4,8-6,3 $\mathrm{mm}($ media $=$ $5,85 \mathrm{~mm}$ ). Igual que la subespecie tiponominal, pero de talla menor, élitros más ovoides; ojos algo más prominentes (convexidad 30\%); puntos de las estrías elitrales algo menores, y las metatibias masculinas con diente, muesca preapical y mucrón laminar transversal (en vez de mucrón simple). Hembras con élitros menos convexos y más 


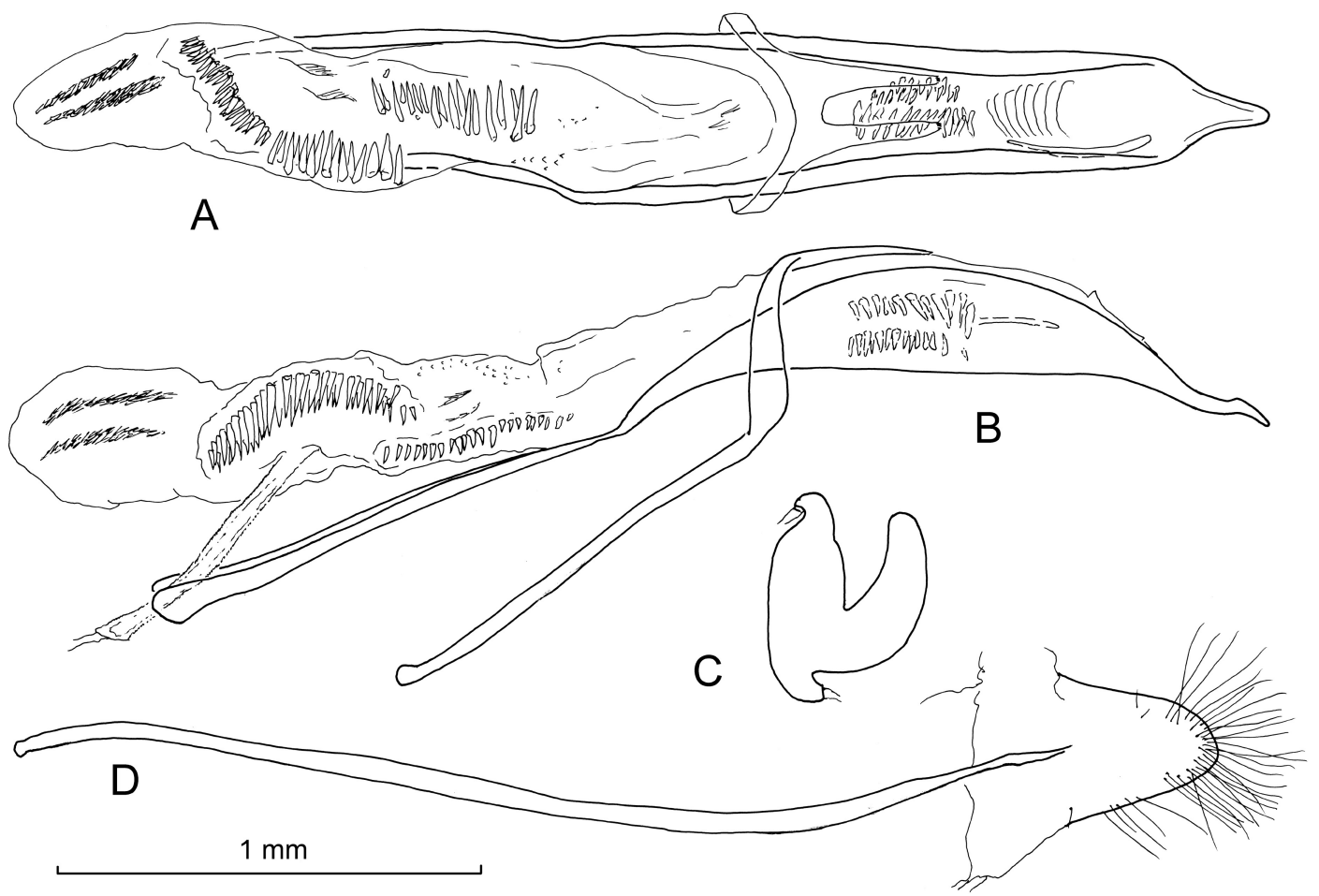

Fig. 15.- Laparocerus xericola n. sp. Edeago en visión dorsal (A) y lateral (B), espermateca (C) y urosternito VIII femenino (D).

Fig. 15.- Laparocerus xericola n. sp. Aedeagus in dorsal view (A) and lateral view (B), spermatheca (C), and female urosternite VIII (D).

cuadrangulares. La diferencia de talla entre machos y hembras es menos acusada que en las otras subespecies. Punta del lóbulo medio del edeago con talón dorsal menos marcado que en la ssp. montanus nov. La espermateca presenta el lóbulo glandular acodado (Fig. 14H).

ETIMOLOGÍA. El adjetivo latino "inexpectatus" adoptado como epíteto subespecífico, alude al reconocimiento inesperado de esta población diferenciada al analizar los microcaracteres del insecto, en fecha bastante posterior a su colecta.

OBSERVACIONES. En Machado (2006) consideré Cyclomaurus tessellatus Hustache, 1932 como sinonimia de Laparocerus susicus, según había sugerido Kocher (1961), tras confirmar Pelletier (2006) que efectivamente se trataba de un Laparocerus y no apreciar diferencia con ejemplares de L. susicus de Agadir que le remití. La duda sobre la validez de esta atribución surgió posterior- mente al examinar sistemáticamente las metatibias de todos los ejemplares marroquíes reunidos, y descubrir una serie colectada entre Tiznit y Aglou Plage (la misma localidad típica de C. tessellatus), que presentaba mucrón laminar transversal precedido por una breve muesca, como ocurre en L. rasus, pero cuyo pronoto lo relaciona claramente con $L$. susicus. He confirmado con el tipo y un paratipo de Hustache colectados en Tiznit (los otros son de Aglou), que se trata del mismo taxón.

Procede, pues, proponer un nombre de reemplazo para la especie descrita por Hustache, ya que se encuentra en homonimia secundaria: $L$. inexpectatus Machado nom. n. para L. tessellatus (Hustache, 1932) non (Brullé, 1839). Dicho taxon no tiene, sin embargo, valor como especie, pero sí como subespecie, por lo que cambia de rango: $L$. inexpectatus $=$ L.susicus inexpectatus (status demotus).

La presencia de L. susicus sucicus en el conjunto de montañas litorales al suroeste de Tiznit (ruta a 
Gourizim), a escasa distancia (18 km) de los llanos sedimentarios que habita L. susicus inexpectatus, induce considerar la posibilidad de que se trate de especies separadas a pesar de su gran parecido, particular que se aclarará cuando concluyan los estudios genéticos.

DisTRIBUCIÓN Y ECOlOGÍA. He colectado Laparocerus susicus inexpectatus en la llanura arcillosa que se extiende entre Tiznit y Aglou-Plage, concretamente en un extenso tabaibal con Euphorbia regis-jubae, Lycium intricatum y Ononis sp. que recuerda a los que abundan en las Canarias orientales. Los ejemplares se capturaron de noche y dispersos, alimentándose de Kleinia anteuphorbium (Asteraceae). Existe un abdomen de El Quatia (Tan-Tan), más al sur de Sidi Ifni, en las estribaciones del Sahara y a la misma latitud de la isla de Fuerteventura (a $245 \mathrm{~km}$ de distancia al Oeste). De tratarse de la subespecie que nos ocupa, ésta se distribuiría (Fig. 1) por la franja SW de la costa marroquí, al menos desde Tiznit hasta Tan-Tan, que engloban las localidades de El-Mers (Coll. Schram) y Foum-Assaka registradas por Kocher (1961) y Reymond (1951), respectivamente.

\section{Laparocerus xericola $\mathrm{n}$. sp.}

(Figs. 8B y 15)

Material examinado. Fuerteventura: Holotipo $10^{7}$ de La Oliva-S, 210 m (UTM 28R 603623 3164978) 8-3-2011 leg. A. Machado (TFMC/CO-15970)._- Paratipos: mismos datos de colecta 35 exx leg. A. Machado (AMC), 26 exx leg. R. García (RGB), 49 exx leg. A. Aguiar (AAC). La Oliva, 9 exx 13-21977 leg. P. Oromí (PO); 13 exx 30-11-1987 leg. J. de Ferrer (MAZ). La Oliva, Montaña de La Arena 1 ex 27-12-2003 leg. M. López (AMC).

No paratipos: Fuerteventura: La Oliva, Rosa de los Negrines 48 exx (inmaturos) 2-12-2001; Tefía 200 m, 3 exx 3-12-2001 leg. A. Machado (AMC). Tindaya 400 m, 2 exx 31-1-2007 leg A. Aguiar (AAC). Corralejo 1 ex 30-11-1987 leg. J. de Ferrer (MAZ). Vega de Río Palmas, 1 ex 12-2-1977; Malpaís de Bayuyo 8 exx 8-2-1997 leg. P. Oromí (ULL), 1 ex 28-2-2006 leg. R. García (RGB). Los Lajiares 6 exx 28-2-2006 leg. R. García (RGB). Las Peñitas 4 exx 13-2-1935 leg. A. Cabrera (MNCN). La Matilla 2 exx 3-2003 leg. S. Scholz (AMC). Malpaís Grande km 28,9, 50 exx 13-1-2005 leg. A. Machado (AMC). Lanzarote: Femés 320 m, 1 ex 12-2-1997 leg. P. Oromí (ULL), 7 exx 30-11-2001 leg. A. Machado (AMC).

MedidAs DEL hOlOtipo ( $\left(\sigma^{7}\right)$. Longitud: total (sin rostro) $5,05 \mathrm{~mm}$, rostro $0,54 \mathrm{~mm}$, escapo $1,44 \mathrm{~mm}$, funículo 1,60 (desmómeros I-IV respectivamente $0,32 / 0,37 / 0,24 / 0,18 \mathrm{~mm}$ ), maza $0,52 \mathrm{~mm}$, ojo $0,43 \mathrm{~mm}$, pronoto $1,12 \mathrm{~mm}$, élitros $3,65 \mathrm{~mm}$, tibias (pro- /meso- /meta-) 1,67 /1,50 /1,67 mm. Anchura: cabeza (a nivel de los ojos) 0,96 mm, (interocular) $0,48 \mathrm{~mm}$; rostro (a nivel de los pterigios) $0,60 \mathrm{~mm}$, (mínimo dorsal) 0,44 mm (mínimo ventral) 0,75 $\mathrm{mm}$; escapo $0,14 \mathrm{~mm}$, maza $0,15 \mathrm{~mm}$, ojo $0,29 \mathrm{~mm}$, pronoto (anterior /máxima /posterior) 1,02 / 1,48/ $1,30 \mathrm{~mm}$ y élitros (máxima) $2,55 \mathrm{~mm}$. Altura: abdomen 2,0 $\mathrm{mm}$.

DESCRIPCIÓN. Machos: Laparocerus de talla mediocre (longitud 4,2-5,8 mm, media 5,05 mm), cuerpo oval-alargado, convexo. Tegumento negruzco, rufescente en las extremidades; brillante; vestimenta densa de escamitas largas y finas (aspecto sedoso), de color hialino, dorado o testáceo, formando dibujo como en L. rasus.

Antenas mediocres, gráciles; escapo 1,3x la longitud del pronoto, algo sinuoso, largamente capitado; desmómero II algo mayor que el I; maza fusiforme $(\mathrm{L} / \mathrm{A}=3,5)$ algo más larga que los tres desmómeros previos reunidos.

Rostro apenas más ancho en la base que largo, subparalelo, de sección trapezoidal; pterigios pequeños, algo prominentes; prorrostro liso y bien delimitado (placa rostral), quilla epistomal muy desarrollada; metarrostro con leve depresión anterior, lateralmente bien perfilado; fóvea frontal corta y profunda, algo prolongada hacia el vértex. Ojos mediocres, algo prominentes, de convexidad uniforme, aunque variable (25-30\%), tangentes al margen frontal. Mandíbulas con tres setas largas en su cara externa.

Pronoto transversal $(\mathrm{L} / \mathrm{A}=0,75)$, lados bastante curvados, más estrechos y enderezados por delante (débil collarín) que por detrás; base en declive abrupto (reborde). Tegumento con punteado menudo abundante y unos pocos puntos dispersos doble de grandes (más abundantes hacia los márgenes). Línea media más o menos desarrollada (a veces a modo de gránulo).

Escudete triangular, finamente punteado.

Élitros ovales $(L / A=1,4)$, convexos, lados uniformemente curvados, máxima anchura a la mitad; base recta, hombros apenas indicados (ángulo humeral muy abierto). Estrías con puntos mediocres, separados un diámetro entre sí; interestrías planas (la $2^{\mathrm{a}}$ con unas 12 escamitas a lo ancho); una pocas escamitas setiformes recurvadas en el ápice, poco aparentes.

Patas largas y gráciles, con pilosidad tibial más larga en mitad distal; protibia recta, algo curvada hacia dentro en el cuarto apical; ángulo externo 
redondeado, interno con pequeño mucrón corto y ancho; mesomucrón igual, y metamucrón más robusto y mayor, pero simple (sin muesca ni pilosidad especialmente larga cubriéndolo). Tarsos robustos, obcónicos.

Cara ventral convexa, con pilosidad rubia separada y corta, algo más larga en trocánteres y coxas, más larga en meso y metasterno. Último esternito abdominal, truncado, ligeramente escotado al medio, con punteado fuerte. Saliente intermesoxocal no desarrollado

Edeago (Figs. 15A-B ); lóbulo medio con punta sinuosa provista de pequeño talón (forma de bota invertida, vista de perfil); bruscamente aguzada en vista dorsal (como en L. rasus jandiensis n. ssp.); divertículo gonoporal del saco interno casi tan largo como el divertículo ciego; campos de dientes posteriores bien desarrollados, el mediano y basal, más pobremente.

Hembras: Longitud 5,2-6,5 mm (media 5,8 mm); igual que el macho y no muy diferentes de aspecto, salvo por la talla algo mayor; élitros igualmente ovales, pero más inflados, puntos de las estrías más pequeños y separados, el tegumento más alutáceo. Tibias inermes, protibias rectas; tarsos menos robustos. Pilosidad ventral más larga solo en base profémur y procoxas. Último esternito abdominal ojival. Espermateca con lóbulo glandular corto y acodado (Fig. 15C): esternito VIII (Fig. 15D) liguliforme, con espículo largo

Etimología. El nombre xericola es un sustantivo en aposición formado por la conjunción de xêrós, seco o árido en griego, e incola, habitante en latín, en alusión al hábitat árido donde habita la especie.

OBSERVACIONES. Por su gran parecido, sobre todo en el dibujo que forman las escamitas en el dorso, L. xericola n. sp. puede confundirse con ejemplares pequeños de cualquiera de las subespecies de L. rasus, pero es fácil de separar inspeccionando las metatibias masculinas que carecen de muesca terminal y presentan un mucrón simple pequeño, en vez de laminar, transversal y grande. Además de su menor talla, los élitros en el macho son uniformemente ovales (no acuminados apicalmente), lo mismo que los de las hembras, que siendo más inflados, no son cuadrangulares con hombros marcados como en L. rasus. El escapo antenal es proporcionalmente algo más corto (longitud escapo/ flagelo $=0,62$ ), los pterigios del rostro más salientes, los ojos menores pero más convexos, y las patas algo más largas, con protibias más curvadas en el ápice. Lo destacado en esta especie es su edeago que termina en punta con talón (aunque no tan marcado), como ocurre en L. rasus jandiensis n. ssp., pero no en las otras subespecies de L. rasus.

Distribución Y ECOlOGíA. Especie endémica de las Canarias orientales. En Fuerteventura se distribuye en su mitad septentrional, y en Lanzarote en su tercio meridional. Ambas islas comparten un mismo zócalo, y durante la última glaciación estuvieron unidas. Habita en los llanos arcillosos con vegetación de matorral xerofítico, en las gavias abandonadas en dicho ámbito, y en los malpaíses con arcillas entre las lavas y vegetación desarrollada, siempre a baja altitud. Se alimenta de plantas como Senecio kleinia, Volutaria bollei y Argyranthemum coronopifolium (Asteraceae), Salsola vermiculata (Chenopodiaceae) o Lycium intricatum (Solanaceae).

\section{Laparocerus colonnellii $\mathbf{n}$. sp.}

(Figs. 5B y 16)

Material examinado. Fuerteventura: Holotipo $10^{7}$ de Pájara, Fayagua Km 8 (UTM 29R 058336 313160) 190 m, 27 1-2008 leg. A. Machado (TFMC/CO-15971)._- Paratipos: 24 exx misma localidad y fecha, 3 exx 6-3-2011 leg. A. Machado (AMC,1 EC), 2 exx idem leg. R. García (RGB), 1 ex idem leg. A. Aguiar (AAC). Pájara, Montaña Blanca 1 ex 19-1-2006 leg. M. Morris (MM).

No paratipos: Caleta de las Ballenas, 1 ex. 18-1-1991, leg. E. Colonnelli (AMC).

Medidas del holotipo $\left(\sigma^{T}\right)$. Longitud: total ( $\sin$ rostro) $4,70 \mathrm{~mm}$, rostro $0,50 \mathrm{~mm}$, escapo $1,26 \mathrm{~mm}$, funículo 1,52 (desmómeros I-IV respectivamente $0,30 / 0,34 / 0,20 / 0,20 \mathrm{~mm})$, maza $0,47 \mathrm{~mm}$, ojo $0,36 \mathrm{~mm}$, pronoto $1,06 \mathrm{~mm}$, élitros $3,1 \mathrm{~mm}$, tibias (pro-/meso- /meta-) 1,50/1,25/1,48 mm. Anchura: cabeza (a nivel de los ojos) 0,89 mm, (interocular) $0,42 \mathrm{~mm}$; rostro (a nivel de los pterigios) $0,54 \mathrm{~mm}$, (mínimo dorsal) 0,34 mm (mínimo ventral) 0,52 $\mathrm{mm}$; escapo $0,12 \mathrm{~mm}$, maza $0,12 \mathrm{~mm}$, ojo $0,29 \mathrm{~mm}$, pronoto (anterior /máxima /posterior) 0,92 / 1,40/ $1,24 \mathrm{~mm}$ y élitros (máxima) 2,00 mm. Altura: abdomen $1,85 \mathrm{~mm}$.

DESCRIPCIÓN. Machos: Laparocerus de talla pequeña (longitud 4,0-4,8 mm; media 4,51 mm), cuerpo elíptico, muy convexo, bastante esbelto. Tegumento brillante de color pardo oscuro, extremidades algo más claras y testáceas (sobre todo antenas y tarsos), vestimenta poco densa de esca- 


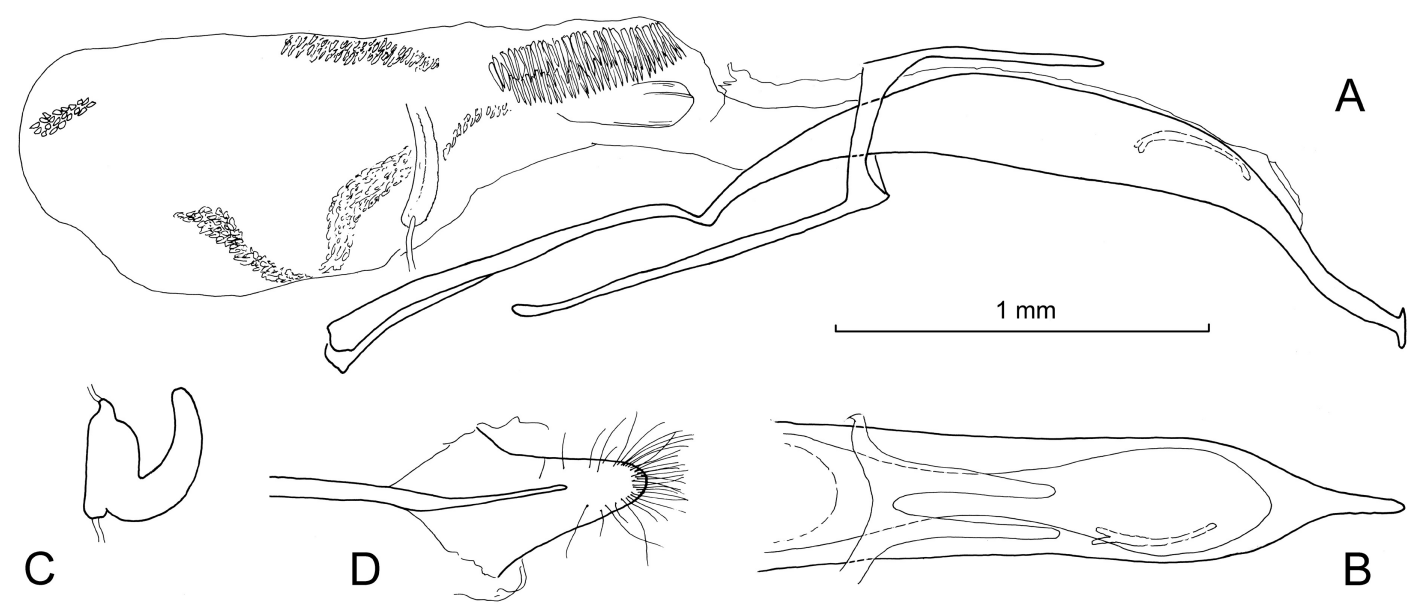

Fig. 16.- Laparocerus colonnellii n. sp. Edeago en visión lateral (A), detalle de su parte anterior en visión dorsal (B), espermateca (C) y placa apical del urosternito VIII femenino (D).

Fig. 16.- Laparocerus colonnellii n. sp. Aedeagus in lateral view (A), detail of its anterior part in dorsal view (B), spermatheca $(\mathrm{C})$, and apical plate of female urosternite VIII (D).

mas adpresas lanceoladas flavas (con visos dorados, glaucos o cobrizos); élitros con hileras abiertas de setas claras, finas, largas y erectas alternando con otras más cortas y arqueadas.

Antenas largas y gráciles; escapo 1,2x la longitud del pronoto, muy delgado, apenas arqueado, brevemente capitado; funículo con desmómero $1^{\circ}$ casi igual al $2^{\circ}, 3^{\circ}$ igual al $4^{\circ}$, el $7^{\circ}$ más grueso; maza fusiforme $(\mathrm{L} / \mathrm{A}=3,9)$, tan larga como los tres desmómeros precedentes juntos.

Cabeza grácil, de base ancha, rostro estrecho (L/A $\approx 1)$, paralelo; pterigios pequeños, apenas sobresalientes; prorrostro bien delimitado, quilla epistomal completa, roma, frecuentemente prolongada en breve carina posterior; prorrostro dorsalmente estrecho (base de antenas y flanco rostral visible desde arriba), no acanalado y márgenes bastante romos; frente no deprimida, foseta frontal pequeña, puntiforme o alargada, no prolongada. Ojos ovales $(\mathrm{L} / \mathrm{A}=1,24)$ grandes (eje mayor $=0,8 \mathrm{x}$ distancia interocular), moderadamente convexos $(36 \%)$, sin surco periocular definido, tangentes al borde de la frente. Tegumento lustroso con muy pocos puntitos y escamas.

Pronoto transversal $(\mathrm{L} / \mathrm{A}=0,75)$, base ligeramente cóncava, con incipiente reborde basal; lados moderadamente curvados, estrechados por delante y máxima anchura después de la mitad. Tegumento lustroso con pocos puntos mayores (mediocres) dispersos y separados, los pequeños escasos, superficiales u obsoletos; sin línea media. Escamitas más concentradas hacia los márgenes, escasas en el disco, algo levantadas en el margen anterior.

Escudete triangular, amplio, tapizado de escamitas.

Élitros elípticos $(\mathrm{L} / \mathrm{A}=1,5)$, truncados en la base, 2,9x la longitud del pronoto y $1,4 \mathrm{x}$ su ancho, muy convexos (convexidad transversal del abdomen $>80 \%$ ), prácticamente sin hombros. Estrías con puntos gruesos, profundos, algo alargados, mayores que los del pronoto. Interestrías a veces algo convexas, con 6-7 escamitas a lo ancho (tumbadas y solapadas a lo largo), bastante dehiscentes, e hilera regular de setas largas erectas (casi tan largas como el oniquio) y otras cortas curvadas, que se alternan. Tegumento brillante, algo pruinoso.

Cara ventral brillante, con rugosidad transversal en el primer ventrito; punteado muy superficial, pilosidad tumbada. Saliente intermesocoxal muy estrecho, apenas elevado. Último ventrito truncado apicalmente, ligeramente escotado y con pilosidad más larga.

Patas delgadas, muy largas, pilosas (pelos notablemente más largos en cara interna de la mitad proximal de tibias y fémures). Protibias ligeramente sinuosas, ápice romo poco curvado y expandido hacia dentro, el ángulo externo subtruncado, mucrón triangular de punta aguda (forma de aleta 
de tiburón), bastante separado del extremo (premucrón). Mesotibias con mucrón similar, más pequeño; metatibias con mucrón laminar transversal precedido de una breve muesca y un diente poco diferenciado. Tarsos estrechos, robustos.

Edeago (Figs. 16A-B): Lóbulo medio rectilíneo al medio, sinuoso en el tercio apical, aguzado en punta larga (vista dorsal) con el extremo en forma de T (vista lateral); saco interno rebasando bastante los temones y voluminoso en su extremo, un campo anterior denso de dientes fuertes, dos medianos de dientes menores (uno corto y otro acintado que va de una cara a la otra), y uno corto impar posterior; el divertículo gonoporal breve, emplazado dorsolateralmente.

Hembras: Longitud 4,2-5,5 mm (media 4,86 mm) como el macho pero mayores, notablemente más anchas, rostro algo trapezoidal (menos paralelo); élitros nada elípticos, inflados, ovalado-globosos, con hombros redondeados, lados mucho menos curvados y declive apical muy pronunciado (ancho élitro /ancho pronoto $=1,7$ en vez de 1,4 de los machos): puntos de las estrías menores, punteado del pronoto algo más denso. Protibias rectas, promucro muy reducido; meso y metatibias inermes. Último ventrito terminado en arco ligeramente ojival. Placa apical del esternito VIII liguliforme (Fig. 16D). Lóbulo glandular de la espermateca corto y oblicuo, el del conducto (nodulus) pequeño (Fig. 16C).

Etimología. La especie está dedicada a su descubridor, el Dr. Enzo Colonnelli, de Roma, entomólogo especialista en curculiónidos Ceutorhynchinae y buen amigo.

OBSERVACIONES. La nueva especie se caracteriza por su pequeño tamaño, forma elíptica con morro paralelo (el macho), ojos grandes moderadamente prominentes, patas largas y tegumentos lisos brillantes, muy poco punteado y élitros provistos de setas blanquecinas largas y separadas dispuestas en hileras. Lo más singular es la conformación de las tibias, con un mucrón (premucrón) muy distanciado del ápice en la protibia, y el mucrón laminar precedido de una muesca en las metatibias. La única otra especie en las Canarias orientales con pilosidad elitral larga es L. maxorata n.sp., de talla siempre mayor $(>5,5 \mathrm{~mm})$ y con el tegumento cefálico y pronotal llamativamente punteado.

Los machos de L. colonnelli n. sp. se parecen mucho a los de L. scapularis, y las hembras a las de cualquiera de las especies que conforman su grupo (propio de las Canarias occidentales); todas presen- tan tamaños similares y setas erectas en los élitros, pero los tegumentos están más profusamente punteados, las protibias terminan ensanchadas a ambos lados en su ápice (a modo de abanico) y, en el caso de los machos, las metatibias carecen de la breve muesca terminal enmarcada por un diente y el mucrón laminar, presentes solo en el grupo de $L$. rasus.

DisTRIBUCIÓN Y ECOLOGÍA. Laparocerus colonnellii $\mathrm{n}$. sp es endémico de Fuerteventura y se sabe poco de su distribución. El primer ejemplar colectado fue una hembra hallada muerta bajo una piedra en el litoral oriental (playa de la Ballena), en la desembocadura del barranco de La Torre, donde se buscó repetidas veces sin éxito alguno. Finalmente, la especie fue localizada viva a unos $24 \mathrm{~km}$ de distancia, en las estribaciones occidentales del macizo central de Betancuria-Pájara, en la otra vertiente de la isla. La localidad (190 m de altitud) es una ladera suave con matorral xerofítico y algunas huertas e invernaderos próximos. Los escasos ejemplares capturados de noche proceden de quenopodiáceas y Argyranthemum (Asteraceae), concentrados en una única huerta abandonada, no muy extensa, tras haber batido amplia e intensamente toda la zona.

\section{Laparocerus dispar Wollaston, 1864}

Laparocerus dispar Wollaston, 1864: 357 — Wollaston, 1865: 323 Marseul, 1872: 531 - Winkler, 1932: 1148 - Uyttenboogaart, 1937: 105 — Lona, 1938: 436 — Lindberg \& Lindberg, 1958: 33 Gurrea \& Sanz, 2000: 337 — Machado \& Oromí, 2000: 78 Oromí et al., 2003: 178 — Machado, 2006: 2014.

Material eXAminAdo. Lanzarote: El Risco [Famara] 1 ex (lectotipo) 4 exx (paralectotipos) 1-1858 leg. T.V. Wollaston (2 NHM, 2 UMO). Risco de Famara 1 ex 3-2-1980 leg. Alluaud (NMNH), 2 exx 31-12-1971, 1 ex 27-2-1973 leg. G. Israelson (NRS). Los Valles 1 ex 3-12-1988, 20 exx 29-11-2002; Haría: Valle Malpaso N 300m, 35 exx (muchos inmaturos) 29-112002 leg. A. Machado (AMC). Montaña Clara: Caldera, interior SE, 1 ex 27-11-2002 leg. A. J. Pérez (ULL). Roque del Este: 4 abdómenes (?) 7-5-1993 leg. P. Oromí (ULL).

Diagnosis. Laparocerus pequeño (longitud $\sigma^{\pi}$ 3,7-4,1 mm). Macho alargado, de color pardo; vestimenta densa de escamitas lanceoladas adpresas con visos metálicos, formando dibujo en parches sobre los élitros (8-9 escamitas a lo ancho de interestría); sin setas erguidas. Escapo grueso desde la base y brevemente capitado; desmómero II del funículo mayor que el I. Rostro claramente convergente hacia delante, pterigios no sobresalientes. Ojos redondos, bastante prominentes (40\%). Pronoto sin estrangulamiento marginal anterior 


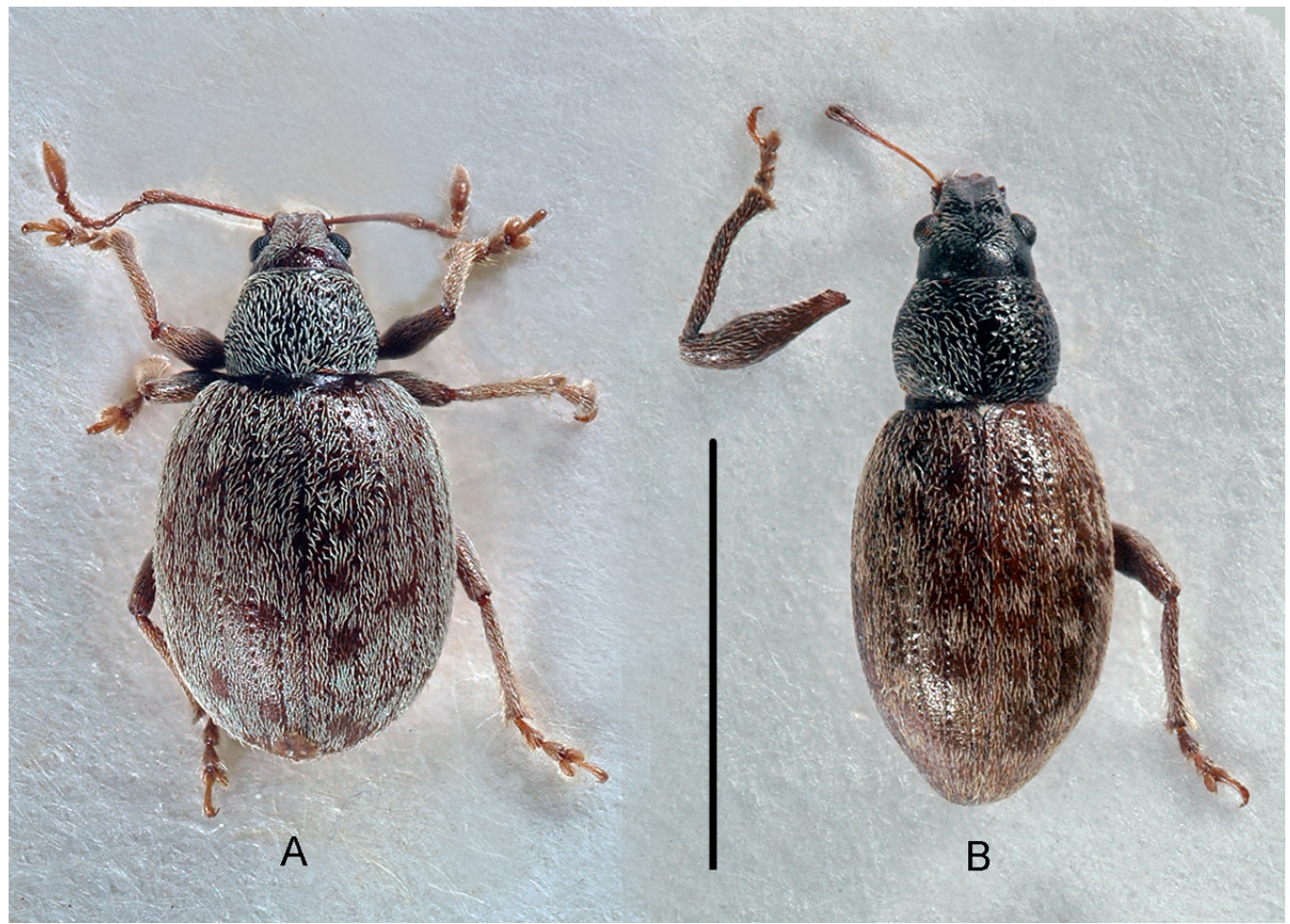

Fig. 17.- Holotipos $\left(\mathrm{O}^{7}\right)$ de Laparocerus garretai albosquamosus n. ssp. (A) y Laparocerus fraterculus n. sp. (B). Escala $3 \mathrm{~mm}$.

Fig. 17.- Holotypes $\left(\sigma^{7}\right)$ of Laparocerus garretai albosquamosus n. ssp. (A) and Laparocerus fraterculus n. sp. (B). Scale $3 \mathrm{~mm}$.

tipo collarín; punteado laxo, grueso, profundo (puntos separados 1-2 diámetros) sobre fondo lustroso (puntitos pequeños rara vez presentes). Élitros oval-alargados, algo acuminados. Cara ventral con pilosidad fina, separada, tumbada y regular. Tarsos más cortos (tarsómero $\mathrm{I}=1,5 \mathrm{x}$ la longitud del II), obcónicos. Protibias $\sigma^{7}$ con mucrón, encorvadas apicalmente, mesotibias con mucrón menor, metatibias inermes. Hembras bastante más robustas y anchas $(\mathrm{L}=3,6-4,6 \mathrm{~mm})$, de aspecto inflado (élitros ovoides); punteado del pronoto menor; tibias rectas.

OBSERVACIONES. La especie parece habitar también en el pequeño Roque del Este, al NE de Lanzarote, donde se han colectado cuatro abdómenes algo más cuadrangulares, que de resto coinciden con el de las hembras de Lanzarote. Dos ejemplares procedentes del islote de de Montaña Clara confirman su presencia al menos en este islote.
DisTRIBUCIÓN Y ECOLOGÍA. Especie endémica de Lanzarote. Se ha colectado de momento en el norte de la isla y en algunos de los islotes que conforman el archipiélago Chinijo. Habita en los tabaibales, habiéndose colectado sobre Senecio kleinia, y menos común sobre Sonchus sp. y Nauplius sericeus (Asteraceae).

\section{Grupo de Laparocerus tessellatus}

Laparocerus garretai garretai Uyttenboogaart, 1940

Laparocerus sp., in Garreta, 1911: 395 — Oromí et al., 1978: 190 Laparocerus garretai Uyttenboogaart, 1940: 56 — Lundblad, 1958: 486 - Oromí, 1983: 282 - Serrano, 1983: 775 - Erber \& Wheater, 1987: 174 - Arechavaleta et al., 2001: 92 - Machado, 2006: 2018.

Material eXAminado. Salvaje Grande: $10^{\pi}$ (holotipo) verano 1911 leg. L. Garreta (Coll. Uyttenboogaart NMNH); 1 ex 8-51980 leg. A. Serrano (AS); 3 exx. 25-2-1976 leg. P. Oromí (3 GO, 9 AMC, 4 POM, 20 TFMC); 2 exx 22-5-1989 leg. M. Arechavaleta (AMC). 

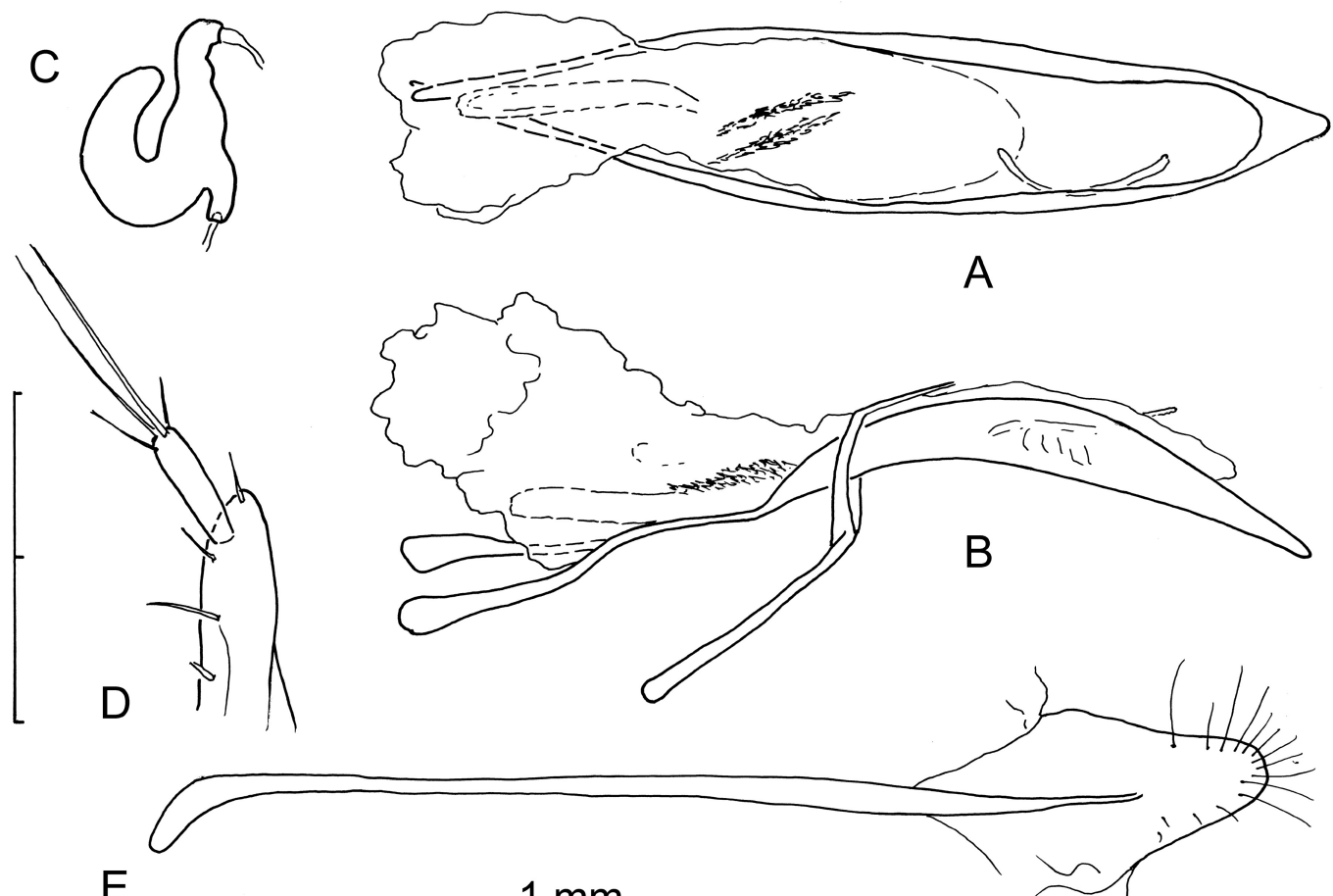

A

$\mathrm{E}$

$1 \mathrm{~mm}$

Fig. 18.- Laparocerus garretai albosquamosus n. ssp. Edeago en visión dorsal (A) y lateral (B), espermateca (C), gonostilo (D) y urosternito VIII femenino (E).

Fig. 18.- Laparocerus garretai albosquamosus n. ssp. Aedeagus in dorsal view (A) and lateral view (B), spermatheca (C), gonostylus (D), and female urosternite VIII (E).

Diagnosis. Laparocerus pequeño (Longitud $\sigma^{\pi} \sigma^{\pi}$ 3,4-36 mm, 우 우 4,0-4,5), de aspecto redondeado. Tegumento pardo, ennegrecido en cabeza y pronoto, con vestimenta llamativa de escamitas adpresas, lanceoladas, finas y de color flavo o dorado, con visos cobrizos, formando dibujo en damero en los élitros. Escapo robusto, arqueado y claviforme. Cabeza con punteado débil y abierto; rostro alargado, bastante paralelo; pterigios salientes; línea media desde quilla epistomal hasta fóvea frontal; ojos mediocres. Puntos del pronoto gruesos, algo alargados, profundos, bastante contiguos (aspecto algo varioloso); intervalos con pocos puntos menores. Élitros ovados y bastante convexos; estrías con puntos pequeños (bien demarcadas entre la vestimenta de escamas); interestrías planas, ocasionalmente con alguna escama recurvada erguida en el tercio apical. Protibias rectas, ángulo externo obtuso y romo, interno agudo, ensanchado, con pequeño mucrón en machos. Hembras de élitros más inflados y hombros algo más anchos.

OBSERVACIONES. El pequeño archipiélago de islas Salvajes se encuentra a unos $165 \mathrm{~km}$ de distancia de Tenerife y a $280 \mathrm{~km}$ de Madeira. Su fauna entomológica tiene mayor afinidad con la canaria que con la maderense. De hecho, el único Laparocerus autóctono conocido $L$. garretai Uyttenboogaart, 1940 pertenece al grupo de L. tessellatus, ampliamente distribuido en las Canarias centrales y occidentales. La especie fue descrita por Uyttenboogaart (1940) sobre un único ejemplar colectado ya muerto por L. Garreta en 1911. Posteriormente, Erber \& Wheater (1987) comentan e ilustran la especie tras estudiar una larga serie (36 exx) colectada por P. Oromí en Salvaje Grande, pero sin haber profundizado, al parecer, en los otros siete ejemplares colectados en Gran Pitón. 
En Salvaje Grande se han encontrado ejemplares de Laparocerus morio Boheman, 1834 que seguramente han sido importados con materiales y provisiones traídas desde Madeira (Alluaud, 1935), pero la especie no parece haberse asentado en la isla de forma permanente. No cabe confusión alguna entre ambas, pues $L$. morio duplica o triplica en talla a $L$. garretai y es alargado y de tegumentos negruzcos.

DiSTRIBUCIÓN Y ECOLOGÍA. Laparocerus garretai garretai es endémico de la mayor de las islas Salvajes: Gran Salvaje, cuya altitud máxima es de $59 \mathrm{~m}$. El ambiente general es árido y los ejemplares fueron encontrados escarbando la tierra bajo matos de Suaeda vera (Chenopodiaceae) (Oromí et al., 1978).

\section{Laparocerus garretai albosquamosus n. ssp.}

(Figs. 17A y 18)

Laparocerus garretai ex. aucct.

Material examinado. Gran Pitón. Holotipo $10^{7}$ 26/29-21976, leg. P. Oromí (TFMC/CO-15972)._- Paratipos: mismos datos 1ex (TFMC), 2 ex (ULL), 3 exx. (AMC), 1 ex 6-5-1953, leg. C. González (MNHN, París, Coll. Roudier). Pitao, 1 ex 56-1970, (NMW, Viena, Coll. Franz).

No paratipos: Ilheu de Fora. 1 ex. 8-4-1986, leg. A.J.P. Zino (MMF).

Medidas del holotipo ( $\left.\sigma^{7}\right)$. Longitud: total ( $\sin$ rostro) $4,90 \mathrm{~mm}$, rostro $0,48 \mathrm{~mm}$, escapo $0,90 \mathrm{~mm}$, funículo 0,82 (desmómeros I-IV respectivamente $0,20 / 0,18 / 0,10 / 0,09 \mathrm{~mm}$ ), maza $0,38 \mathrm{~mm}$, ojo $0,27 \mathrm{~mm}$, pronoto $0,72 \mathrm{~mm}$, élitros $2,80 \mathrm{~mm}$, tibias (pro- /meso- /meta-) 0,96/0,88/1,06 mm. Anchura: cabeza (a nivel de los ojos) 0,69 mm, (interocular) $0,38 \mathrm{~mm}$; rostro (a nivel de los pterigios) $0,50 \mathrm{~mm}$, (mínimo dorsal) $0,32 \mathrm{~mm}$ (mínimo ventral) 0,40 $\mathrm{mm}$; escapo $0,12 \mathrm{~mm}$, maza $0,12 \mathrm{~mm}$, ojo $0,18 \mathrm{~mm}$, pronoto (anterior /máxima /posterior) 0,82 / 1,04/ $1,00 \mathrm{~mm}$ y élitros (máxima) 2,15 mm. Altura: abdomen 1,64 $\mathrm{mm}$.

DiAgNOSIS DIFERENCIAL. (Longitud $\sigma^{\pi} \sigma^{\pi}$ 3,4-36 $\mathrm{mm}$, ㅇ ㅇ 4,0-4,5) Igual que la subespecie tiponominal pero de contorno más ovoide, la vestimenta de escamas más uniforme y de color blanquecino bastante llamativo (las escamas son algo más gruesas); los puntos del pronoto son generalmente más redondos; los élitros son algo más rectangulares, con los lados visiblemente más paralelos (la máxima anchura a veces desplazada a la mitad posterior), sobre todo en las hembras, cuyos hombros están mucho más marcados y el dorso es mucho menos convexo. Las interestrías presentan a su largo escamitas erguidas recurvadas. En el edeago, espermateca y urosternito VIII femenino no se aprecian diferencias relevantes (Fig. 18).

Eтimología. El epíteto subespecífico es el adjetivo latino albosquamosus en alusión a las escamas blancas que definen el colorido general del animal.

DisTRIBUCIÓN Y ECOLOGÍA. Laparocerus garretai albosquamosus habita en Pitón Grande (= Salvaje pequeña) y el islote de Pitón Pequeño (= Ilheu de Fora), situados a $15 \mathrm{~km}$ al Sur de Salvaje Grande. Pitón Grande apenas alcanza 20 hectáreas de superficie, y el insecto vive en iguales circunstancias que su vicariante de Salvaje Grande, en matorral de Suaeda vera (Chenopodiaceae) (Oromí et al. 1978). Es el único Laparocerus nativo conocido en estos islotes. Las citas de Laparocerus morio Boheman, 1834 (Marseul, 1872; Alluaud, 1935 y Serrano, 1983) deben corresponder a ejemplares importados fortuitamente desde Madeira, circunscripción política a la que pertenecen estos territorios deshabitados, que antes eran visitados por pescadores y colectores de pardelas. Actualmente existe una pequeña estación biológica en Salvaje Grande.

\section{Agradecimientos}

El autor expresa su agradecimiento a todos los colegas que le han cedido su material de Laparocerus para estudio, y muy particularmente al Dr. Enzo Colonnelli, de Roma, y M. Jean Pelletier, de Monnaie. El Dr. Heinrich Schönmann facilitó el acceso al estudio de la Colección Franz en el Naturhistorisches Museum Wien, la Dra. Hélène Perrin a las colecciones de Museum nationale d'Histoire Naturelle de París (Colecciones Antoine, Hoffmann y Roudier), y el Dr Max Barclay, a la Colección Wollaston en el Natural History Museum (Londres). El Dr. Michael Morris revisó la versión inglesa de las claves.

\section{Referencias}

Alluaud, C., 1935. Les coléoptères des îles Salvages. Revue française d'Entomologie, 2: 35-44.

Arechavaleta, M., Zurita, N. \& Oromí, P., 2001. Nuevos datos sobre la fauna de artrópodos de las islas Salvajes. Revista de la Academia Canaria de Ciencias, [2000], 12(3-4): 83-99.

Braun Blanquet, J. \& Maire, R., 1924. Études sur la végétation et la flore marocaines. Mémoires de la Societé des sciences naturelles du Maroc, 8: 1-244. 


\section{CLAVE DE LOS LAPAROCERUS DE LAS CANARIAS ORIENTALES, ISLAS SALVAJES Y MARRUECOS}

1 Élitros con pelos erectos o suberectos, largos y finos, al menos en su tercio apical ……….................................................................. 2

- Élitros sin pilosidad larga, con escamas, pequeñas setas cortas o glabros ................................................................................................3

2 Cabeza y pronoto con puntos mayores separados entre sí, los pequeños superficiales y poco notorios. Pelos de los élitros bastante separados. Talla menor (longitud $\sigma^{\pi}<6 \mathrm{~mm}$ ), ojos grandes (Fuerteventura) ........................................... Laparocerus colonnellii $\mathrm{n}$. sp.

- Cabeza y pronoto con punteado doble fuerte y denso, muy marcado. Pilosidad elitral más apretada, ocasionalmente restringida al ápice. Talla mayor (longitud $O^{7}>6 \mathrm{~mm}$ ), ojos pequeños (Fuerteventura) Laparocerus maxorata n. sp.

3 Tegumento en la vertex de la cabeza con microrreticulación bien marcada 4

- Tegumentos en el vértex de la cabeza sin microrreticulación destacada entre el punteado

4 Microrreticulación limitada al vértex y occipucio cefálico; pronoto y élitros con escamas lanceoladas (Fuerteventura)

Laparocerus fraterculus $\mathrm{n} . \mathrm{sp}$.

- Microrreticulación extendida por toda la cabeza y el pronoto; élitros y pronoto desprovisto de escamas, setas o pelos (Fuerteventura)

Laparocerus calvus n. sp.

5 Protibias fuertemente ensanchadas hacia ambos lados en su ápice, a modo de abanico. Pronoto brillante, con punteado superficial, desvanecido

- Protibias al menos con el ángulo externo romo, curvado hacia dentro o apenas saliente. Pronoto con punteado bien impreso, más o menos denso

6 Pronoto y élitros con vestimenta rala de escamitas adpresas, cortas y glaucas, formando dibujo en parches más o menos definido (Fuerteventura)

Laparocerus curvipes espanoli Roudier, 1954

- Pronoto y élitros con algunas escamitas vestigiales, prácticamente desprovisto de ellas (Lanzarote)

Laparocerus curvipes famarae n. ssp.

7 Base del escapo antenal fina o gruesa. Densidad de escamas menor ( $2^{a}$ interestría en el disco $<12$ escamas a lo ancho) ............... 8

- Base del escapo antenal siempre fina. Densidad de escamas mayor ( $2^{\mathrm{a}}$ interestría en el disco $>12$ escamas a lo ancho) ..............11

8 Élitros estrechos y muy alargados (longitud élitro/pronoto $>3,5$ ), con hileras de setas cortas erguidas. Pronoto con punteado doble (Fuerteventura) ................................................................................................................................... Laparocerus longipennis $\mathrm{n}$. $\mathrm{sp}$

- Élitros anchos, ovales o subglobosos (longitud élitro/pronoto < 3,5), con setas curvadas a lo sumo en el tercio apical ......................9

9 Ojos bastante prominentes y redondeados (convexidad 40\%). Puntos gruesos del pronoto separados más de un diámetro entre sí; micropuntos en los intervalos conspicuos (Lanzarote)

Laparocerus dispar Wollaston, 1864

- Ojos poco prominentes (convexidad < 35\%). Puntos gruesos del pronoto más densos y foveiformes, separados menos de un diámetro entre sí (aspecto algo varioloso)

10 Escamas más finas, flavas o doradas, adpresas. Sin o con muy pocas escamas emergentes arqueadas (Salvaje Grande)

Laparocerus garretai garretai Uyttenboogaart, 1940

- Escamas algo más anchas y blancas o glaucas. Con hileras de escamas emergentes recurvadas en todo el élitro (Gran Pitón) ........... Laparocerus garretai albosquamosus $\mathrm{n}$. ssp.

11 Punteado del pronoto muy denso y abigarrado; puntos grandes más del doble de grande que los pequeños, ambos bien impresos y profundos (Marruecos)

- Punteado del pronoto denso, pero los puntos más separados entre sí; los puntos menores superficiales o si son algo profundos, entonces son mayores que la mitad de un punto grueso (Canarias)

12 Metatibias masculinas con un diente romo y muesca terminal precediendo al mucrón, que es grande y laminar, dispuesto transversalmente. Élitros $\sigma^{7} \sigma^{7}$ ovoides, uniformemente convexos en el disco. Talla menor ( $0^{7} \sigma^{7}<6 \mathrm{~mm}$ ), hembras poco mayores que los machos (ca. Tiznit)

Laparocerus susicus inexpectatus nom. nov.

- Metatibias masculinas sin muesca terminal y con mucrón pequeño simple, dentiforme. Élitros algo deprimidos en el disco. Tallas mayores, hembras generalmente bastante mayores que los machos

13 Élitros $0^{7} O^{T}$ ovales y algo acuminados, máxima anchura hacia la mitad; escapo antenal más abruptamente capitado (Marruecos occidental, zona costera)

Laparocerus susicus susicus (Escalera, 1914)

- Élitros $\sigma^{7} \sigma^{7}$ oblongos, mitad anterior menos curvada y convergente hacia delante, máxima anchura pasada la mitad; escapo antenal engrosándose progresivamente en su tercio apical (Marruecos occidental, zona del interior)

Laparocerus susicus montanus $\mathrm{n}$. $\mathrm{sp}$.

14 Longitud generalmente inferior a $6 \mathrm{~mm}$. Metatibias masculinas con mucrón simple, pequeño y dentiforme rodeado de setas largas normales. Élitros de las hembras ovoides, como en los machos (Fuerteventura y Lanzarote) ........................... Laparocerus xericola $\mathrm{n}$. $\mathrm{sp}$.

- Longitud mayor $\left(\sigma^{7} \sigma^{7}\right.$ generalmente $>6 \mathrm{~mm}$, $ᄋ$ $\left.\odot>7 \mathrm{~mm}\right)$. Metatibias masculinas con un diente romo y muesca terminal precediendo al mucrón, que es grande, laminar y dispuesto transversalmente, recubierto por setas finas muy largas y curvadas apicalmente. Élitros masculinos subelípticos, los femeninos oval-alargados y muy inflados (algo cuadrangulares)

15 Élitros, al menos en su mitad posterior, con cerdas negruzcas y recurvadas dirigidas hacia atrás, tan o más largas que una uña (Fuerteventura, zona central)

Laparocerus rasus betancor $\mathrm{n}$. $\mathrm{spp}$.

- Élitros sin setas recurvadas o a lo sumo unas pocas, menores que una uña, y muy tumbadas en el cuarto apical, ..............................16

16 Tegumento del pronoto entre los puntos visiblemente reticulado. Escapo antenal más larga y progresivamente engrosado hacia su ápice. Edeago, visto de perfil, con un pequeño talón dorsal en su punta (forma de bota invertida) (Fuerteventura, península de Jandía)

Laparocerus rasus jandiensis $\mathrm{n}$. ssp.

- Tegumento del pronoto entre los puntos liso. Escapo antenar más breve y abruptamente engrosado apicalmente. Edeago, visto de perfil, con la punta lisa, sinuosa, sin talón dorsal (Lanzarote) Laparocerus rasus rasus Wollaston, 1864 


\section{KEY TO THE SPECIES OF LAPAROCERUS FROM THE EASTERN CANARIES, THE SELVAGE ISLANDS AND MOROCCO}

1 Elytra with straight or suberect fine and long hairs, at least in their apical third

- Elytra devoid of long hairs; with scales, small short setae or completely glabrous

2 Head and pronotum with large rather separate punctures; the small punctures superficial and inconspicuous. Elytral hairs widely separated. Smaller size (Length $\sigma^{x}<5 \mathrm{~mm}$ ) and bigger eyes (Fuerteventura) .............................................. Laparocerus colonnellii $\mathrm{n}$. sp.

- Head and pronotum densely covered with small and large punctures, strongly impressed. Elytral hairs more closely disposed, occasionally restricted to apical area. Larger size (Length $\sigma^{7}>6 \mathrm{~mm}$ ) and smaller eyes (Fuerteventura) .... Laparocerus maxorata $\mathrm{n}$. $\mathrm{sp}$.

3 Tegument at head vertex with well impressed microreticulation

- Tegument at head vertex smooth, only with punctures Microreticulation limited to vertex (male) and occiput of head. Pronotum and elytra with lanceolate scales (Fuerteventura) ....................

Laparocerus fraterculus $\mathrm{n}$. $\mathrm{sp}$.

Head and pronotum conspicuously microreticulated. Pronotum and elytra without scales, hairs or piles (Fuerteventura)

Laparocerus calvus n. sp.

5 Protibiae broadly expanded at apex to both sides (fan-like). Pronotum shiny, with superficial or almost imperceptible punctures ...... 6

- Protibiae with external apical angle rounded, incurved or hardly prominent. Pronotum more or less densely punctured; punctures well impressed

6 Pronotum and elytra with a poor loose vestiture of short, glaucous, adpressed scales, in a more or less defined patch design (Fuerteventura)

Laparocerus curvipes espanoli Roudier, 1954

- Pronotum and elytra with some vestigial scales, practically bare (Lanzarote)

Laparocerus curvipes famarae $\mathrm{n}$. ssp.

7 Base of antennal scape thick or thin. Scale vestiture less dense (2nd interstriae at disc $<12$ scales across)

- Base of antennal scape always thin. Scale vestiture more dense (2nd interstriae at disc > 12 scales across) .................................11

8 Elytra narrow and elongate (length elytra/pronotum $>3.5$ ), with rows of short erect setae. Pronotum with double puncturation (Fuerteventura)

Laparocerus longipennis $\mathrm{n} . \mathrm{sp}$.

- Elytra wide, ovate or subglobose (length elytra/pronotum <3,5), at most with small recurved setae at apical third ........................... 9

9 Eyes more prominent (40\% convexity). Pronotum with large punctures separated more than one diameter, and small conspicuous punctures in between (Lanzarote)

Laparocerus dispar Wollaston, 1864

- Eyes less prominent $(<35 \%$ convexity). Pronotum with large foveiform punctures, separated less than one diameter (aspect somewhat variolose)

10 Scales thinner, of golden or testaceous colour. Elytra without or with a few protruding curved scales (Salvagem Grande)

Laparocerus garretai garretai Uyttenboogaart, 1940

- Scales a trifle broader, of white or glaucous colour. Elytra all-over with raws of curved protruding scales (Selvagem Pequena $=\mathrm{Gran}$ Pitón)

Laparocerus garretai albosquamosus n. ssp.

11 Pronotal punctures close; large punctures more than twice the size of the small ones; both well impressed and deep (Morocco) ..12

- Pronotal densely punctured, but punctures more separate; the small ones superficial or, if somewhat deep, then largerer than half the size of a large point (Canaries)

12 Male metatibiae with a blunt tooth and terminal notch just before the mucro, which is long, laminar and transversal. Male elytra ovoid, uniformly convex at disc. Usually smaller and females not much bigger than males (Morocco, Tiznit)

- Male metatibiae not notched and with simple small pointed mucro. Elytra a little depressed at disc. Usually larger, with females much bigger than males

13 Male elytra ovate and more acuminate (sub-elliptic); greatest width at middle. Antennal scape more abruptly capitate (coast of WestMorocco)

Laparocerus susicus susicus (Escalera, 1914)

- Male elytra oblong and less acuminate, laterally less curved and convergent in basal half; widest past middle. Antennal scape progressively incrassating in its apical third (interior of West Morocco)

Laparocerus susicus montanus $\mathrm{n}$. $\mathrm{sp}$.

14 Normal length less than $6 \mathrm{~mm}$. Male metatibiae with simple small pointed mucro flanked by ordinary long setae. Elytra of male and female of ovoid shape. (Fuerteventura and Lanzarote)

Laparocerus xericola n. sp.

- Length greater (usually $0^{7} 0^{7}>6 \mathrm{~mm}, \& ᄋ>7 \mathrm{~mm}$ ). Male metatibiae with a blunt tooth and terminal notch just before the mucro, which is long, laminar and transversal, and is surpassed by longer thin apically curved setae. Elytra subelliptical in males, very inflated and long-ovate or somewhat squarish in females

15 Elytra all-over or at least in its second half with blackish recurved back-pointing setae, as long or longer than a claw (Fuerteventura, central region)

Laparocerus rasus betancor $\mathrm{n} . \mathrm{spp}$

- Elytra without recurved protruding setae; if any then shorter than a claw, little protruding and limited to the apical fourth ................ 16

16 Tegument of pronotum reticulated between the punctures. Antennal scape progressively incrassating in its apical half. Aedeagus in lateral view with a small dorsal heel (inverted boot shape) (Fuerteventura, Jandia Peninsula) .......... Laparocerus rasus jandiensis $n$. ssp.

- Tegument of pronotum smooth between the punctures. Antennal scape shortly and more abruptly incrassate apically. Aedeagus in lateral view with a sinuate smooth point, without dorsal heel (Lanzarote) Laparocerus rasus rasus Wollaston, 1864 
Brullé, G. A., 1839. Insectes. In: P. B. Webb \& S. Berthelot. Histoire Naturelle des îles Canaries (1836-1844). Tome II ( $2^{\text {eme }}$ Partie). Bethune. Paris: 54-95.

Carine, M. A., Russell, S. J., Santos-Guerra, A. \& FranciscoOrtega, J., 2004. Relationships of the Macaronesian and Mediterranean floras: molecular evidence for multiple colonizations into Macaronesia and black-colonization of the continent in Convolvulus (Convolvulaceae). American Journal of Botany, 91(7): 1070-1085. doi: 10.3732/ajb.91.7.1070

Erber, D. \& Wheater, C. P., 1987. The coleoptera of the Selvagem Islands, including a catalogue of the specimens in the Museu Municipal do Funchal. Boletim do Museu Municipal do Funchal, 39(193): 156-187.

Escalera, M. M., 1914. Los coleópteros de Marruecos. Trabajos del Museo Nacional de Ciencias Naturales, Serie zoológica 11. Madrid. 553 pp.

Garreta, L., 1911. Les insectes de l'île Grande Salvage. Boletim do Museu Municipal do Funchal, 1911: 392397.

Gurrea, M. P. \& Sanz, M. J., 2000. Endemismos de Curculionoidea (Coleoptera) de la Península Ibérica, Islas Baleares y Canarias. Universidad Autónoma de Madrid. Madrid. 384 pp.

Hantzsch, V., 1907. Quedenfeld, Max. In: Allgemeine Deutsche Biographie. Historischen Kommission bei der Bayerischen Akademie der Wissenschaften, München, 53: 176-179.

Hustache, A., 1932. Quelques curculionides nouveaux du Maroc et d'Algerie. Bulletin de la Société des Sciences naturelles du Maroc, 12(1-3): 40-53.

Kocher, L., 1961. Catalogue commenté des coléoptères du Maroc. Fascicule IX. Rhynchophores. Travaux de l'Institut Scientifique Chérifien, Série Zoologie, 24: 1-263.

Lindberg, H., 1953. Zweiter Beitrag zur Kenntnis der Käferfauna der Kanarischen Inseln. Commentationes biologicae, Societas Scientiarum Fennica, 13(12): 1-18.

Lindberg, H. \& Lindberg, H., 1958. Entomologische Ergebnisse der finnländischen Kanaren-Expedition 1947-51. No. 14. Coleoptera Insularum Canariensium. I. Aglycyderidae und Curculionidae. Commentationes biologicae, Societas Scientiarum Fennica, 17(1): 1-97.

Lona, C., 1938. Curculionidae: Otiorhynchinae III. In: W. Junk \& S. Schenkling (eds.). Coleopterorum Catalogus. Dr. W. Junk. Gravenhage: 413-600.

Lundblad, O., 1958. XXXV. Die Käferfauna der Insel Madeira. In: Die Arthropodenfauna von Madeira nach den Ergebnissen der Reise von Prof. Dr. O. Lundblad Juli-August 1935. Arkiv för Zoologi, 11(30): 461-524.

Machado, A., 2006. The type material of the species of Laparocerus Schönherr, 1834 (Coleoptera, Curculionidae, Entiminae). Journal of Natural History, 40(35-37): 2001-2055. doi: 10.1080/002229306010 46659
Machado, A., 2010. La morfología de Laparocerus undatus Wollaston, 1864 y consideraciones sobre la tribu Laparocerini Lacordaire, 1863 (Coleoptera, Curculionidae, Entiminae). Graellsia, 66(2): 233280. doi: 10.3989/graellsia.2010.v66.025

Machado, A. \& Oromí, P., 2000. Elenco de los coleópteros de las islas Canarias. Catalogue of the coleoptera of the Canary Islands. Instituto de Estudios Canarios (Monografía 70). La Laguna. 307 pp.

Maddison, W. P. \& Knowles, L. L., 2006. Inferring phylogeny despite incomplete lineage sorting. Systematic Biology, 55 (1): 21-30. doi: 10.1080/10635150500354 928

Marseul, S. A. d., 1872-1873. Monographie des Otiorhynchides d'apres les travaux de MM, les docteurs Seidlitz \& Stierlin, coordonnés par M. S.-A. de Marseul. L'Abeille, 11(Deuxième Série, Tome V): 449-557.

Mort, M. E., Solits, D. E., Solte, P. S., Francisco Ortega, J. \& Santos Guerra, A., 2002. Phylogenetics and evolution of the Macaronesian clade of Crassulaceae inferred from nuclear and chloroplast sequence data. Systematic Botany, 27(2): 2771-288. doi: 10.1043/0363-644527.2.271

Oromí, P., 1983. Sobre el origen de la fauna entomológica de las Islas Salvajes. Vieraea, [1982], 12(1-2): 271293.

Oromí, P., Báez, M. \& Machado, A., 1978. 17. Contribución al estudio de los artrópodos de las islas Salvajes. In: Contribución al estudio de la historia natural de las islas Salvajes. Resultados de la expedición científica "Agamenon 78" (23 de febrero 3 de marzo de 1976). Museo de Ciencias Naturales del Cabildo Insular de Santa Cruz de Tenerife, Aula de Cultura de Tenerife. Santa Cruz de Tenerife: 177-194.

Oromí, P., López, H., Arechavaleta, M., Contreras Díaz, H. \& Rodríguez, B., 2003. Fauna de artrópodos de Montaña Clara (islas Canarias) I: Coleópteros. Vieraea, 31: 167-182.

Pelletier, J., 2006. Révision du genre Cyclomaurus Fairmaire, 1860 (Coleoptera, Curculionidae). Biocosme Mésogéen, 23(1): 21-40.

Pelletier, J., 2007. Révision du genre Cyclobarus Faust, 1886 (Coleoptera, Curculionidae, Entiminae). Bulletin de la Société entomologique de France, 112(4): 455471.

Peyerimhoff, P. de, 1946. Les Coléoptères des Atlantides et l'élément atlantique. In: Varios. Contribution à l'étude du peuplement des Îles Atlantides. Mémoires de la Société de Biogéographie, 8: 153-97.

Reyes-Betancort, J. A. \& Santos Guerra, A., 2010. Tras las rutas florísticas macaronésicas continentales. Viajes de ida y vuelta al suroeste de Marruecos. Rincones del Atlántico, 6/7: 192-203.

Reymond, A., 1951. Captures de coléoptères à l'occasion des crues. Bulletin de la Société des Sciences naturelles du Maroc, 31: 93-102. 
Roudier, A., 1954. Coléoptères Curculionides nouveaux ou peu connus (Espagne, Îles Baleares, Îles Canaries) (lire $\& 2^{\text {ème }}$ notes). Bulletin de la Société Entomologique de France, 59: 83-88.

Roudier, A., 1957. Curculionides nouveaux ou peu connus des îles Canaries (Col.). Annales de la Société Entomologique de France, [1956], 125: 17-55.

Ruter, G., 1945. Un Laparocerus marocain (Col. Curculionidae). Bulletin de la Société entomologique de France, 1945(Avril): 44-45.

Serrano, A. R. M., 1983. Os coleopteros do arquipélago das Selvagens. Actas I Congreso ibérico de Entomología, León, 2: 759-776.

Uyttenboogaart, D. L., 1937. Contributions to the knowledge of the fauna of the Canary islands XIX. Tijdschrift voor Entomologie, 80: 75-118.

Uyttenboogaart, D. L., 1940. Voyages de M. Ch. Alluaud aux Iles Canaries (1889-90) et à l'archipel de Madère (1938). Coléoptères Curculionides. (Contributions to the knowledge of the fauna of the Canary Islands, XXIV). Revue française d'Entomologie, 7: 49-69.

Winkler, A. (ed.), 1924-1932. Catalogus Coleopterorum regionis palaearcticae. Albert Winkler. Wien. 1698 pp.
Wollaston, T. V., 1864. Catalogue of the coleopterous insects of the Canaries in the collection of the British Museum. Trustees of the British Museum. London. $13+648 \mathrm{pp}$.

Wollaston, T. V., 1865. Coleoptera Atlantidum, being an enumeration of the Coleopterous insects of the Madeiras, Salvages and Canaries. Taylor \& Francis. London. $47+526$ pp.

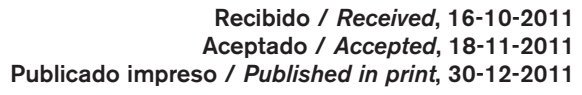

